2012

\title{
Reservoir heterogeneity in a carbon sequestration target: The Donovan Sand member of the Rodessa Formation, Citronelle field, Alabama
}

Keith Coffindaffer

West Virginia University

Follow this and additional works at: https://researchrepository.wvu.edu/etd

\section{Recommended Citation}

Coffindaffer, Keith, "Reservoir heterogeneity in a carbon sequestration target: The Donovan Sand member of the Rodessa Formation, Citronelle field, Alabama" (2012). Graduate Theses, Dissertations, and Problem Reports. 3506.

https://researchrepository.wvu.edu/etd/3506 


\title{
RESERVOIR HETEROGENEITY IN A CARBON SEQUESTRATION TARGET: THE DONOVAN SAND MEMBER OF THE RODESSA FORMATION, CITRONELLE FIELD, ALABAMA
}

Keith Coffindaffer

\author{
Thesis submitted to the \\ College of Arts and Sciences \\ at West Virginia University \\ in partial fulfillment of the requirements \\ for the degree of \\ Master of Science \\ in \\ Geology \\ Graduate Committee: \\ Dr. Amy Weislogel, Ph.D., Chair \\ Dr. Tim Carr, Ph.D. \\ Dr. Tom Wilson, Ph.D. \\ Department of Geology and Geography \\ Morgantown, WV \\ 2012
}

Keywords: Citronelle Field, Donovan Sand, Petrology, Rodessa Formation, Sequestration Copyright 2012 Keith Coffindaffer 


\section{ABSTRACT: \\ RESERVOIR HETEROGENEITY IN A CARBON SEQUESTRATION TARGET: THE DONOVAN SAND MEMBER OF THE RODESSA FORMATION, CITRONELLE FIELD, ALABAMA}

Keith Coffindaffer

The Citronelle field, located in Mobile County, Alabama, has been chosen as a U.S. Department of Energy (DOE) Carbon Capture and Storage (CCS) pilot site, and supercritical $\mathrm{CO}_{2}$ has been injected for the combined purposes of long-term storage testing and enhanced oil recovery (EOR). The target formation for injection is the Early Cretaceous Donovan Sand of the Rodessa Formation, and is characterized by discontinuous fine- to medium-grained, heterogeneous arkosic fluvial sandstones interbedded with fissile mudstones and micaceous silts. Based upon core analysis of the Donovan Sand, depofacies indicate a fluviodeltaic/estuarine depositional environment for the Donovan Sand. Probable sources of the Donovan sediments are the Motts Gneiss and the Hospilika Granite, both of which are exposed within the Pine Mountain Window at the Georgia/Alabama state border and into central Georgia. Through synthesis of core, thin section, and well log analysis, reservoir heterogeneity and porosity development within the Upper Donovan Sand is highly variable, with porosity averages of $\sim 2-5 \%$, but locally can be up to $\sim 13 \%$. In more porous zones there is more evidence of grain alteration and creation of secondary porosity, while in the lower porosity sections cementation or high matrix content fill interstitial space and the main pore type is primary pores. Porosity and cement percentages, rather than mineralogic composition, were used to categorize sandstones into petrofacies due to the consistent mineral composition of the Donovan Sand. According to petrofacies-to-well log correlations, the most porous petrofacies are present within the same stratigraphic zone (defined herein as a 'high porosity zone') and this zone is interpreted to represent a porous ( $>5 \% \phi)$ fluid migration pathway in the subsurface. An Upper Donovan Sand structure map, thickness map, and average porosity map generated using transform equations from SP and bulk density curves show that the thickest portions of the Upper Donovan do not directly correlate with the most porous areas within the formation. This research may serve as an analog for other mature oil and gas fields and CCS sites targeting fluvial-deltaic reservoirs. 


\section{Acknowledgments}

Many people have helped me over the course of my academic and professional career to this point. I would like to thank the entire faculty of the Department of Geology and Geography at West Virginia University for their patience and encouragement through my undergraduate as well as graduate studies. I've been very blessed to have had encouragement and guidance from the faculty at this school. In particular I would like to thank Dr. Amy Weislogel for her positive feedback from countless questions that I've asked over the course of writing this thesis, constant encouragement through the editing process, and most importantly her patience in dealing with a student with many geologic and writing concerns over the course of this research. I sincerely appreciate your guidance and encouragement, without which this thesis surely would not have been possible.

I'd like to thank Dr. Richard Smosna for his tutelage and patience during the early portion of my graduate work which encouraged and accelerated my understanding of sedimentary systems and energy, which are now my two main interests in geology in part due to his courses which I enjoyed and learned so much from. Dr. Tim Carr introduced me to indepth petrophysical analysis via his well logging class as well as through his role as a mentor during the Imperial Barrel competition. I thank him for the continued willingness to answer my many questions over my graduate career as well as for instilling in me the insight to also think of the business side of geology. I thank Dr. Tom Wilson for his encouragement through both my undergraduate and graduate studies. He also taught me the use of geologic software packages, which is an integral skill that was put to use in this thesis and will certainly be useful going forward in my professional career. For teaching me these skills and generously troubleshooting my technical dilemmas when called upon I thank you. I also thank Craig Eckert for his assistance in brainstorming for ideas within my eventual study area, as well as for his professional and geological advice during my time working for EQT in Pittsburgh, PA. All of those mentioned here as well as the many unlisted faculty that I've studied under have contributed to my becoming a better professional geologist, and I thank you all very much for that.

There are many people that helped with the data collection portion of this thesis, and I'd like to thank the following people from the Geological Survey of Alabama for their help in arranging the core study during my time in Tuscaloosa: David Kopaska-Merkel, Jack Pashin, Denise Hills, Lewis Dean, and Ed Osborne. I'd also like to thank the Geological Survey of Alabama for their contribution of the graphic log for well permit \#706 for incorporation into my database, Dr. Peter Walsh from the University of Alabama at Birmingham, and Dr. Rona Donahoe at the University of Alabama for her hospitality and geologic counsel. Additionally, I thank David Kopaska-Merkel for allowing me to show his photomicrographs taken at the Geological Survey of Alabama in this thesis. 
Thank you to George Case and Asa Mullenex who both contributed many hours of work to the overall project even though they had their own undergraduate time commitments at West Virginia University. George also was responsible for taking photomicrographs of thin sections, one of which was incorporated into this thesis (Fig. 19). Thank you both for giving $100 \%$ effort during your time with the project, as this research was made possible by your hands as well. Thank you all for your time, generosity, and hard work put towards this research. I count myself lucky to have worked and learned with both of you.

Most importantly, I'd like to thank my family. To my parents Ernie and Carol, I can't thank you enough for all of your selfless encouragement, endless patience, and unconditional love you've provided through all the years. Thank you for always believing in me, no matter what the circumstance. These things have helped me become a better geologist, and more importantly, a better person. I would not be where I am today without you. To my sisters Kelly and Sarah thank you for your encouragement and advice throughout this writing process as well as throughout my life. Thank you both for helping me through the stressful times in my education and for being there to celebrate the good times. To my grandparents Billy and Norma, thank you for the unconditional love and support through the years and particularly during my graduate student career. You've taught me many lessons that I will carry with me for the rest of my life. You all mean so much to me, and I thank you all for helping me endeavor to persevere. 


\section{Table of Contents}

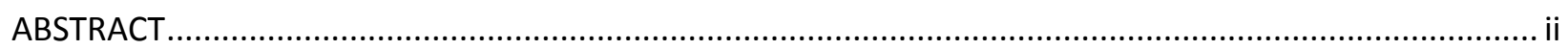

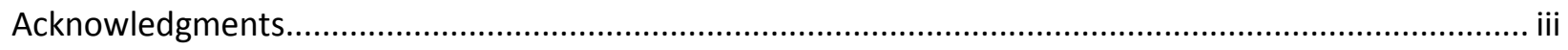

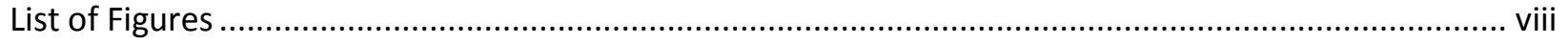

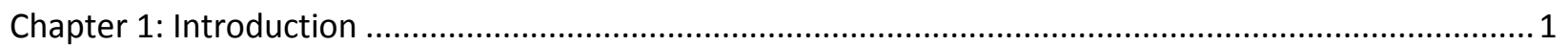

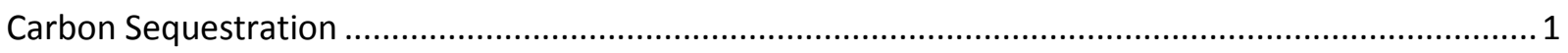

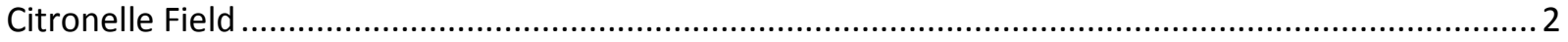

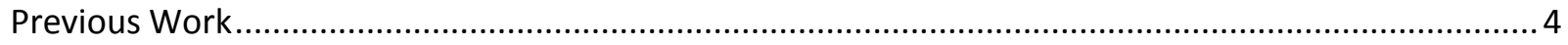

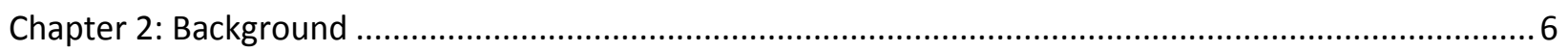

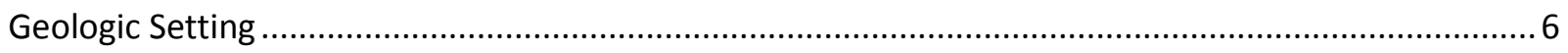

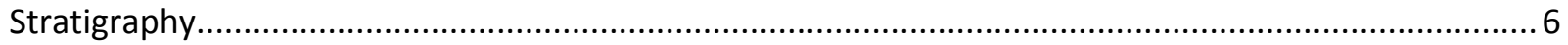

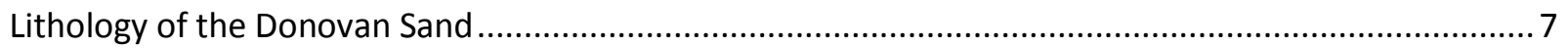

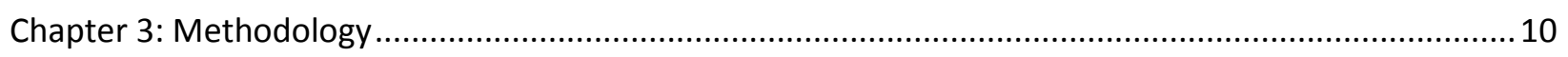

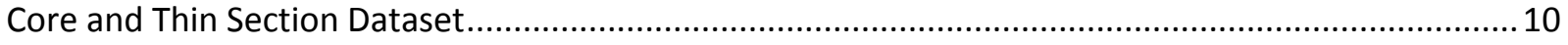

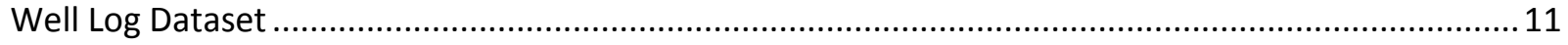

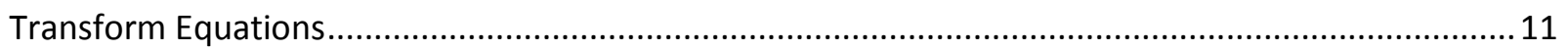

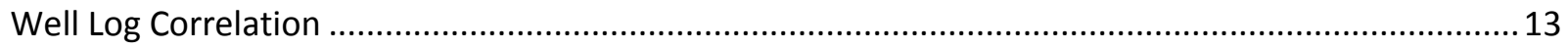

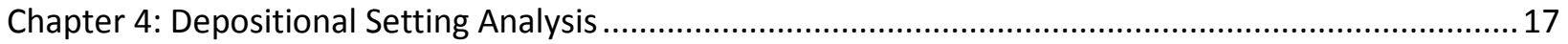

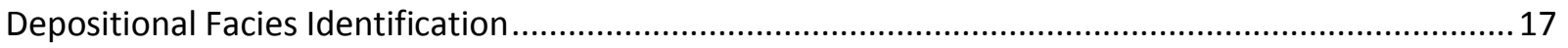

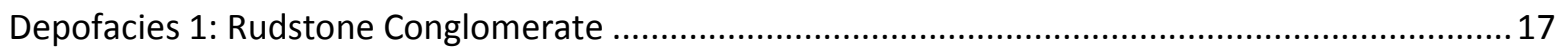

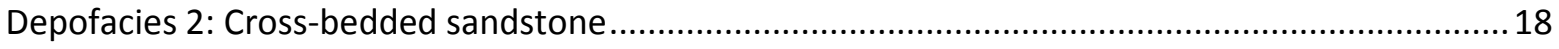

Depofacies 3: Massive to horizontally laminated sandstone ….....................................................20

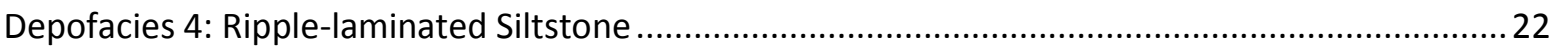

Depofacies 5: Massive to horizontally laminated siltstone ........................................................... 22

Depofacies 6: Bioturbated and Burrowed Mudstones and Shales .................................................. 23

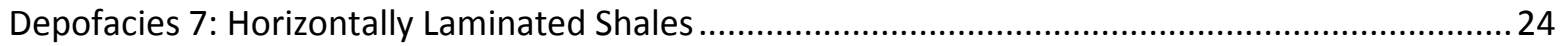

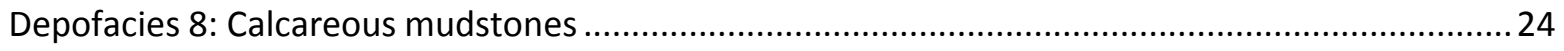

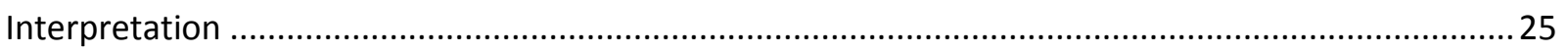

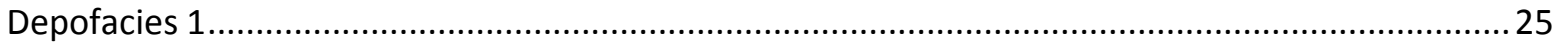

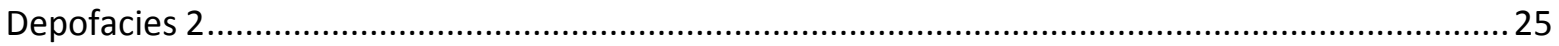

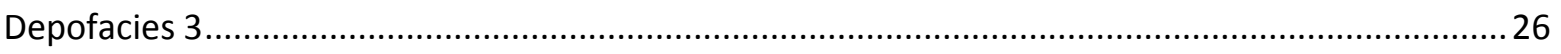

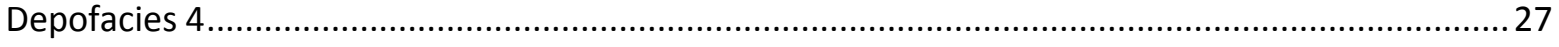




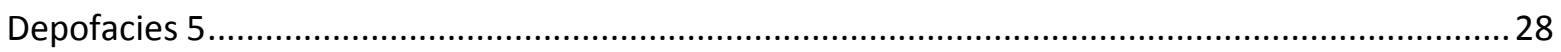

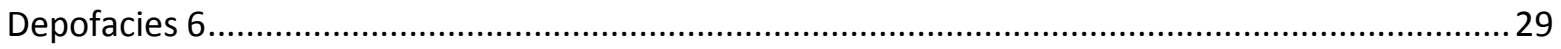

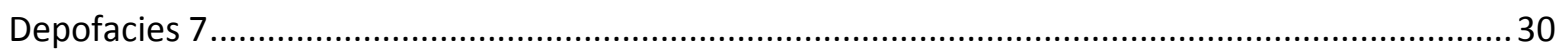

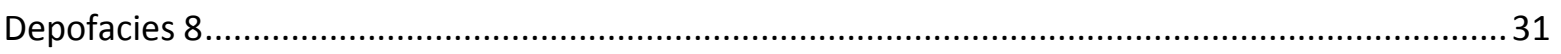

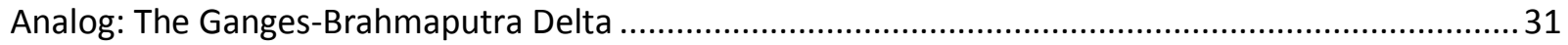

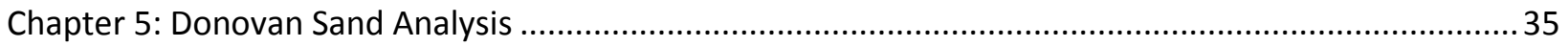

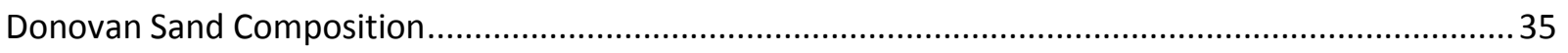

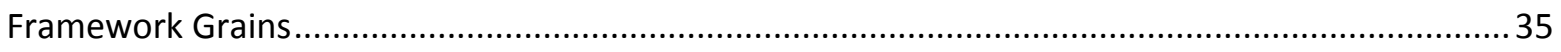

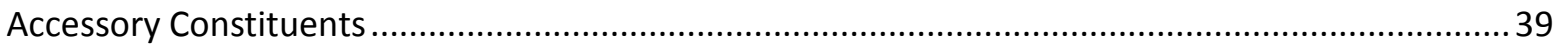

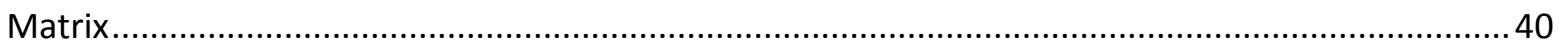

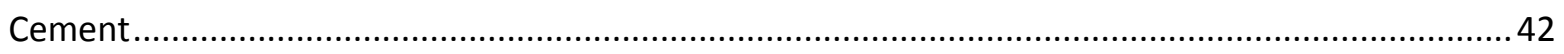

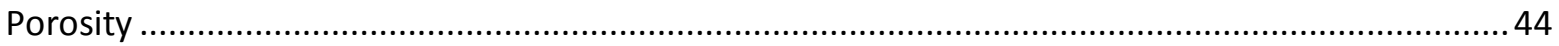

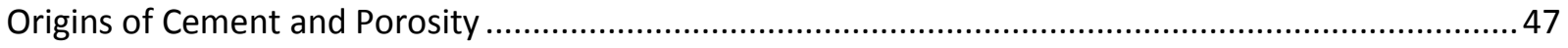

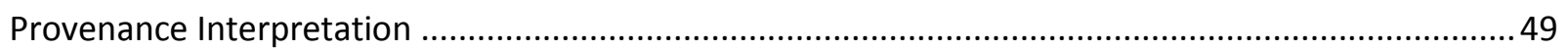

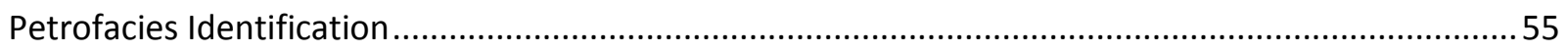

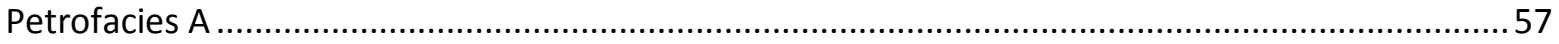

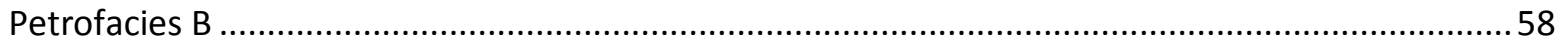

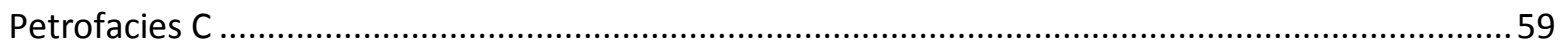

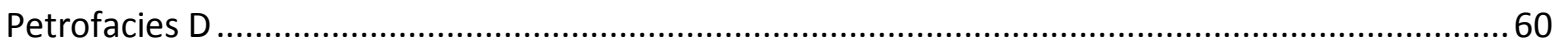

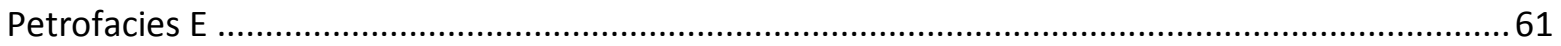

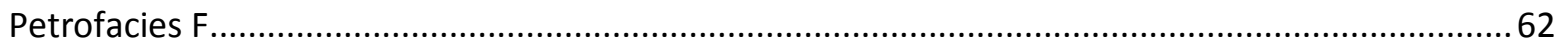

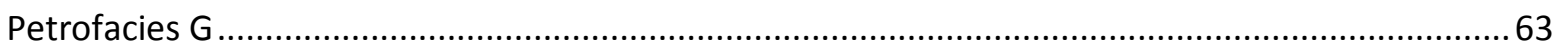

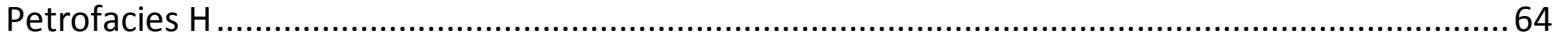

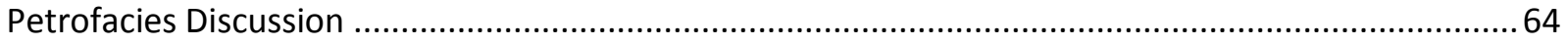

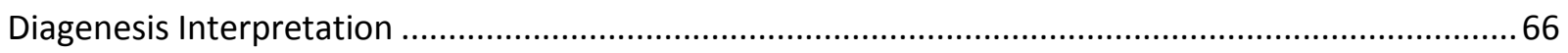

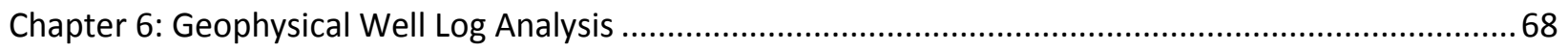

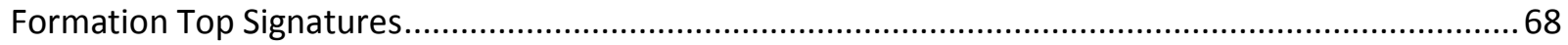

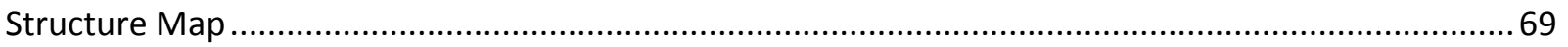

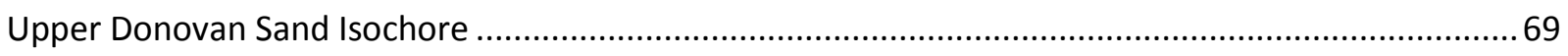

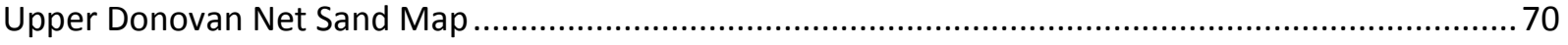

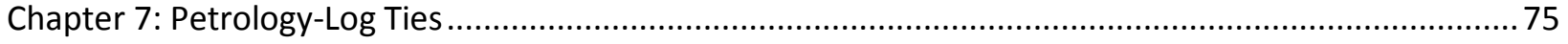

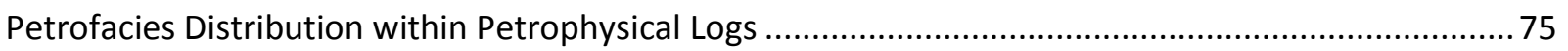




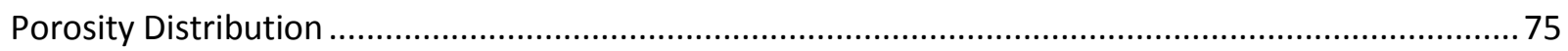

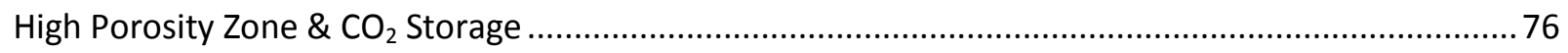

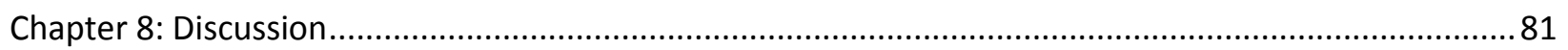

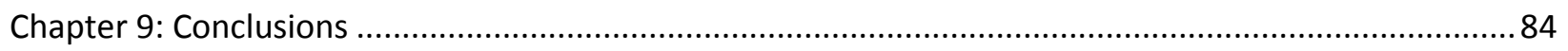

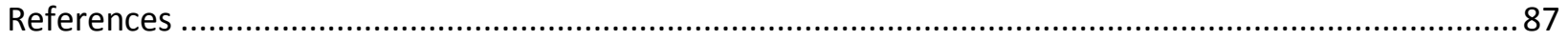




\section{List of Figures}

Figure 1. Location map of Citronelle Field, Mobile County, Alabama. ................................................... 4

Figure 2. Geologic structure map of the Citronelle Field.................................................................... 5

Figure 3. Paleogeographic reconstruction of the Laurentian supercontinent during the early Jurassic (180

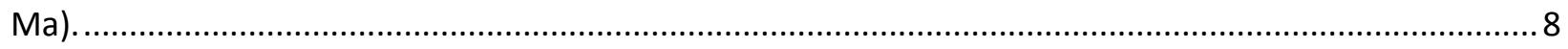

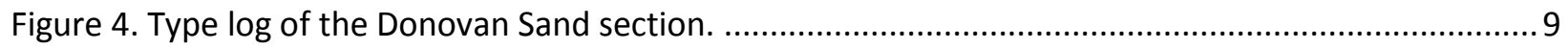

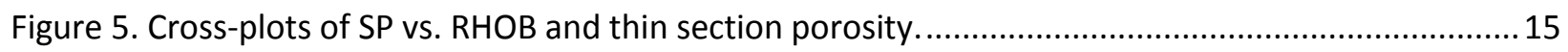

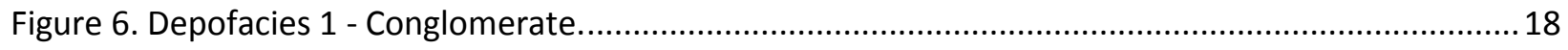

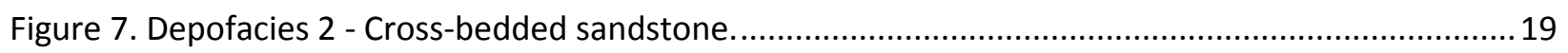

Figure 8. Depofacies 3 - Massive to horizontally laminated sandstone. ............................................... 20

Figure 9. Depofacies 3 - Massive sandstone with calcite concretions and pebble-sized carbonate clasts.21

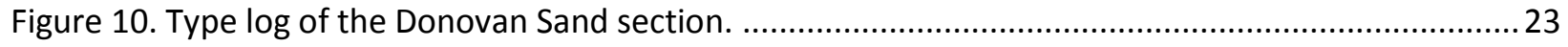

Figure 11. The Ganges-Brahmaputra Delta System......................................................................... 34

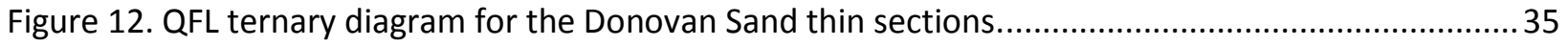

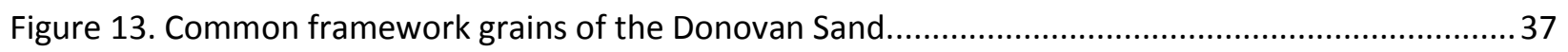

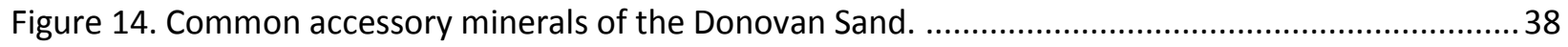

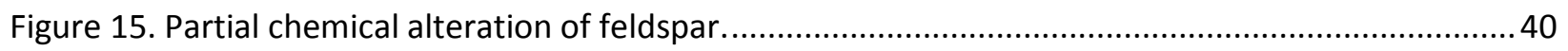

Figure 16. Alteration of plagioclase feldspar along twinning planes.................................................... 41

Figure 17. Typical Donovan section subrounded mudstone lithic fragment containing some silt-sized

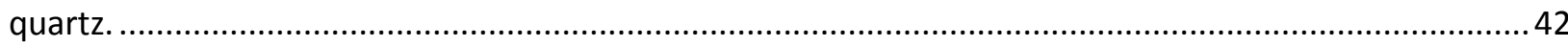

Figure 18. Photomicrograph of an altered mica book within thin section 3086-10941 under plane-

polarized light.

Figure 19. Photomicrograph of thin section 3232-10815 showing the blue titanium oxide mineral under

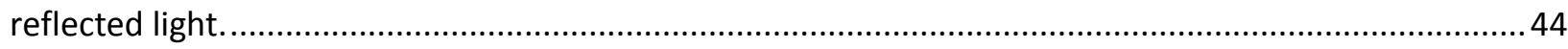

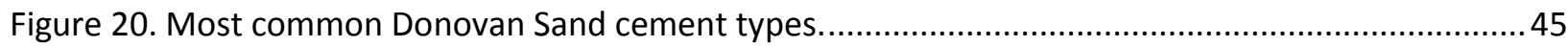

Figure 21. Anhydrite as seen under cross-polarized light.................................................................... 46

Figure 22. Photomicrograph showing highly-cemented fine-grained sandstone within the Donovan Sand.

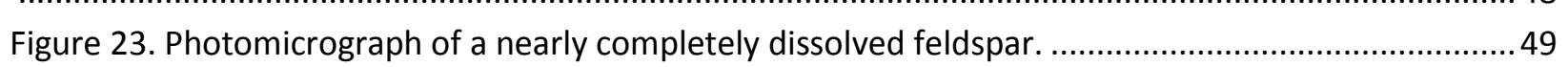

Figure 24. Dolomitic cementation of a secondary pore within the Donovan Sand.................................50

Figure 25. Diagram of rhombohedral packing in an ideal sediment.....................................................50

Figure 26. The Pine Mountain Window. .......................................................................................... 53

Figure 27. Map of the Piedmont region of the Eastern United States. ...................................................54

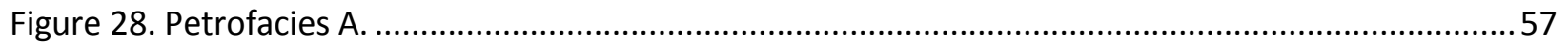

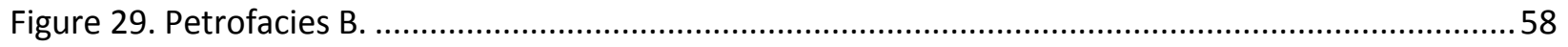

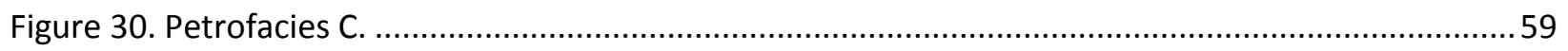

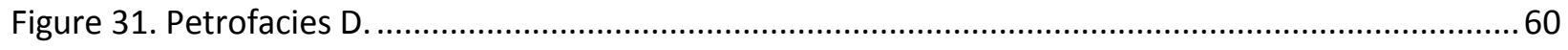

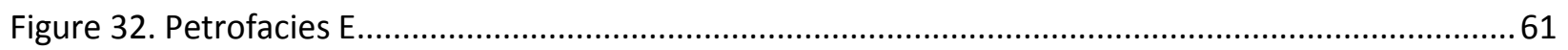

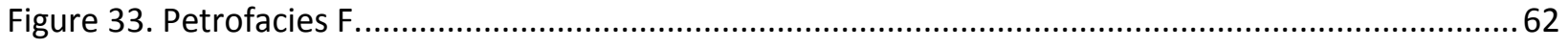

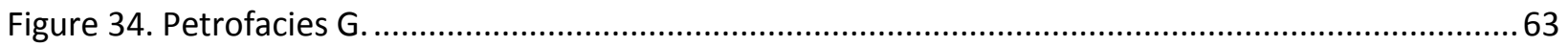




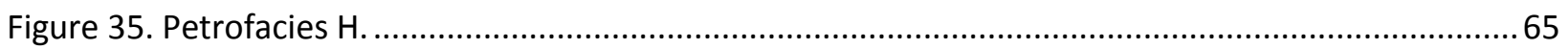

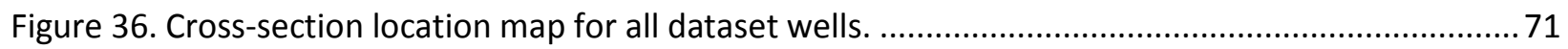

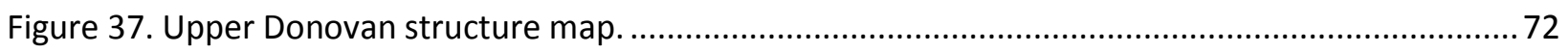

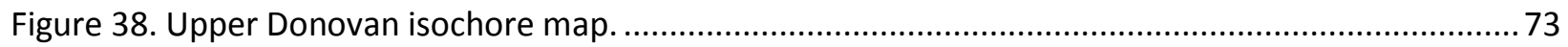

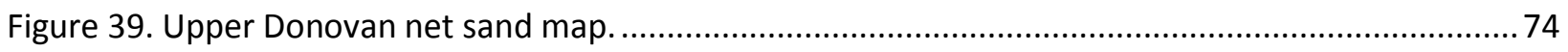

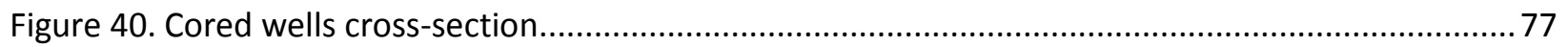

Figure 41. Upper Donovan Sand porosity distribution map .............................................................. 78 


\section{Chapter 1: Introduction}

\section{Carbon Sequestration}

In recent years, much effort has been made in order to assess the viability of carbon capture and storage (CCS) in geologic reservoirs as a way to reduce the amount of $\mathrm{CO}_{2}$ expelled into the atmosphere from anthropogenic sources. Geologic carbon sequestration involves four steps (Myer, 2008):

1. Capture of $\mathrm{CO}_{2}$ from flue gas or some fossil fuel-burning source (such as a coal-fired power plant).

2. Drying of the $\mathrm{CO}_{2}$, and compression of the gas to $\sim 100$ bars.

3. Transport of the compressed gas to the injection site.

4. Injection of the $\mathrm{CO}_{2}$ at high pressures into a geologic formation at depth, and monitoring of the plume as time progresses.

The main targets for geologic CCS are deep coal beds that cannot be mined, saline formations (with total dissolved solids $>10,000$ pm per EPA regulations), and as in this study, produced or producing mature oil and gas reservoirs. Sequestration within producing petroleum reservoirs is also beneficial because storage operations can be performed simultaneously with enhanced oil recovery (EOR) efforts. EOR operations have been performed using $\mathrm{CO}_{2}$ in the United States since the early 1970s (United States Department of Energy, 2011) to attempt to produce any remaining hydrocarbon after initial producing stages.

$\mathrm{CO}_{2}$ EOR was developed based upon the premise that the $\mathrm{CO}_{2}$ will miscibly mix with the oil in the formation to reduce viscosity, allowing the oil that remains in situ to migrate towards the wellbore (Meyer, 2007). A waterflood normally follows the $\mathrm{CO}_{2}$ injection, and acts as the 
driving force to push the hydrocarbon towards the borehole. Evidence that $\mathrm{CO}_{2}$ can successfully be contained in geologic formations is plentiful (e.g., Bachu, 2002; Hadlow, 2002; Meyer, 2007; Myer, 2008; United States Department of Energy, 2011). $\mathrm{CO}_{2}$ is known to occur naturally within oil and gas reservoirs, suggesting that reservoirs can effectively hold $\mathrm{CO}_{2}$ for long periods of time (Myer, 2008). In fact, $\mathrm{CO}_{2}$ is effectively being stored during $\mathrm{CO}_{2}$-EOR operations as well. According to Hadlow (1992), oilfield production history shows that approximately $40 \%$ of the originally injected $\mathrm{CO}_{2}$ is being produced at the pump and re-injected which suggests a gross $\mathrm{CO}_{2}$ retention efficiency of $\sim 60 \%$ during the EOR process (Bachu, 2001). This further reinforces the claim that geologic storage is a plausible method for long-term $\mathrm{CO}_{2}$ emission mitigation.

The target CCS reservoir must be deemed as appropriately sealed in order to store the $\mathrm{CO}_{2}$. The fluid flow dynamics must also be adequately defined so as not to allow for unwanted underground transport of the $\mathrm{CO}_{2}$ to freshwater aquifers or to other unpredictable flow zones. Variable pressure and temperature of the target sequestration reservoir could result in changes in the state of the injected $\mathrm{CO}_{2}$ once it is within the formation. This should be avoided due to the increased mobility of $\mathrm{CO}_{2}$ in a gaseous versus a supercritical liquid state (Bachu, 2002). The reservoir that is being considered for geologic $\mathrm{CO}_{2}$ sequestration must also be laterally extant and structurally sound. There must not be fractures which allow for unwanted or uncontrolled migration of the $\mathrm{CO}_{2}$ out of the target formation.

\section{Citronelle Field}

The Citronelle oil field (Fig. 1), Alabama's largest oil and gas producing field, sits overtop a salt-cored anticline (Fig. 2) and has produced 168MMbbl of oil (Esposito et al., 2008) and 15Bcf of gas since 1955 (Pashin et al., 2007). It is estimated that supercritical $\mathrm{CO}_{2}$-EOR should 
increase production from the Donovan Sand by about 20\% (Pashin et al., 2007). After the injection of the first 7500 ton slug of $\mathrm{CO}_{2}$ and the subsequent waterflood, there was a decrease in the rate of injection (P. Walsh, personal communication, 2011). This shows that some downhole factor has changed, and this research will qualitatively and quantitatively characterize stratigraphic porosity and mineralogy within the Donovan Sand so that it can be used to investigate why injection rate changed.

$\mathrm{CO}_{2}$ injection for the purposes of EOR operations has been implemented in hydrocarbon production in Citronelle Field since 1981 (Pashin et al., 2007). Typically with this type of operation, the $\mathrm{CO}_{2}$ is actually produced with the hydrocarbon, separated, and reinjected into the formation for continuation of EOR; this type of recovery is possible with most conventional reservoirs. However, with the advent of $\mathrm{CO}_{2}$ injection for storage purposes, it is now important to identify possible long-term storage reservoirs across the nation. In looking for storage fields, there are certain qualities that must be considered: basin geology and hydrogeology, hydrodynamics of the targeted reservoir, depth of the reservoir, pressure and temperature of the reservoir, the physical extent and structural integrity of the reservoir, storage capacity of the reservoir, and porosity and permeability within the reservoir (Bachu, 2002; Kovscek, 2002).

The Citronelle Field is a good candidate for geologic carbon sequestration because it is a mature oil field that: 1) has been recently waterflooded and injected with $\mathrm{CO}_{2}, 2$ ) already possesses the deep well infrastructure necessary for the $\mathrm{CO}_{2}$ injection, and 3 ) is near ( $\sim 10$ miles; $16 \mathrm{~km}$ ) away from Plant Barry, the eventual anthropogenic source of the $\mathrm{CO}_{2}$. Furthermore, geologically, it is located overtop of a gently sloping, structurally competent dome which provides four-way structural closure, and the targeted Donovan sand is overlain and sealed by 
the thick and extensive Ferry Lake Anhydrite (Esposito et al., 2008; United States Department of Energy, 2007). These factors make the Citronelle oil field a prime candidate for geologic carbon sequestration.

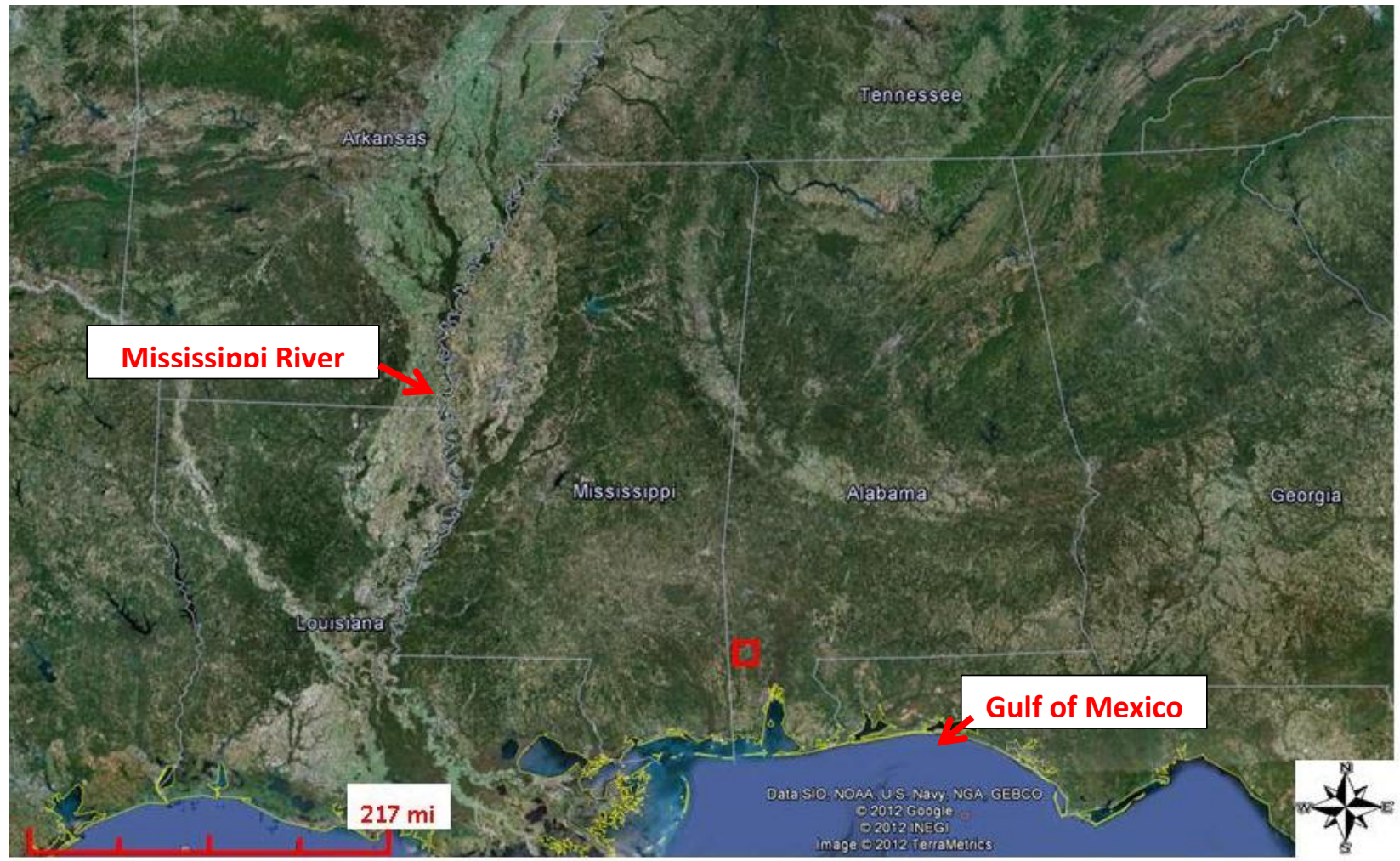

Figure 1. Location map of Citronelle Field, Mobile County, Alabama.

Citronelle Field is outlined with the red rectangle. State boundaries are represented by the gray lines and state names are in white font, while country borders are shown with yellow lines. Gulf of Mexico and Mississippi River are labeled for geographic reference (Modified from Google Inc., 2012.)

\section{Previous Work}

Limited work has been published concerning the potential of the Rodessa Formation as a viable carbon sequestration target. Most published information pertains to the production of hydrocarbons and includes general stratigraphic identification, lithology descriptions, 
production-related volumetric analyses, and permeability data collection (Pashin et al., 2007; Esposito et al., 2008; Esposito et al., 2010). However, Esposito et al. (2010) reported planning for CCS pilot test operations in the form of injection of two 7500 short-ton slugs, one at a time, and with a waterflood phase directly after the injection of each slug.

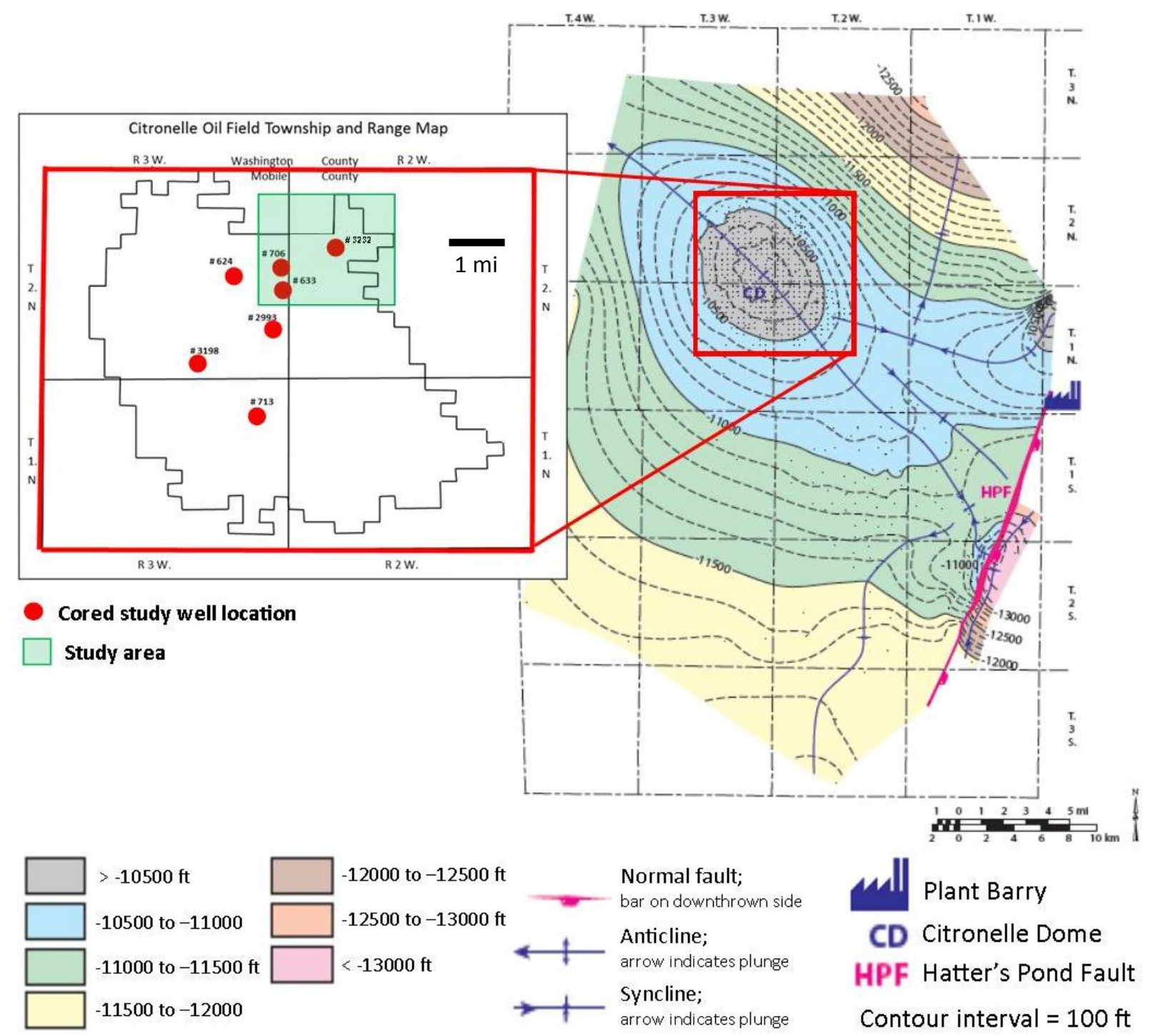

Figure 2. Geologic structure map of the Citronelle Field.

Note the Citronelle Field inset with locations of cored study wells and the study area. (Modified from Pashin et al., 2007). 


\section{Chapter 2: Background}

\section{Geologic Setting}

Situated on the edge of the present-day Gulf of Mexico (GOM), southwestern Alabama underwent geologic changes associated with evolution of the GOM (Fig. 1). The GOM originated as a rift basin that began opening in the Late Triassic- Early Jurassic as the Pangean supercontinent was breaking up (Pindell and Kennan, 2001; Bird et al., 2005; Stern and Dickinson, 2010). Marine water first entered the GOM basin during the late Bathonian- Early Callovian (Fig. 3), probably through intermittent connections with the paleo-Pacific Ocean to the west (Salvador, 1987; 1991). The arid climate caused evaporation of shallow saltwater lakes and the precipitation of widespread salt (Salvador, 1987). During the Callovian, thick salt was deposited over the thin transitional crust and in lows in the region of thicker transitional crust in the northern GOM basin. Along with the salts, terrigenous redbed sediments and basaltic dikes and sills associated with initial Early Jurassic magmatic activity within the basin (Dobson and Buffler, 1997; Salvador, 1987) filled the small proto-basins within the GOM. Active rifting of the GOM is generally thought to have ceased by the earliest Cretaceous (Berriasian), and sedimentation persisted through to the present day (Galloway, 2000; Bird et al., 2005).

\section{Stratigraphy}

The Lower Cretaceous Rodessa Formation (Fig. 4) does not crop out at the surface; however its western equivalent, the Glen Rose Formation, does crop out in east-central Texas (Mancini and Scott, 2006). The Glen Rose is lithologically quite different from the Rodessa Formation in Alabama, as it is composed primarily of limestone, dolostone, and thin beds of carbonate mudstone and marlstone (Mancini and Scott, 2006). In contrast, the Rodessa 
Formation in Alabama is a primarily siliciclastic unit that contains the Donovan sand, which is itself divided into three members from top to bottom: Upper, Lower, and Middle (Fig. 4). All three members were deposited in a nearshore to fluvio-deltaic complex (Raymond et al., 1988) and are characterized by lenticular, discontinuous sand bodies interbedded with coastal plain shales and siltstones with some intraclast carbonate conglomerate and limestone facies, including rudstone and carbonate mudstone, respectively. A distinguishing aspect of the Donovan sand is that the Upper and Lower Donovan members are both oil-bearing, whereas the Middle Donovan produces mainly brine. As a result, the Upper and Lower have been targets for oil and gas exploration. Typically, the depths at which the total Upper Donovan thickness can be determined within Citronelle Field are $\sim 10,800-11,000 \mathrm{ft}(\sim 3,291-3,352 \mathrm{~m})$ subsea.

The Ferry Lake Anhydrite overlies the Upper Donovan Sand, and regional sealing formation to the Donovan Sand (Fig. 4). Below the Lower Donovan sand is the Pine Island Formation, and is comprised of mainly of red clastic sediments and some interbedded variegated shale (Raymond et al., 1988). This unit can be distinguished from the Lower Donovan in Citronelle Field by its lack of oil and its red color versus the tan/white coloration of the Donovan, as well as the Pine Island's significantly lower SP-signature than those of the Lower Donovan (Fig. 4).

\section{Lithology of the Donovan Sand}

Overall, the Donovan Sand is comprised of fluvial/marginal marine sandstones with grain sizes ranging from very fine to fine and in some portions, medium. Gray siltstones and some horizontally bioturbated and variegated overbank and marginal marine mudstones are interbedded within the Donovan sand bodies. 


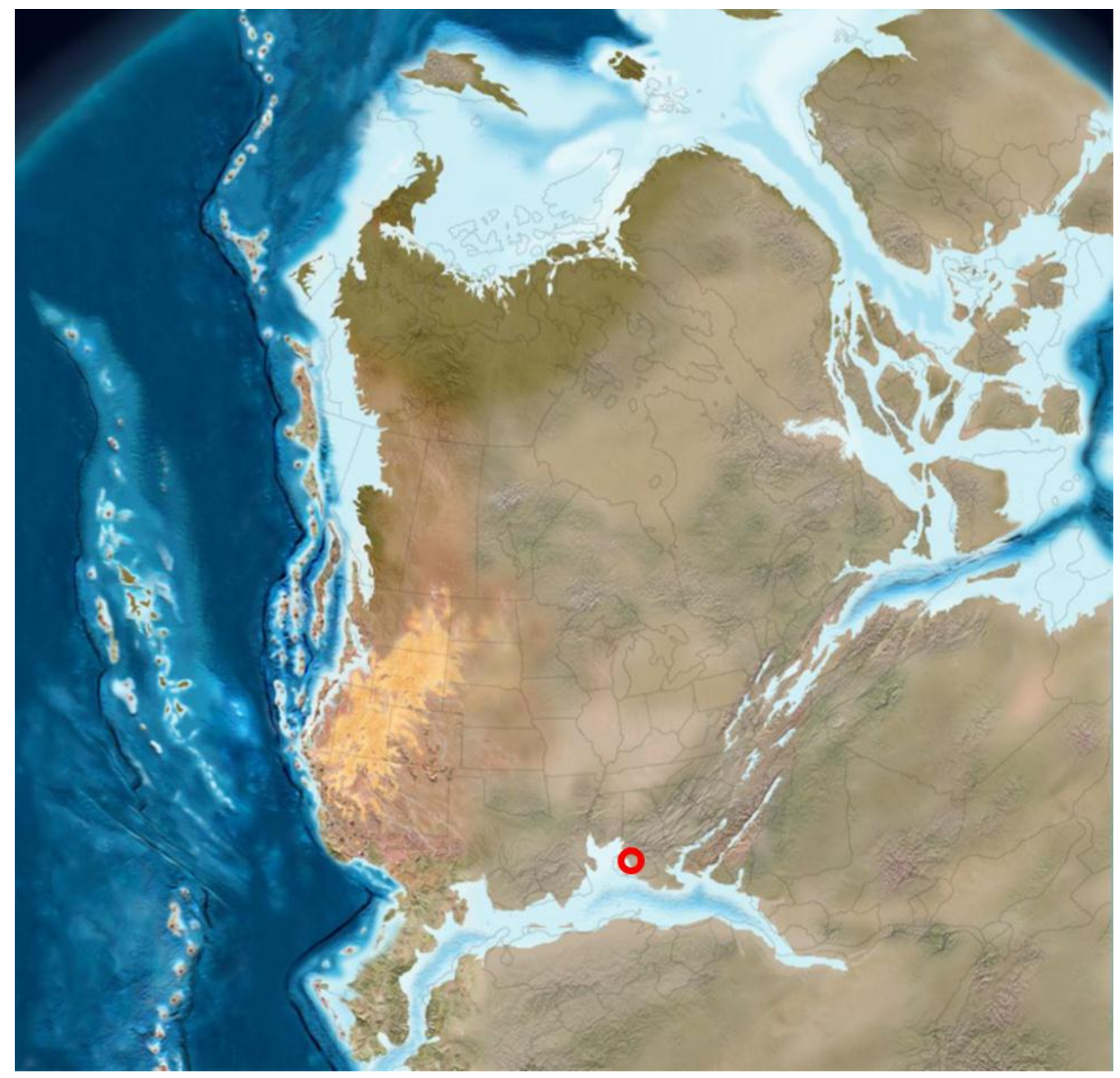

Figure 3. Paleogeographic reconstruction of the Laurentian supercontinent during the early Jurassic (180 Ma).

This figure shows the beginning stage of the creation of the proto-Gulf of Mexico via rifting. Location of the Citronelle Field is highlighted with the red circle (Modified from Blakey, 2010). 


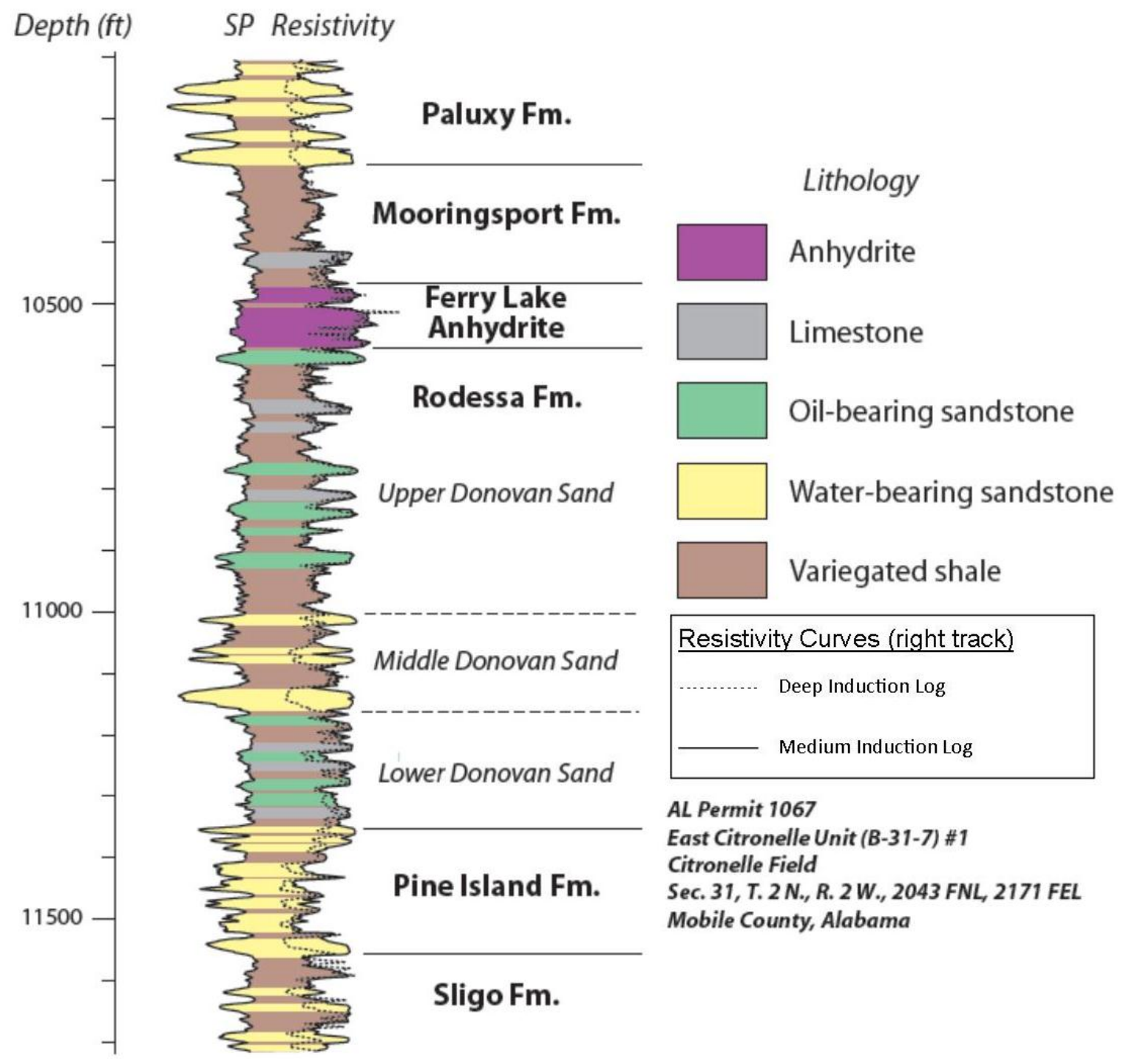

Figure 4. Type log of the Donovan Sand section.

This type log shows the Lower, Middle, and Upper Donovan Sand members (modified from Pashin et al., 2007). Deep and medium induction resistivity logs are represented by the dotted and solid lines in the resistivity track, respectively. The spontaneous potential (SP) log shows electric potential of the rock formation 


\section{Chapter 3: Methodology}

\section{Core and Thin Section Dataset}

Six cores from wells that had penetrated the Donovan sand were described and sampled for thin sections at the Geological Survey of Alabama in Tuscaloosa, Alabama. Well permit number 706 was not described by hand sample but rather by using a previously constructed graphic log that was generously supplied by the Geological Survey of Alabama after this core was viewed. The cored wells include the $\mathrm{CO}_{2}$-injection well and its nearest cored offset as well as 4 other wells within 4 miles $(\sim 6.4 \mathrm{~km})$ of the injection well (Fig. 2). Sedimentary structures, fossils, and lithologies, were observed in core samples. Graphic logs were created from core descriptions using the program SedLog (Zervas et al., 2009). These graphic logs give a visual representation of the core descriptions and show grain sizes, lithology types, interpreted depositional facies, sedimentary structures, fossils (if present), and presence of oil staining. In some cases, the cores that were to be described were not continuous. Absence of core from within the cored intervals was not accounted for in the graphic logs. In other words, the graphic logs do not necessarily reflect continuous cored section, but instead only represent description at the depths from which core samples were preserved.

Thirty-eight thin sections were point counted for compositional analysis and described for textural analysis. Point counting of thin sections allows for compositional determination of the reservoir, and was conducted with the use of a mechanical stepping stage, a Nikon Eclipse LV100 POL microscope, and the geologic point counting software Petrog Lite. The pointcounting process involved placing a thin section within the mechanical stepping stage and using Petrog Lite computer software to advance the stage and count grains using pre-programmed 
keys on the keyboard. The stage was set to move horizontally by 100 microns after each keystroke. Framework grains, cement, matrix, and pore spaces, were counted until 400 framework grains were counted in each thin section.

\section{Well Log Dataset}

Wireline logs supplied by the Geological Survey of Alabama were used for identification and correlation of petrofacies according to core-calibrated log character. In order to produce the structure map, thickness map, net sand map, and cross-section network, approximately 47 well logs, selected based upon proximity to the injector well, log availability, and log quality, were imported into GeoGraphix Discovery software suite and then interpreted. Given that Citronelle Field is a relatively mature oil field, the quality of some logs acquired from early on ( 1960-70) in the field's development was not ideal for incorporation into the project. Typically a spontaneous potential log (SP) and a resistivity log (RHOD) were available for each well, although a few wells included gamma ray (GR) and bulk density (RHOB) logs as well (Plate 1cross-sections).

\section{Transform Equations}

Using transform equation operations within the GeoGraphix PRIZM module, an estimation of bulk density (EstRHOB) was derived from SP log data (Formula \#1). First, in order to correctly assess the relationship between RHOB and SP, four cross-plots (Fig. 5, part A) were made in Microsoft Excel of the four well records within this dataset that contain both bulk density (RHOB) and spontaneous potential (SP) logs. From this plot, the mathematical relationship between $\mathrm{SP}$ and $\mathrm{RHOB}$ data was then defined in $\mathrm{y}=\mathrm{mx}+\mathrm{b}$ form, as follows: 


\section{(Formula \#1) $\quad$ EstRHOB $=0.00265(\mathrm{SP})+2.4550$}

where 'EstRHOB' represents the bulk density estimated from the relationship between actual SP and RHOB measurements demonstrated in the four well set with SP and RHOB logs available, and 'SP' represents the vector value at any given depth at which there was a SP measurement taken. The constant values '0.00265' and '2.4550' are values which were averaged from the four cross-plot regression line equations for the SP and RHOB relationships, respectively. Since there was a strong relationship between the two logs, this transform equation was used to create a new log for all logs in the data set. Hence, all dataset wells with an SP curve now also had an EstRHOB curve, since the EstRHOB equation was based off of values taken from the SP log.

Taking values from the newly created EstRHOB curve, another transform equation was used in order to produce a curve showing estimated porosity (Formula \#2).

(Formula \#2)

$$
\text { PHID }=\frac{\text { RhoM }- \text { EstRHOB }}{\text { RhoM-RhoF }}
$$

where 'PHID' represents the estimated porosity, 'RhoM' represents the density of the rock within the formation of interest, and 'RhoF' represents the density of the formation fluid. For this study, the RhoM of the Donovan Sand was assumed to be $2.556 \mathrm{~g} / \mathrm{cm}^{3}$. This value was chosen because the sands within the Donovan interval are arkosic in nature, meaning that using the RhoM values for pure quartz $\left(2.64 \mathrm{~g} / \mathrm{cm}^{3}\right)$ or pure orthoclase feldspar $\left(2.52 \mathrm{~g} / \mathrm{cm}^{3}\right)$ would be incorrect. A distribution of $70 \% / 30 \%$ in favor of orthoclase feldspar was applied to the two 
values in order to produce the weighted value of $2.556 \mathrm{~g} / \mathrm{cm}^{3}$, which represents RHOM of an arkosic sandstone composed of 70\% feldspar and 30\% quartz. Orthoclase feldspar was chosen over other feldspar types because it is the predominant feldspar type within the Upper Donovan sand, representing about $75 \%$ of the total feldspar content in most samples. There is inherently some error in this value as the sands within the Donovan Sand interval are not entirely pure orthoclase and pure quartz, however given the relatively consistent feldspar and quartz distribution within the reservoir this approach yields an adequate approximation. 'RhoF' is the density of the formation fluid and for this calculation the value was assumed to be 1.00

$\mathrm{g} / \mathrm{cm}^{3}$. Using these values, the PHID curve was created for all wells in the database. In order to show porosity distributions the average value of the PHID curve within the Upper Donovan Sand was taken using curve statistics operations within PRIZM, applied to all wells, and then posted to a WellBase layer within GeoAtlas. From this set of posted porosity averages, the Upper Donovan Sand porosity distribution map was created and then contoured manually. Manual contouring was chosen over computer-generated contouring within GeoGraphix in order to minimize error within the interpretation of the data, as the automatic contouring sometimes accentuates gaps in the data (i.e., data busts) and complicates the interpretation.

\section{Well Log Correlation}

Interpretation of the well logs consisted of using the type log to define signatures of formation tops and then picking the top and bottom of the reservoir unit in well logs across the study area. For the petrofacies correlation, a core was chosen from well permit number 3232 and converted into graphic log format. 


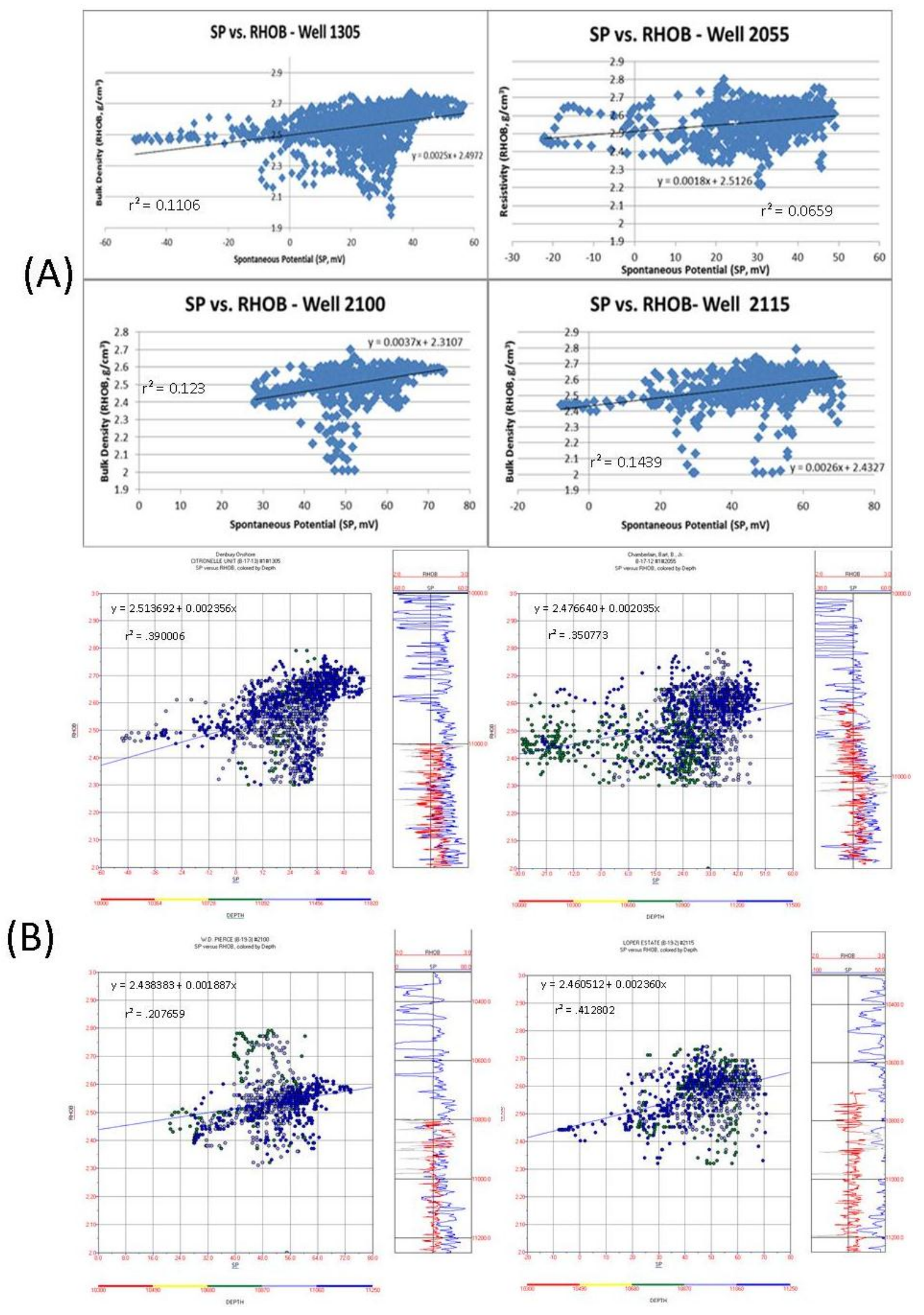




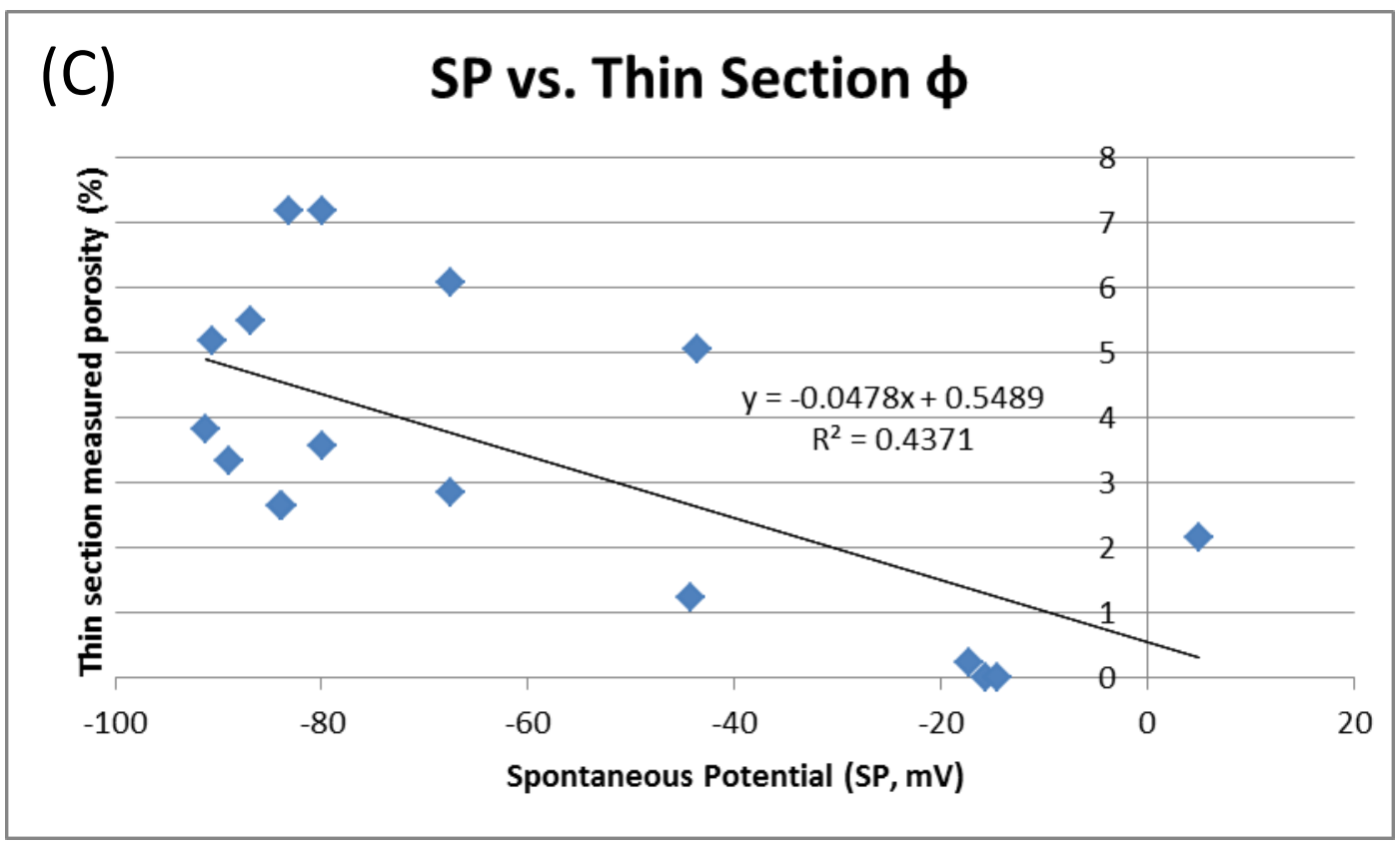

Figure 5. Cross-plots of SP vs. RHOB and thin section porosity.

(A) Cross-plots of the SP ( $x$-axis) versus RHOB ( $y$-axis) vector log values taken during logging of well permit numbers $1305,2055,2100$, and 2115 . Note the linear correlations and the equations given for the lines of best fit. (B) Same data shown in GeoGraphix cross-plot view showing increased $r^{2}$ correlation values when data points from oil and gas-charged zones have been removed. These points may be seen in (A) at $y$-axis values less than 2.3. Part (B) also shows color-coding of the data by depth, with blue and red representing the deepest and shallowest depths, respectively. (C) Cross-plot showing SP values taken from thin sectionsampled depths plotted against point-counted porosity from thin section.

Using the graphic log, the depth of the cored reservoir sample was matched with the petrophysical log signature at that same depth to create a type log section which was correlated to other nearby wells. This process was repeated for the other cored wells which had logs (well permit numbers 706 and 633) within the dataset. Upon completion of this correlation from core-graphic log-petrophysical log, the petrofacies were correlated across the rest of the well log dataset in the form of the high porosity zone (outlined in chapter 7). The Upper Donovan formation top pick chosen within the well logs served as a boundary for petrofacies 
correlation, as the petrofacies represented within the graphic logs were all identified within the Upper Donovan Sand interval. 


\section{Chapter 4: Depositional Setting Analysis}

\section{Depositional Facies Identification}

Eight depositional facies (depofacies) were defined within the Upper Donovan Sand based upon sedimentary structures, color, grain size and shape, grain sorting, composition, presence of fossils, and diagenetic facies features.

\section{Depofacies 1: Rudstone Conglomerate}

Depofacies 1 is characterized by dark gray, subangular to subrounded gravel- to pebblesized clasts (2-10 mm ( 0.078-0.393 in) in diameter) of lime mudstone and soil carbonate within the lighter gray-colored matrix of silt and very fine-grained sand with some minor amounts of coarse-grained silicate sand as well (Fig. 6). The pedogenic carbonate clasts are roughly $2-5 \mathrm{~mm}$ ( 0.078-0.196 in) in diameter and are typically light brown in color. They are also usually subrounded to rounded, and may show evidence of alteration around their edges in the form of a usually dark brown color. Some of the mudstone clasts are elongate, with the longer axis parallel to horizontal. Thin ( $<2 \mathrm{~mm} / 0.078 \mathrm{in}$ ) thick) layers of dark gray/black micaceous mudstone are sometimes evident in this facies, and fractures, if present, tend to develop along these layers. Any porosity within this facies type oftentimes has been nearly entirely filled by calcite cement, and there is no pyrobitumen staining within this facies. The matrix within this conglomerate is typically carbonate mud, and this facies fits the description for a rudstone as per the revised limestone classification scheme of Dunham (1962) by Emery and Klovan (1972). In rudstone samples, there are often dark gray stylolites evident within core samples. 


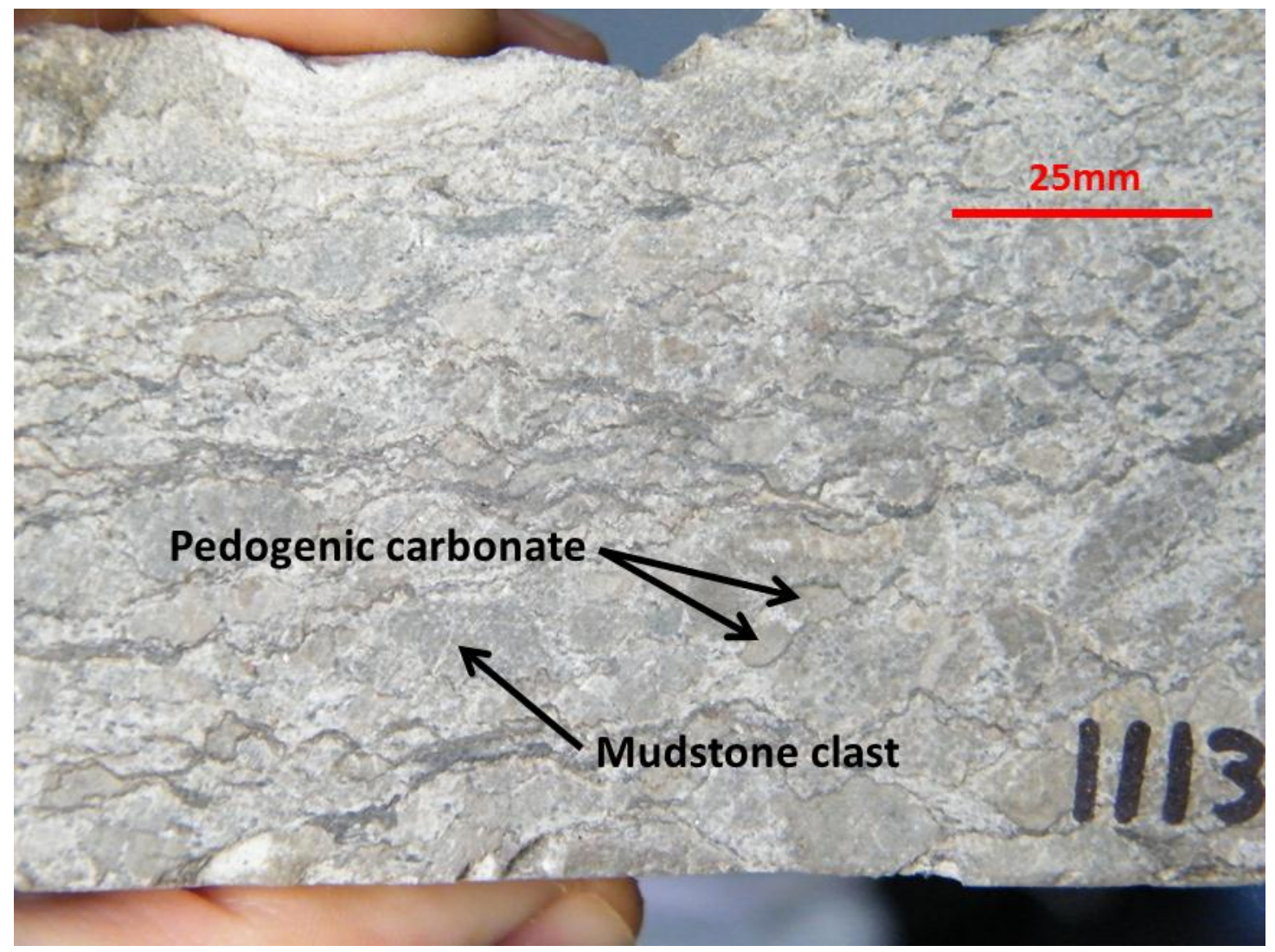

Figure 6. Depofacies 1 - Rudstone Conglomerate.

Sample was taken from well permit \# 3198 at a depth of 11,130 feet $(\sim 3,392 \mathrm{~m})$. This is a typical sample for this depofacies, with lime mudstone lithic clasts and some pedogenic carbonate fragments.

\section{Depofacies 2: Cross-bedded sandstone}

Depofacies 2 is composed of white to tan-colored, cross-bedded moderately-well sorted sandstone (Fig. 7). Cross-bed contacts within this facies are usually planar in nature. This facies can range from $\sim 0.2$ to $\sim 12$ meters ( $\sim 0.656$ to $\sim 39.37$ feet) thick (see Plate 2 ). Grain sizes within this facies range from very fine- to fine-grained and sometimes medium, and the grain shape is subangular to subrounded. Mica fragments within this facies may be as large as mediumgrained sand. Like most sandstones within the Upper Donovan interval, the composition of the 
cross-bedded sandstone is arkosic and lithic fragments comprise a small portion $(<1 \%)$ of the sandstone framework grain distribution. (Table 1, in Appendix).

Cementation of this depofacies is variable, and where there is porosity, light-dark brown/black pyrobitumen staining is apparent. This staining is typically bound to $\sim 1$ meter ( 3 $\mathrm{ft}$ ) intervals, and is typically sharply interrupted as facies change within the core. Calcitic to dolomitic concretions ranging from 6-10 mm ( 0.236-0.393 inches) are present in some zones where pyrobitumen staining is evident. Secondary porosity due to cement and framework grain dissolution is evident in thin-section samples of this facies, and contributes significantly to the overall porosity amount.

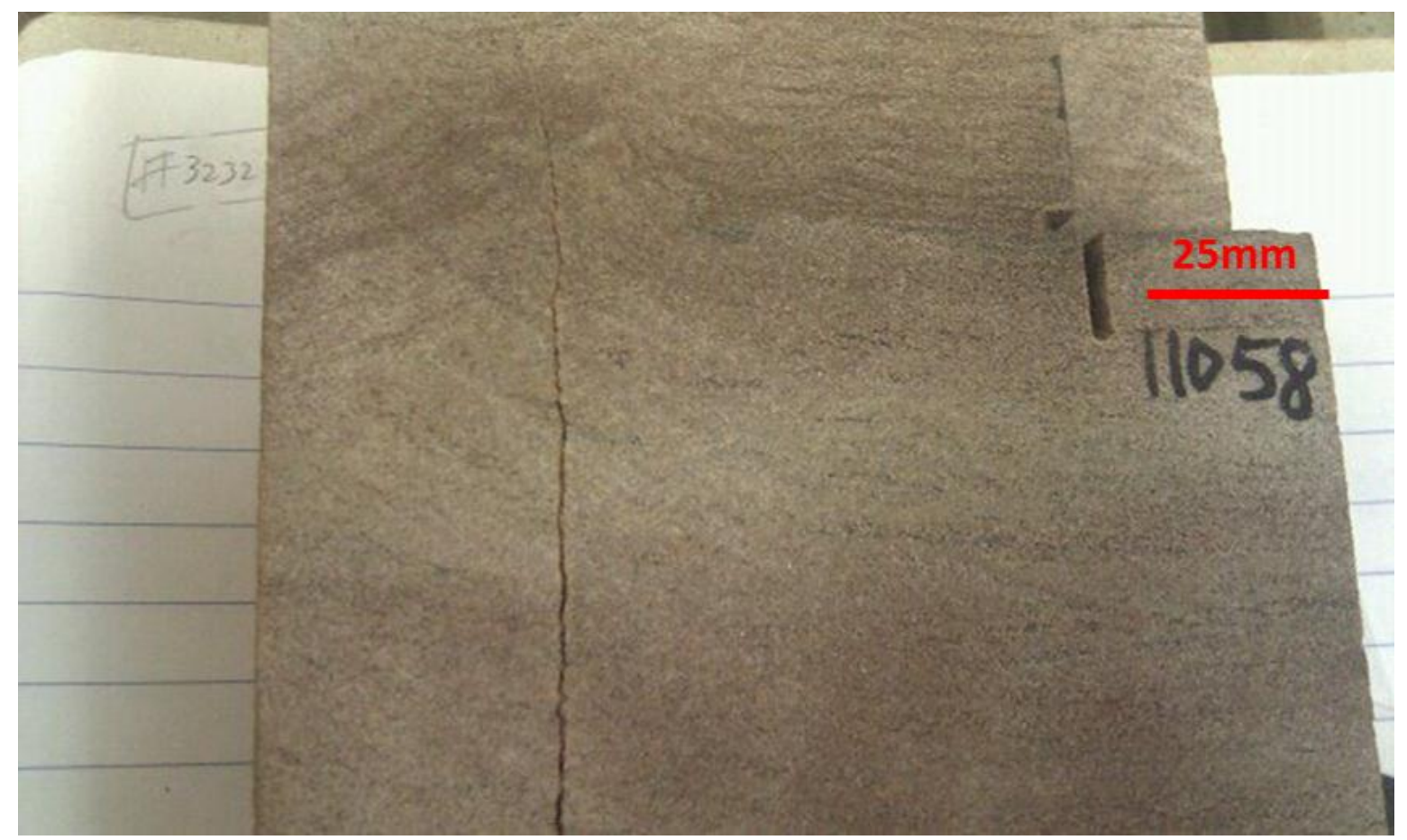

Figure 7. Depofacies 2 - Cross-bedded sandstone.

Core was taken from well permit \# 3232 at a depth of 11,058 feet ( 3,370m). Fracture was likely created during the coring process and did not occur naturally. 


\section{Depofacies 3: Massive to horizontally laminated sandstone}

Depofacies 3 (Fig. 8) consists of primarily featureless or horizontally-stratified poorlysorted sandstone. Bed thicknesses may range from 1-2 meters up to 5-6 meters ( 3-19 ft). Much like depofacies 2, the grain size of this facies is very fine to fine, and grain shape is subangular to subrounded. This facies is also characterized by a beige/tan/white color and a slightly higher amount of mica than depofacies 2.

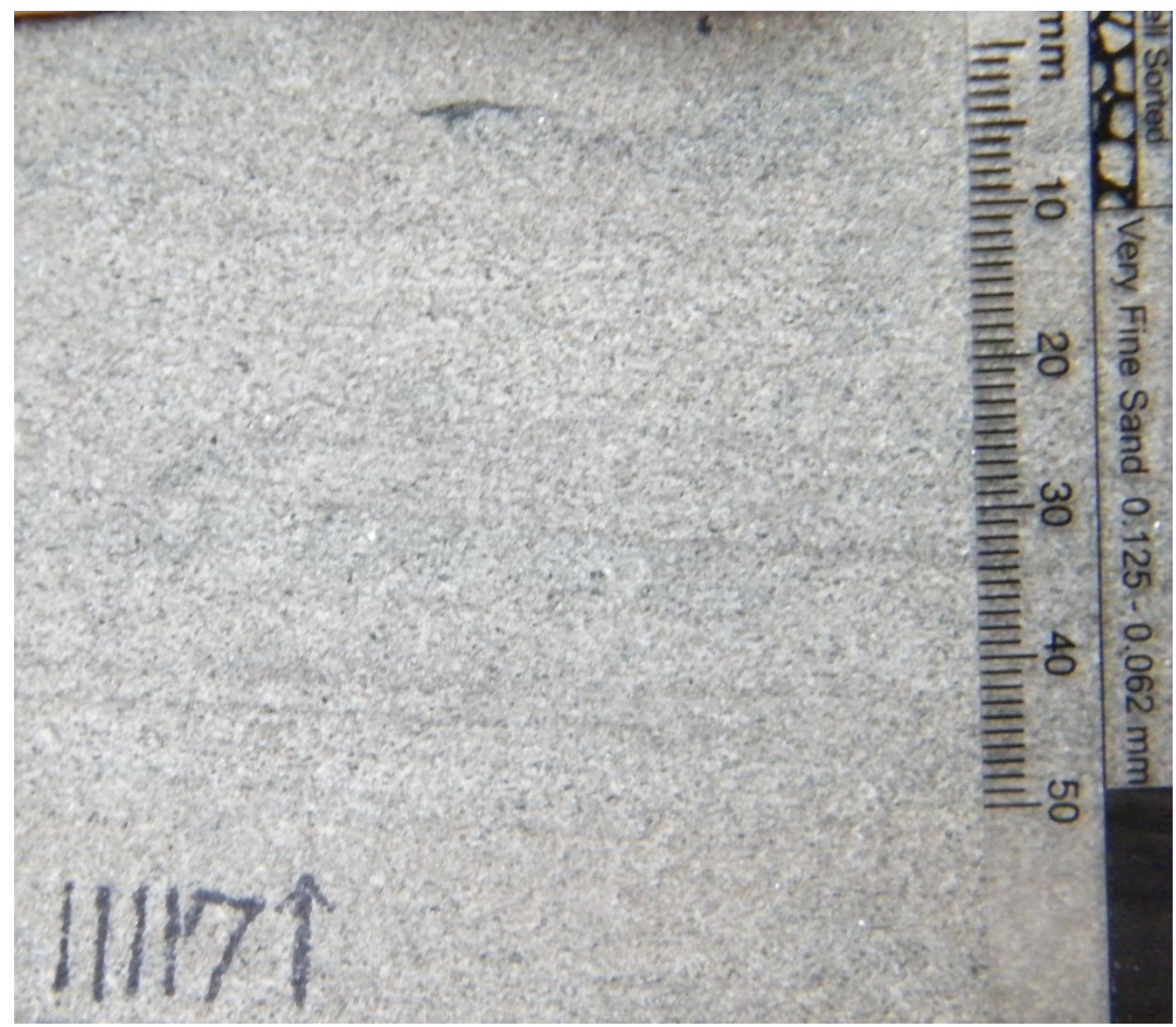

Figure 8. Depofacies 3 - Massive to horizontally laminated sandstone.

Sample was taken from well permit number 3198 at a depth of 11117 feet $(\sim 3,388 \mathrm{~m})$. Notice the darker laminations through this core sample and the black, flattened organic matter fragment within the upper portion. 
Pyrobitumen and live oil staining are relatively common within porous zones of this depofacies, and these stained zones are sharply truncated rather than gradational in the vertical direction. Degree of cementation varies from well-cemented to semi-friable, and the dominant cement phase observed in thin-section is calcite. There are zones within this depofacies that have numerous small (6-10 mm/0.236-0.393 in) in diameter) calcite/dolomite concretions (Fig. 9) in an otherwise moderately-cemented zone, but the concretions are not so many in number as to degrade the overall porosity within this depofacies.

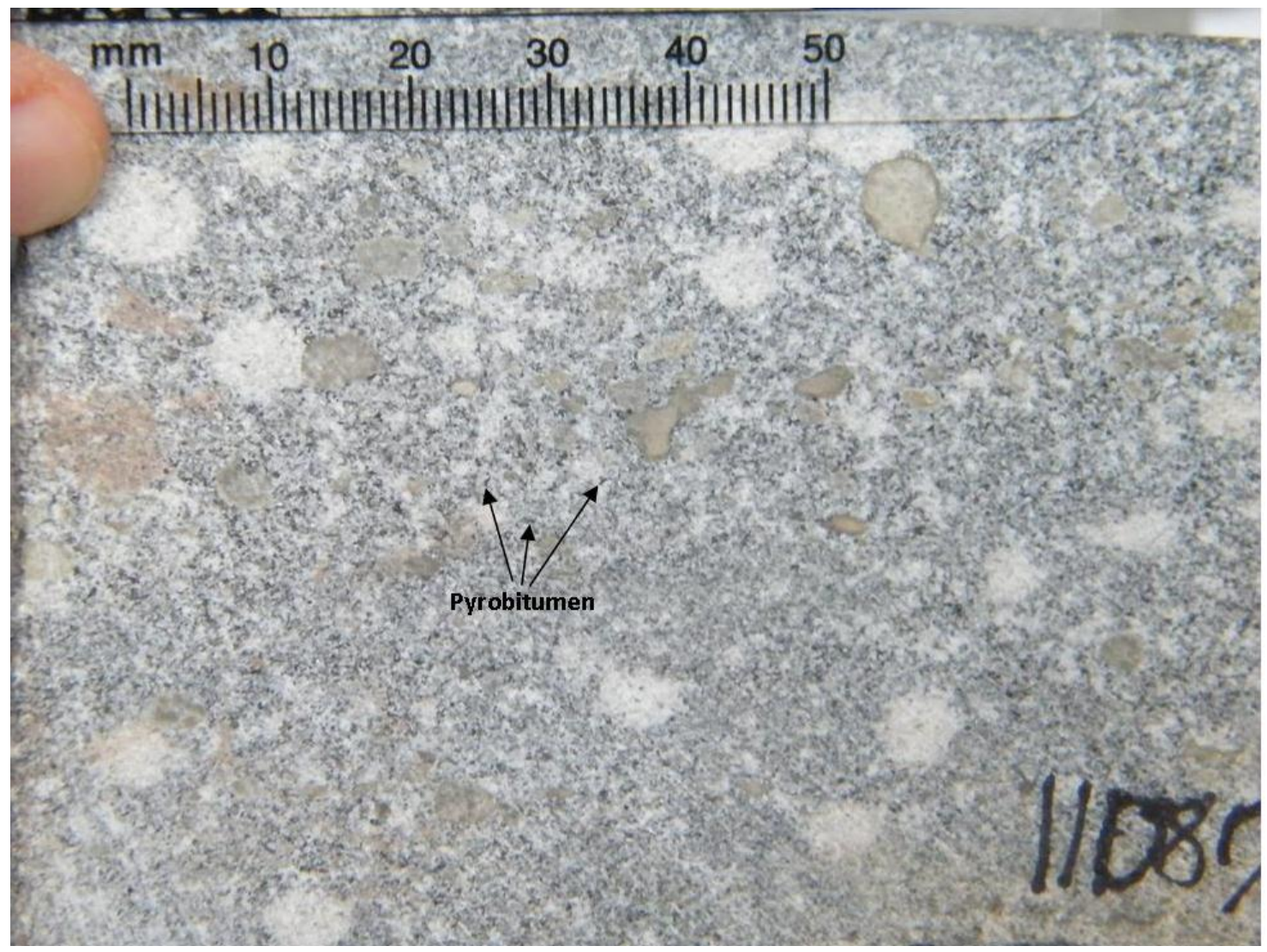

Figure 9. Depofacies 3 - Massive sandstone with calcite concretions and pebble-sized carbonate clasts.

Sample was taken from well permit \# 3198 at a depth of 11087 feet $(\sim 3,379 \mathrm{~m})$. Notice the white calcite concretions and the more brown/tan colored pedogenic carbonate fragments. Black staining of the rock is due to dead oil within pore spaces. 
As in depofacies 2, the composition of the sand is arkosic and secondary porosity created via cement and framework grain dissolution is a major pore type within this depofacies.

\section{Depofacies 4: Ripple-laminated Siltstone}

Within this facies, gray and sometimes red siltstones show ripple laminations and occasionally some additional small amounts of very fine white to gray subangular sand. This facies is predominantly composed of silt-sized quartz and an argillaceous matrix with large amounts of muscovite and sometimes biotite micas. Scour marks as well as planar crossbeds are present. Vertical burrow traces and moderately to heavily bioturbated zones are commonly found in this depofacies. White-colored plant root traces are rarely found within this zone. Planar laminae of this facies fracture readily and are lined with silt- to very fine grained sandsized mica grains. These fractures provide high porosity zones, but pyrobitumen staining of some portions of the siltstone indicates additional pore space. Sometimes the dead oil may be found in zones that have small (6-10mm/0.236-0.393 in) in diameter) and numerous calcite concretions.

\section{Depofacies 5: Massive to horizontally laminated siltstone}

Alternating red/green and sometimes gray-colored massive and horizontally stratified siltstone deposits dominate depofacies 5. Compositionally, this facies is very similar to depofacies 4 but with approximately $30-40 \%$ more mud within the matrix in most cases as well as with inclusions of some lighter gray-colored lithic fragments. Pyrobitumen may be found in this depofacies, typically within zones where there are numerous dolomite-cemented concretions. These concretions are roughly $6-10 \mathrm{~mm}(0.236-0.393 \mathrm{in})$ in diameter and are also found in depofacies 2-4. There are also mainly horizontal rather than vertical burrows, and 
degrees of bioturbation are generally higher in this depofacies than depofacies 1-4. Level of bioturbation is equivalent to ichnofacies 3 (10-40\% of bedding disturbed) of Droser and Bottjer's (1986) ichnofacies fabric index.

\section{Depofacies 6: Bioturbated and Burrowed Mudstones and Shales}

Bioturbated and burrowed gray/green and sometimes red shales and mudstones are

present in depofacies 6 . Most deposits are moderately to heavily bioturbated, with $40-60 \%$ of bedding disturbed; only the last remnants of bedding discernible (ichnofacies 4, Droser and Bottjer, 1986) and both vertical and horizontal burrows are evident in core samples.

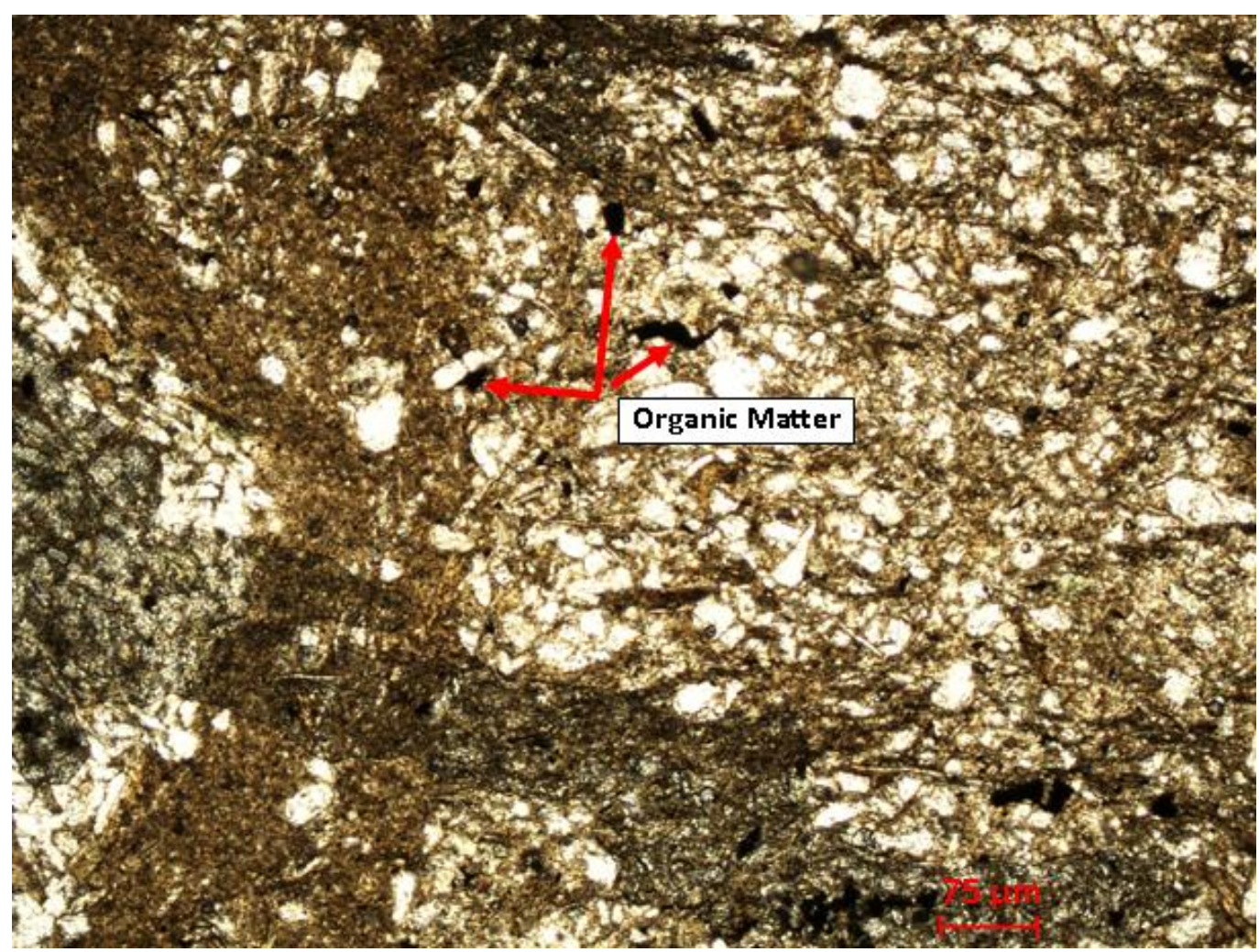

Figure 10. Depofacies 6 - Bioturbated and burrowed mudstones and shales.

Notice the organic matter (black fragments, denoted by red arrows) within the silty mudstone matrix. (From sample 624-11410.) 
Oyster shell fragments in this facies are the only described body fossils within this depofacies but are not seen in every deposit. Organic plant material is also present in the form of black fragments (Fig. 10). Depofacies 6 is mainly composed of clay with some micaceous silty sections. Where the siltstone is absent, mudstones of this facies are quite soft and may be scratched with a fingernail. Horizontal fractures may be present, and there has been no evidence of pyrobitumen staining along fractures within this facies. These fractures appear to be naturally occurring, rather than having been created by coring-related stresses because the fractures appear to follow bedding planes versus randomly oriented. The fractures are also relatively clean breaks within the rock rather than having broken the majority of the rock in this section as may occur in drilling.

\section{Depofacies 7: Horizontally Laminated Shales}

Depofacies 7 is comprised of horizontally laminated shales with no evidence of fossils, bioturbation, or grains larger than silt. Black and dark gray shales are diagnostic of this depofacies, and they are typically homogeneously comprised of clay minerals with some organic matter. Beds within this depofacies are often up to 5-7 meters (16-22 ft) thick, but may be as thin as 0.3 meter ( $1 \mathrm{ft})$, and this depofacies also is sometimes truncated on its upper bedding plane by an erosional surface and a coarser-grained deposit immediately above.

\section{Depofacies 8: Calcareous mudstones}

These mudstones are somewhat rare within the Donovan interval, and are gray to light gray in color. There are fractures within some limestone intervals, and occasionally there is evidence of hydrocarbon staining within them. Beds of this mudstone are typically thin, ranging in thickness from 0.2 meter to 1 meter $(\sim 0.6-3 \mathrm{ft})$. 


\section{Interpretation}

\section{Depofacies 1}

The nature of the conglomerate depofacies indicates very high energy turbulent flow during deposition. However, given that the sorting is poor within this depofacies, a combination of both high energy and low energy flow regimes could be responsible for this deposit. During the early Cretaceous sea level was fluctuating, with alternating phases of regression and transgression (Mancini and Puckett, 2002). Given the larger clast size and the inclusion of the pedogenic carbonate clasts, the interpreted fluvial character for the other depofacies, the lack of grading within this depofacies that would suggest waning flow (e.g., flood currents), and the fluctuating sea level during time of deposition (Mancini and Puckett, 2002), this facies is interpreted to have been formed from fluvial valley incision or downcutting of a tidal ravine (c.f., Esposito, 2010). As the fluvial system incised into the substrate, soil horizons within which these carbonate clasts formed were reworked. The clasts were incorporated directly into the fluvial system as bedload and accumulated along with other bedload sediments. The mudstone fragments could have been incorporated in the same manner as the pedogenic carbonate, but could be sourced from a mudstone layer rather than a paleosol. The possibility exists, however, that the mudstone clasts may have simply been sourced from the same muddy paleosol as the pedogenic carbonate clasts.

\section{Depofacies 2}

The cross-bedded sandstone of this depofacies indicates that unidirectional flow existed and that the sediment transport mechanism was mainly fluvial channel bedload rather than suspended load. Grain size ranges within this depofacies provide evidence for moderate energy 
flows, as sands ranging from very fine- to medium-grained are present. Fluctuating flow levels and unidirectional flow orientation are both consistent with a fluvial setting for deposition (Allen and Collinson, 1974). Occasional climbing ripple cross-stratification indicates that there may have been rapid deceleration of flow that was carrying a high amount of suspended veryfine sand (Ashley et al., 1982). These small-scale $(<\sim 5 \mathrm{~cm} / \sim 1.968$ in thick) deposits could be representative of crevasse splay deposits that had broken through the channel levee, as the deceleration would have been provided by dispersion of unidirectional flow once the water had escaped the channel.

Concretions within this depofacies are interpreted to be diagenetic in nature due to their nearly spherical shape as well as the carbonate cement's crystalline structure that has often been preserved within the thin sections taken from this depofacies. Depofacies 2 is interpreted as representing the fluvial channel deposits. This is in agreement with previous interpretation of the Donovan Sand as a vertical conglomeration of fluvial channels (Esposito, 2010).

\section{Depofacies 3}

Without any sort of sedimentary structure, aside from some horizontal laminations, this depofacies is mainly comprised of massive, featureless sandstone. Concretions seen within this depofacies are of the same nature as those within depofacies 2,4 , and 5 . The sandstone composition is nearly identical to depofacies 2 , but there is no cross-bedding in this depofacies. A possible explanation for this lack of sedimentary structure is that there could have been rapid deposition which could have suppressed formation of any ripple marks or bedforms that could be generated by unidirectional flow, but not so fast as to allow for large-scale dunes to develop 
(Ashley et al., 1982). The subrounded grain shape dictates that the sediment would have had to have been transported over a significantly longer distance than the sediments in depofacies 2 , that the sediments in depofacies 3 were delivered by a slightly higher energy system, or that the sediments were reworked by shoreface or eolian processes.

A braided stream environment is consistent with evidence supporting high energy flow regimes and the poor grain sorting evident in this depofacies. Featureless sandstones may be deposited within a braided stream if the channel flow velocities are very concentrated and did not allow for planar cross-bedding to occur (Martin and Turner, 1998). The concentrated flow would need to fit the velocity conditions outlined previously by Ashley et al. (1982) in order to preclude the formation of ripple crossbeds, but horizontal laminations and featureless sandstone deposits may be formed within a braided reach of the stream systems. The increased thickness of this depofacies also indicates that there was a high sediment bedload, which is key to the formation of a braided stream (Prothero and Schwab, 2003).

\section{Depofacies 4}

Ripple laminations are an indication of unidirectional flow under lower flow regime conditions. In siltstones, these laminations indicate that there was a relatively low energy level, as silts tend to remain in suspended load if flow is highly turbulent. The presence of both vertical and horizontal burrow traces within these sediments suggests that organisms were active within this depofacies.

Unidirectional flow is consistent with a fluvio-deltaic environment. The finer-grained sediments in depofacies 4 could have been transported by the same fluvial system as that of depofacies 2, but these silts would have been deposited once the energy level had dropped, 
hence bypassing the higher energy braided stream reach. The ripple laminations must have been created due to minor bedload transport, and this could have occurred along a channel once there a decrease of the flow velocity. Preserved plant root traces within this depofacies also lend to the interpretation that this was a lower energy environment. These roots could have been present just outside of the channel, along the banks or levees that may have been present at the stream's edge or between distributary channels within a delta. A low-energy channel that transports mainly silt can be present in a braided stream system (Allison, 1998), however given the mud content of this depofacies and the degree of bioturbation, a tidallyinfluenced deltaic distributary channel is the inferred environment for deposition of this facies. Silts may be interbedded with mud laminae within a tidal channel, but are rarely seen in high energy, non-abandoned fluvial channels. Hence, the tidal environment better suits this depofacies because it offers an explanation for the higher amounts of mud in the channel.

\section{Depofacies 5}

Red-colored silt deposits of this depofacies indicate oxidation of iron-bearing minerals within the sediments via exposure to atmospheric oxygen. This depofacies contains more mud than any of those previously discussed, but also contains the same type of concretions that have been seen in depofacies 2,3 , and 4 . The greater abundance of mud within these siltstones indicates deposition from by suspended load. Horizontal laminations of these finer-grained sediments indicate suspension fall out in a very low-energy environment, as the laminations would likely be disturbed if currents interacted with them. Some horizontal burrows also indicate that the energy level within depofacies 5 may have been lower than in the previously 
discussed depofacies, because organisms will burrow vertically into the underlying sediment for self-preservation purposes in high energy environments (e.g., Buatois et al., 2008).

A low energy environment that is tied to fluvial systems is the floodplain. A large enough flood to increase the energy level to that necessary to transport silt would allow for silt and muddy sediments to be transported to the floodplain (Hudson, 2005). Although these periodic floods occurred, the presence of anhydrite in many thin section samples indicates that there was a semi-arid to arid climate (Esposito, 2010) during the deposition of the Donovan Sand. The horizontal lamination of the silts indicates that upon deposition, the sedimentary structure was not disturbed except from minor bioturbation. Higher amounts of bioturbation (ichnofabric 4; Droser and Bottjer, 1986)) also provide evidence for a low energy environment because burrows have higher preservation potential in a lower-energy versus a higher-energy environment for reasons discussed previously. The reddish-green color suggests these sediments were exposed to subaerial conditions upon deposition. Oxidation of these sediments may have occurred after the floodwaters subsided, leaving only the sediments exposed subaerially on the floodplain.

\section{Depofacies 6}

Muddy lithologies of depofacies 6 indicate that the majority of the sediment deposited in these zones was transported via suspended load. Deposition of this suspended load, as with the floodplain muds in depofacies 5 , requires the energy to be very low during deposition. However, the inclusion of some silt and organic fragments may mean that there was some turbulence of the water. 
These features indicate an estuarine environment interpretation for depofacies 6.

Suspended load sediments, including the organic matter and silts, could have been carried to a more distal environment than that of depofacies 5. It would be within this distal environment that these sediments would fall out of suspension if the stream's energy slightly decreased. At freshwater-saltwater mixing zones within estuarine environments, the density of the saltwater in comparison to the freshwater effectively halts slower bedload transport (Nichols and Biggs, 1985) causing, the silty bedload fraction to be immediately deposited at this interface. The oyster shell fragments within these mudstones and shales also indicate a brackish water setting for deposition, which is consistent with the depositional setting of an estuary.

\section{Depofacies 7}

Horizontally laminated shales are indicators of low energy deposits formed by deposition of platy clay particle from suspension. Considering that this is the most fine-grained depofacies within the dataset, this is the lowest energy clastic depofacies. The occasional black coloration of these deposits indicates anoxic conditions during deposition. The greater thickness of this depofacies indicates that sedimentation occurred consistently rather than episodically. The Donovan Sand has been interpreted in the past as being deposited during an overall marine transgression (Mancini and Puckett, 2002), and as such this depofacies is interpreted to represent a prodelta shale. Graphic logs within which this depofacies is present show a coarsening upward succession in deposits stratigraphically just above these shales, and these shales typically mark the top portion of a fining-upward sequence. These factors combined reinforce that sea level could have been fluctuating during deposition of this 
depofacies, but that this facies was deposited during a localized (due to abandoned delta lobe subsidence), global (eustatic), or combined local and global marine transgression.

\section{Depofacies 8}

Limestones are deposited as the result of a lack of clastic deposition. During times when there was no transport mechanism for sediments in this deposystem, limestones were forming. These periods of nondeposition were relatively short-lived, because the thickness of these beds would be much greater otherwise. This facies is typified almost exclusively by lime muds with no observed fossils in the cores.

Factors such as sand influx, water temperature, and depth would all play a significant role in the deposition of this limestone depofacies. Given the an overall transgressive behavior

of the shoreline during Donovan time, and clastic deposition occurring within the estuary which would have precluded abundant limestone deposition, this depofacies is interpreted to have occurred on the shallow marine shelf seaward of the prodelta environment. Limestone has been documented to have deposited during marine transgressions in the past, particularly within marine shelf regions, as part of cyclothems (Caldwell, 1983). Although these Citronelle deposits are not interpreted to be cyclothems, the process for limestone deposition during transgression applies to these deposits.

\section{Analog: The Ganges-Brahmaputra Delta}

The Ganges-Brahmaputra (G-B) delta, located in the People's Republic of Bangladesh, is currently the world's largest delta and is named for the confluence of the two major sediment delivering rivers within it (Fig. 11). It is the drainage basin for streams beginning in the Himalayan Mountains and ending in the Bay of Bengal. The upper portion of the delta is 
essentially a braided river-type system with multiple freshwater channels and silty interfluves. Most of the sediment fraction is comprised of silt-sized particles with some fine sand and mud (Allison, 1998). Landward of the G-B delta, the Brahmaputra River is a braided stream, with voluminous sandy sediments and inadequate flow to remove these sediments. The Ganges on the other hand, carries silt and mud with some very fine-grained sand as bedload (Allison, 1998; Goodbred et al., 2003).

The smaller, lower energy channels within the lower reaches of the G-B delta are prone to rapid and major lateral avulsion, creating multiple and widespread overbank deposits as they do so (Goodbred et al., 2003). At the mouth of the G-B delta system is the Meghna estuary region, which consists of multiple islands and channels. Diurnal tides create stacked sequences of silt and mud as they flood the channels which deliver the sediment to the delta (Allison, 1998).

The upper fluvial-dominated reaches of the G-B delta are interpreted to be analogous to depofacies 1, 2, and 3. Sea level was fluctuating during the early Cretaceous (Mancini and Puckett, 2002), and during regressions, the stream responsible for delivering the Donovan sediment incised into the underlying substrate in response to the drop in base level; depofacies 1 would be deposited within this incised valley. Higher energy deposits such as the crossbedded channel sands and braided stream deposits of depofacies 2 and 3, respectively, are analogous to deposits of the braided fluvial environment of the upper G-B delta. As the slope decreases, so too does the energy of the fluvial system. However, there are periods of monsoon rains that affect the G-B delta and increase the energy level of the streams (Allison, 1998; Goodbred et al., 2003). When floods occur as a result of these monsoons, the channel cannot 
contain the higher volume of water and the floodplains become inundated with sediment-laden water. Depofacies 5 represents the floodplain deposits that were accumulated as a result of these periodic events.

In the lower reaches (Fig. 11), the coarser-grained sediments are deposited as the gradient and energy level of the fluvial system continues to diminish and silts and muds become the dominant caliber of the sediment load. As the fluvial system terminates in the estuary and the mixing of freshwater and seawater occurs, as within the Meghna estuary within the G-B delta, the fluvial system transforms into a number of tidally-influenced deltaic distributary channels (depofacies 6). The most seaward portion of this delta distributary complex would be the prodelta, which is typified by the muddy deposits of depofacies 7. Because the climate was semi-arid to arid (Esposito, 2010), the discharge of the sediment system may have periodically been diminished. This drastic change in sediment delivery to the basin would have allowed for limestone deposition at the distal portions of the marine shelf. This portion of the sedimentary system would become the carbonate shelf, and deposits within this marine shelf consist of limestones outlined in depofacies 8. 


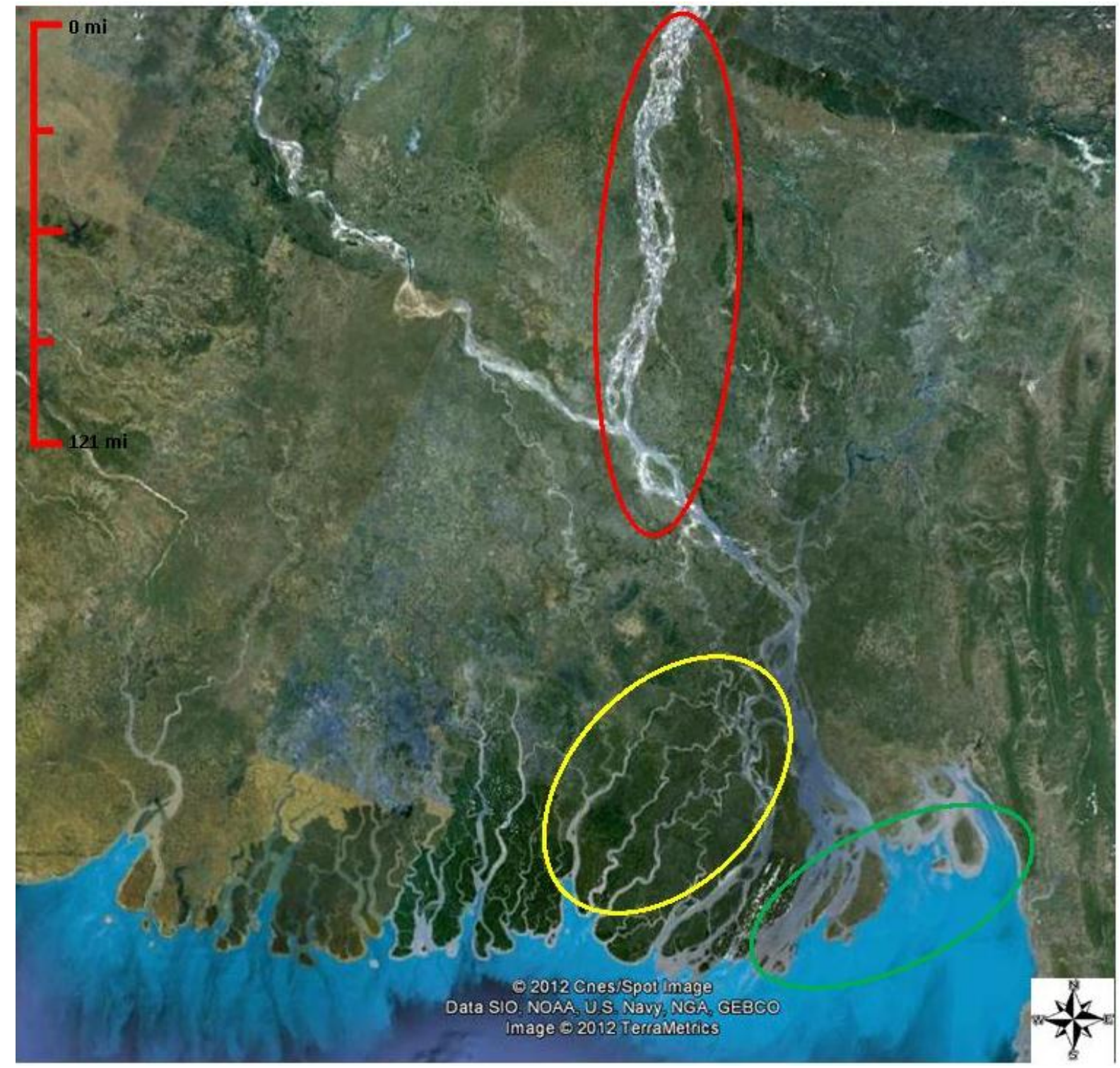

Figure 11. The Ganges-Brahmaputra Delta System.

Note the upper braided stream reach (outlined in red), the lower meandering stream reach (partly outlined in yellow), and the lower tidally-influenced estuarine region (outlined in green). (Modified from Google Inc., 2012.) 


\section{Chapter 5: Donovan Sand Analysis}

\section{Donovan Sand Composition}

\section{Framework Grains}

The three main framework minerals within the Donovan Sand are quartz, feldspar, and lithic fragments (Fig. 12; percentages listed in Table 2 in appendix). Quartz grains are typically subangular to subrounded and ranged in size from very fine-grained to medium grained (Fig. 13). They also were primarily monocrystalline, though there are some portions of the reservoir that contain minor ( $1-2 \%$ of total framework grain count) polycrystalline quartz. Roughly $60 \%$ of the quartz grains exhibited undulatory extinction when viewed under crossed polarizers.

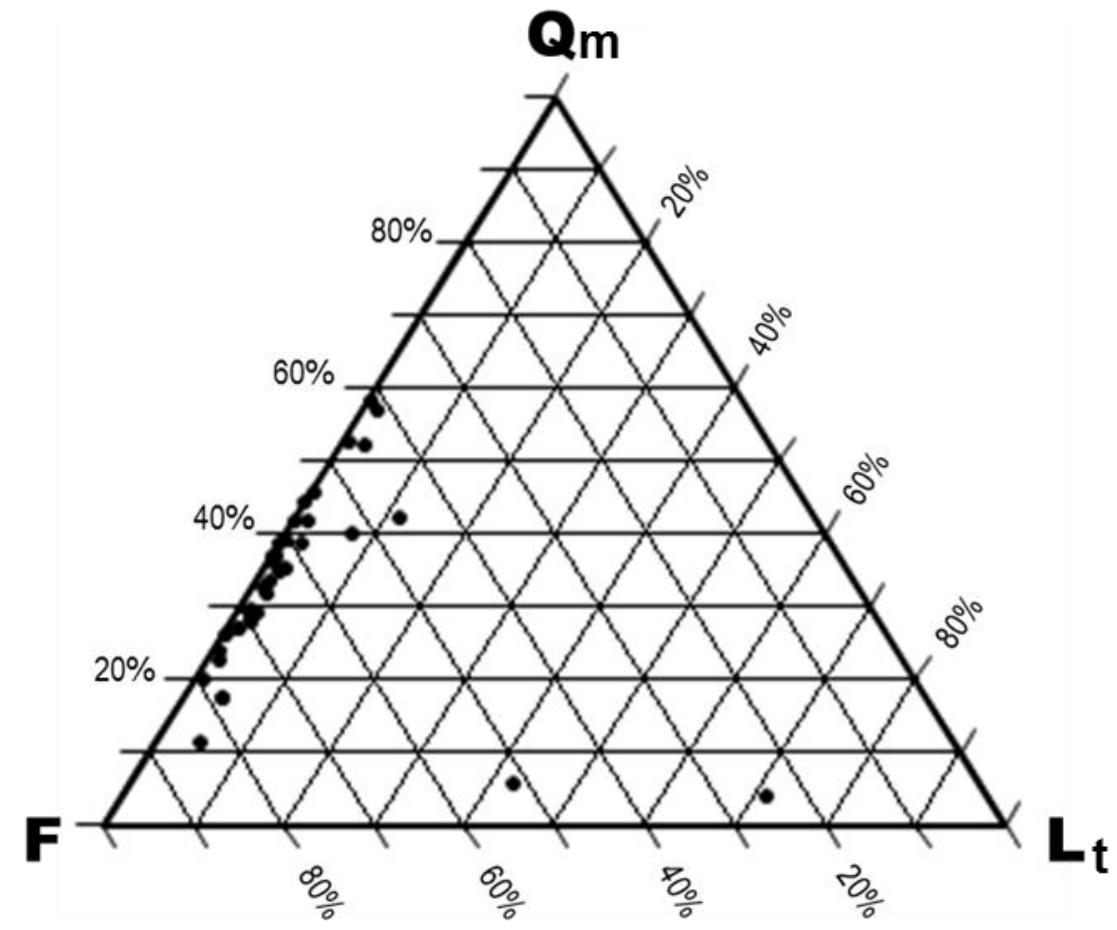

Figure 12. QFL ternary diagram for the Donovan Sand thin sections.

Compositional data were gathered by point-counting 400 framework grains in thin-section samples. Data presented in the form of Qm-F-Lt, with $\mathrm{Qm}$ representing monocrystalline quartz, F representing all feldspars, and Lt representing all lithics (including polycrystalline quartz). The majority of the thin-sectioned reservoir samples have high amounts of feldspar and few lithics. Ternary plot formulae and design from Graham and Midgley (2000). 
Lightly altered feldspars in the Donovan usually were rectangular in shape, but were also subrounded to subangular in some cases. Plagioclase feldspar was also seen in minor amounts and most of the time exhibited albite twinning. Orthoclase may be distinguished from some plagioclase by nature of the distinctive albite twinning in plagioclase as well as the alteration pattern of plagioclase along its twinning planes, although these twins are not evident in all plagioclase feldspars. Because the sections were not stained for feldspar, it was not always possible to distinguish untwinned plagioclase from orthoclase. Microcline feldspar was present in a minor amount within some thin sections, and it is distinguishable from other feldspars by its tartan-plaid twinning (see Fig. 14). As with the plagioclase feldspar, microcline was subject to chemical alteration along its twinning planes as well as the grain edges. Feldspars showed evidence of dissolution along the twinning planes as well as around the grain edges (Figs. 13, 15 , and 16). Occasionally feldspar grains contained some other mineral phase such as calcite or clay such as sericite, within the grain framework as products of alteration. Intragranular void space, as well as dissolution of the grain edge was a result of dissolution of the secondary mineral alteration product. Feldspars also show evidence of compaction within the reservoir, as some grains exhibited sutured grain boundaries.

Mudstone lithic fragments seen in thin section are typically subrounded and flattened due to compaction. Most of these lithic fragments were partly opaque under plane-polarized light, but exhibited a beige to brown color under cross-polarized light (Fig. 17). Limestone and dolostone lithic fragments typically showed a particular mineral cleavage under crossed polarized light. 


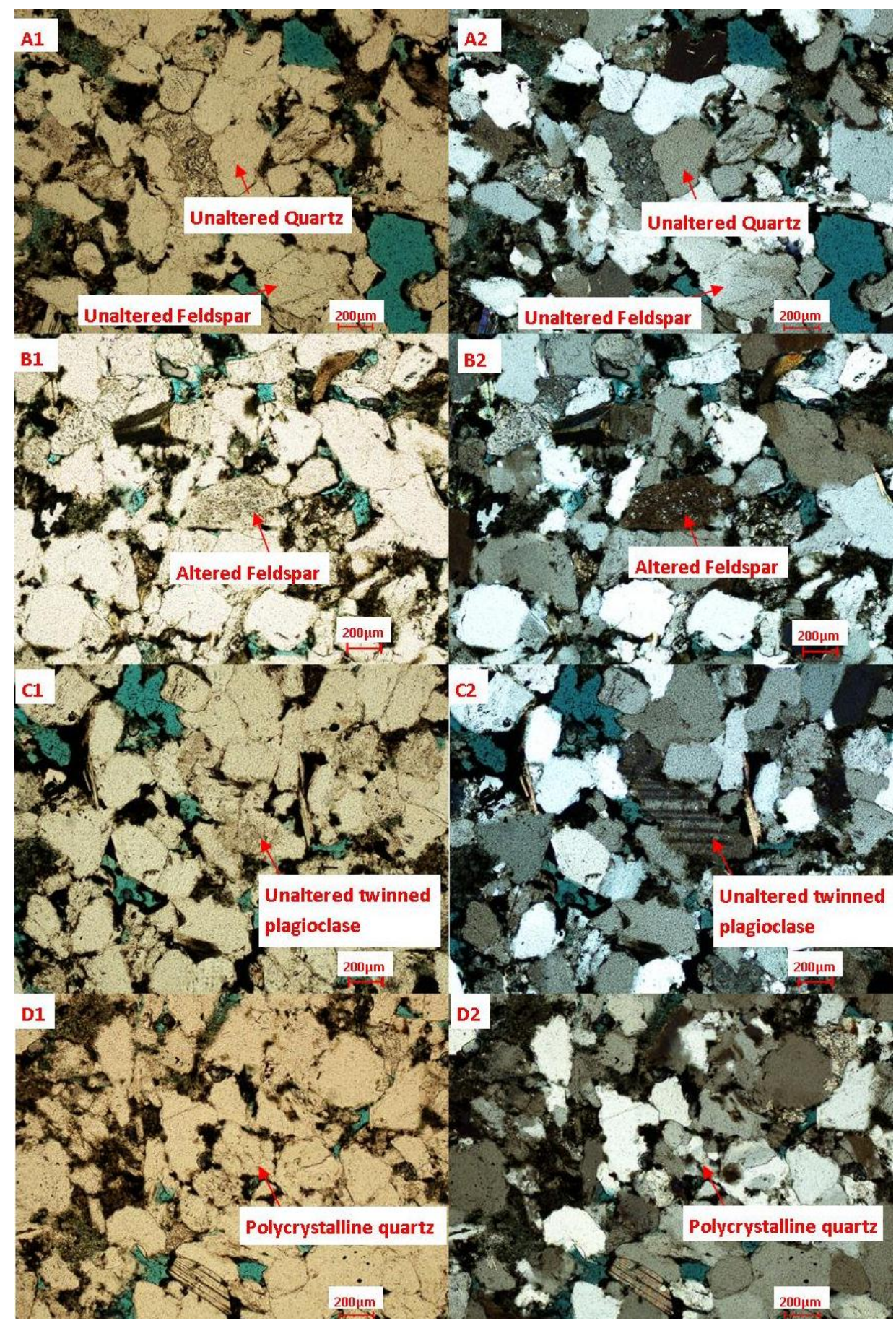

Figure 13. Common framework grains of the Donovan Sand.

Photomicrographs of minerals in plane-polarized light (PPL; left) and cross-polarized light (XPL; right). $A 1$ and $A 2$ : Unaltered quartz and feldspar grains as seen in PPL (A1) and XPL (A2). B1 and B2: Altered feldspar grains as seen in PPL (B1) and XPL (B2). C1 and C2: Unaltered albitetwinned plagioclase as seen in PPL (C1) and XPL (C2). D1 and D2: Polycrystalline quartz grain as seen in PPL (D1) and XPL (D2). All photomicrographs in this figure are from sample 3232-11378. 


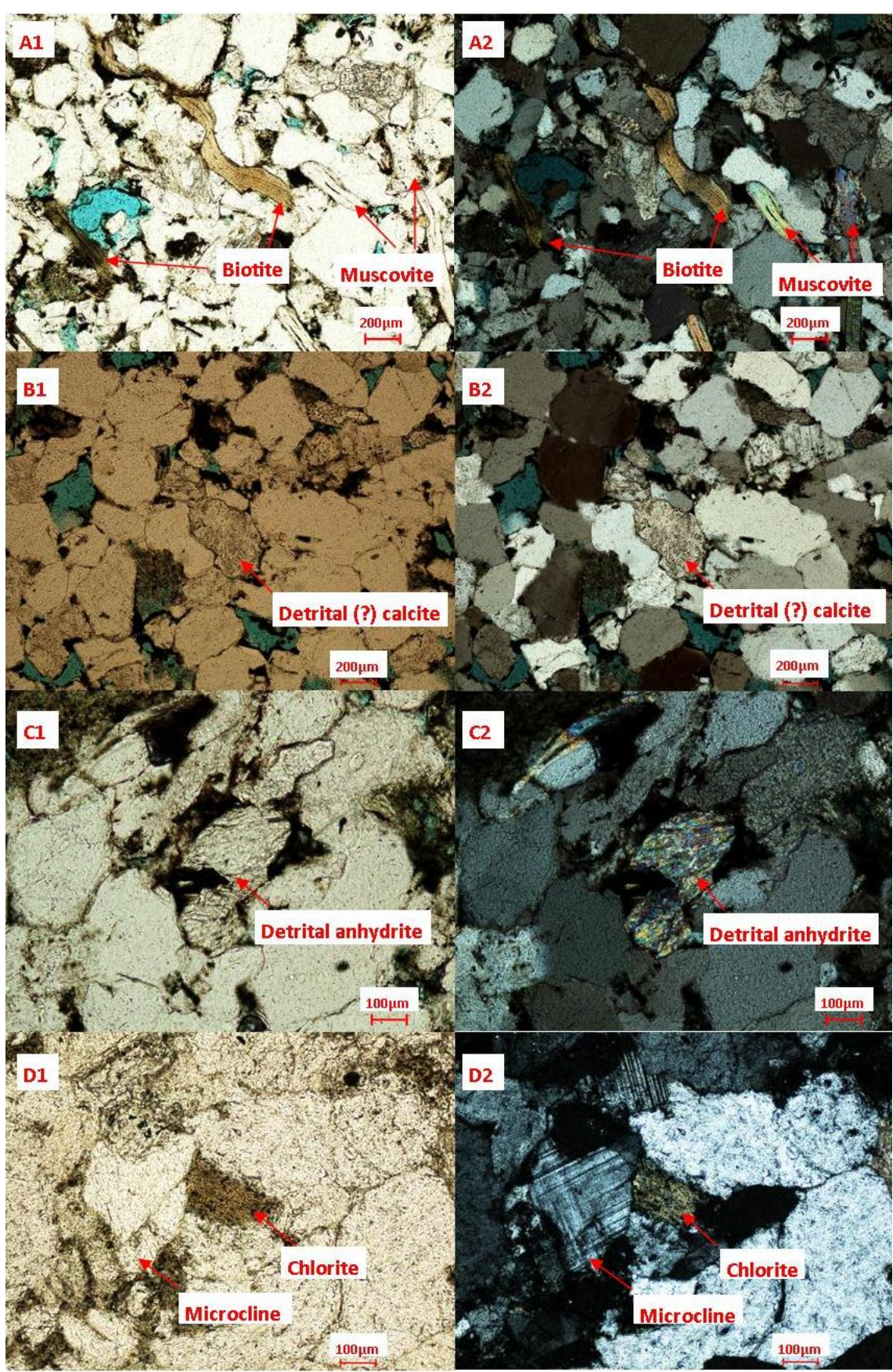

Figure 14. Common accessory minerals of the Donovan Sand.

Photomicrographs of minerals in plane-polarized light (PPL; left) and cross-polarized light (XPL; right). $A 1$ and $A 2$ : Biotite and muscovite micas as seen in PPL (A1) and XPL (A2). B1 and B2: Detrital (?) calcite grain as seen in PPL (B1) and XPL (B2). Note the grain-like shape and the roundedness of the grain edges. C1 and C2: Detrital anhydrite as seen in PPL (C1) and XPL (C2). Note the grain shape and truncation of the anhydrite fibers at the grain edge. D1 and D2: Altered chloritic biotite and microcline feldspar grains as seen in PPL (D1) and XPL (D2). Photomicrographs within this figure were all taken of portions of thin section sample 323211378 except for D1 and D2, which are from sample 3198-11087. 
Individual calcite and dolomite rhombs are diagnostic of these calcareous lithic fragment types, and where these rhombs are not present, the limestone fragments mainly contain microcrystalline calcite or micrite.

\section{Accessory Constituents}

Accessory constituents included muscovite and biotite micas, chlorite, organic material, detrital (?) anhydrite, detrital hematite, detrital calcite, opaque minerals, and pyrobitumen (Fig. 14). Muscovite mica was evident in nearly every thin section, and was the most abundant accessory mineral. Flakes of muscovite and biotite mica were slightly larger than the dominant grain size for a given sample. There were also samples that showed cross-sections of books of mica, exhibiting the ordered sheet structure (Fig. 18). Chlorite grains within the sediment were light green in color under plane- and cross-polarized light. These grains were often subrounded and slightly altered around the grain edges. Anhydrite was also found in the samples, and in places exhibits a fibrous crystal habit (Fig. 14). Some anhydrite fragments within the sediment have been crushed over time due to compaction, and exhibit a fragmented and flattened structure in the vertical direction. Grain sizes of both the chlorite and anhydrite range from very fine-fine.

A subrounded mineral that was opaque in transmitted light and blue in plane light (Fig. 19) was also counted in some thin sections. The grain size for this mineral typically did not exceed medium grain size, and in sections where it was present it accounted for less than $5 \%$ of the total point count. Based on pilot Raman spectroscopy investigation, this mineral is likely a titanium-oxide mineral (A. Weislogel, personal communication, 2011). Calcite was present in some samples as detrital grains (Fig. 14). The calcite fragments exhibited very high 
birefringence under cross-polarized light, were typically subrounded, and were the same grain size as the rest of the thin section sample in most cases.

\section{Matrix}

Matrix was typically comprised of clay and silt-sized particles of accessory constituents (Fig. 20) and coalified plant matter. Organic matter appeared black in reflected light and was opaque in transmitted light. It generally was the same size as the surrounding grains; however there were some fragments that were flattened by compaction and these tend to be one to two times larger than the overall grain size in the long-axis direction.

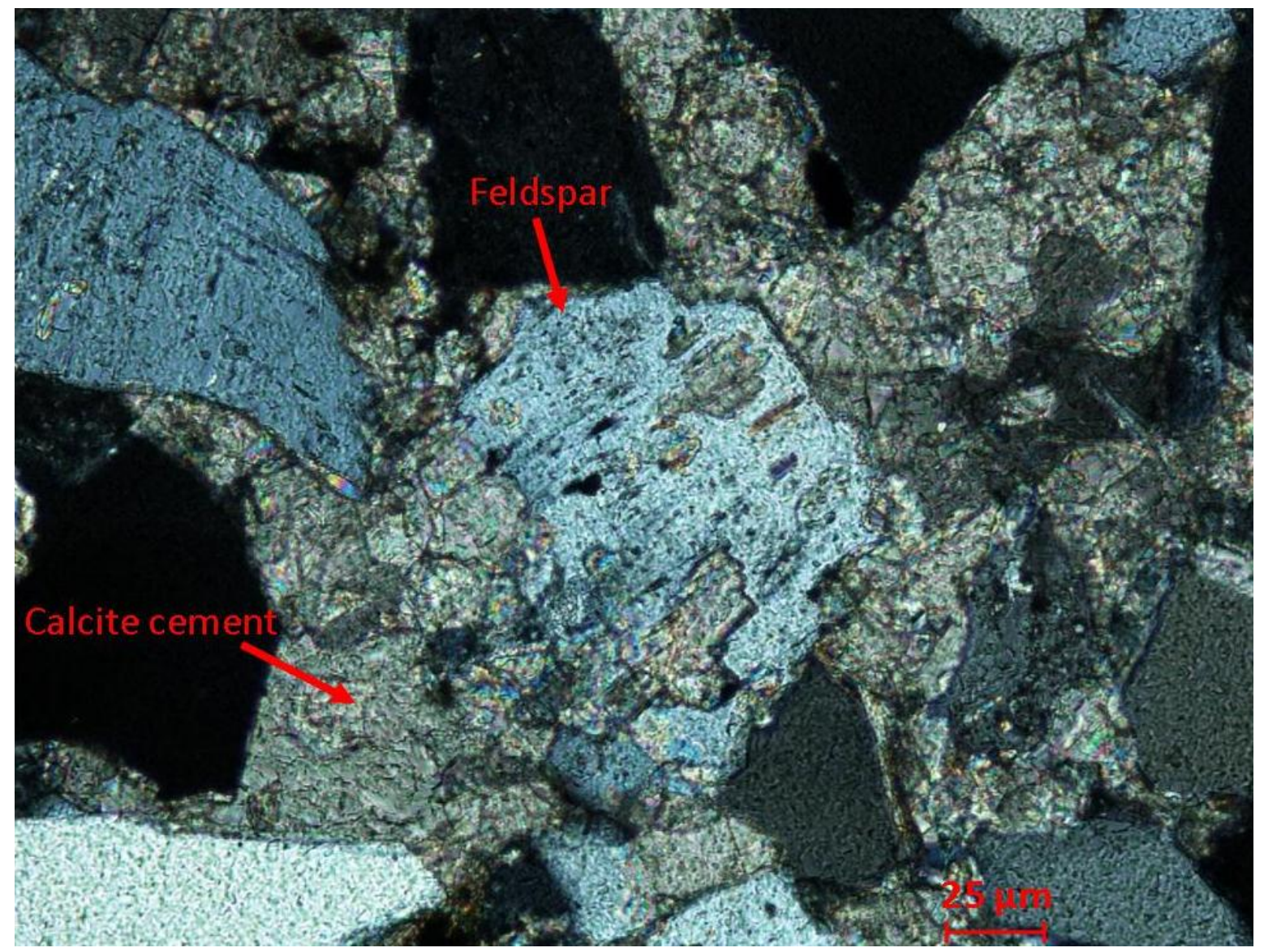

Figure 15. Partial chemical alteration of feldspar.

Thin section sample 706-10854. Note the cavities within the feldspar likely filled with cement after alteration of the grain since the cavity would have to be present to have been in-filled. 


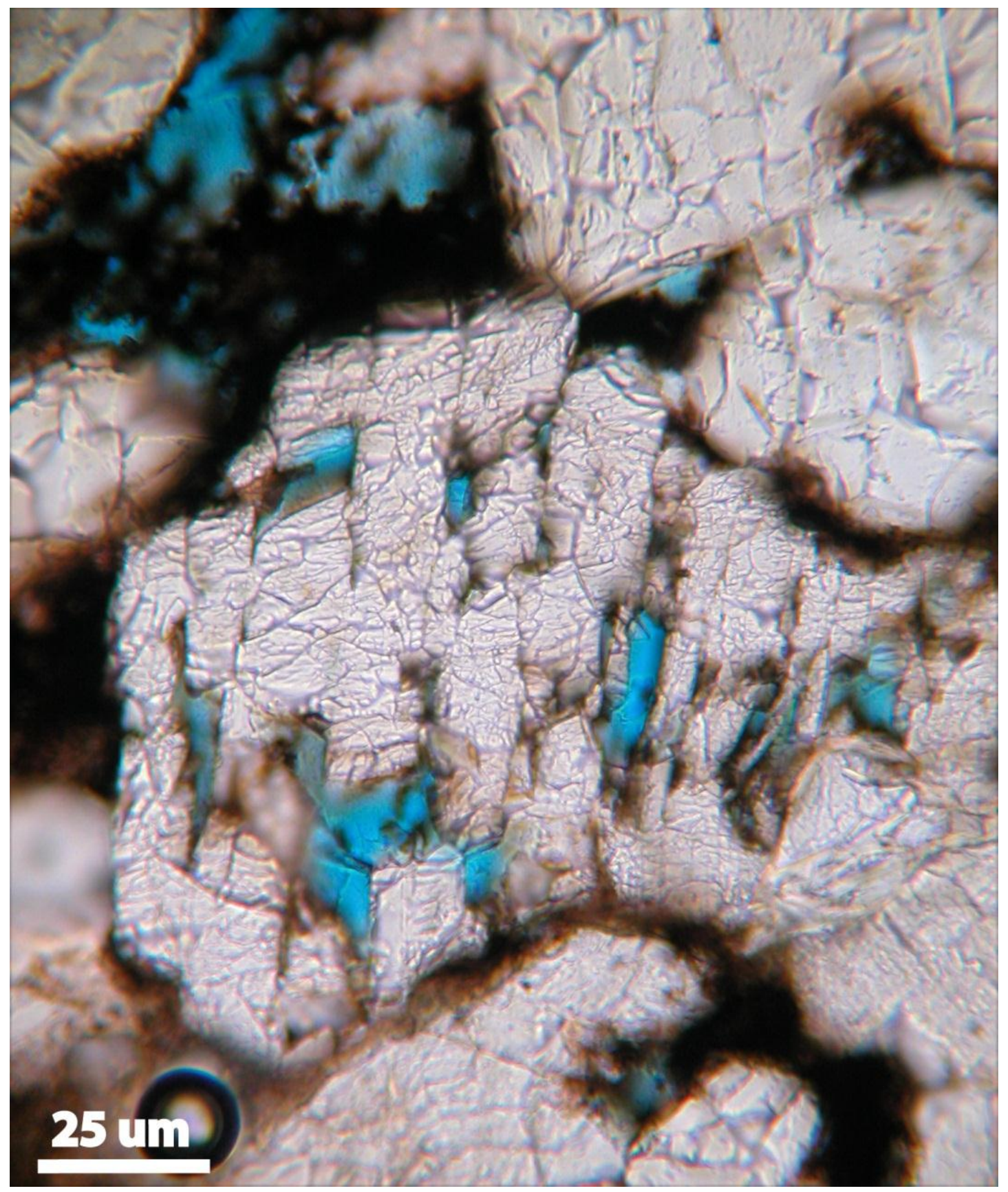

Figure 16. Alteration of plagioclase feldspar along twinning planes.

Also notice black/brown pyrobitumen staining within pores between grains. (Taken from thin section sample 3086-10817.5. Photomicrograph courtesy of Geological Survey of Alabama.) 


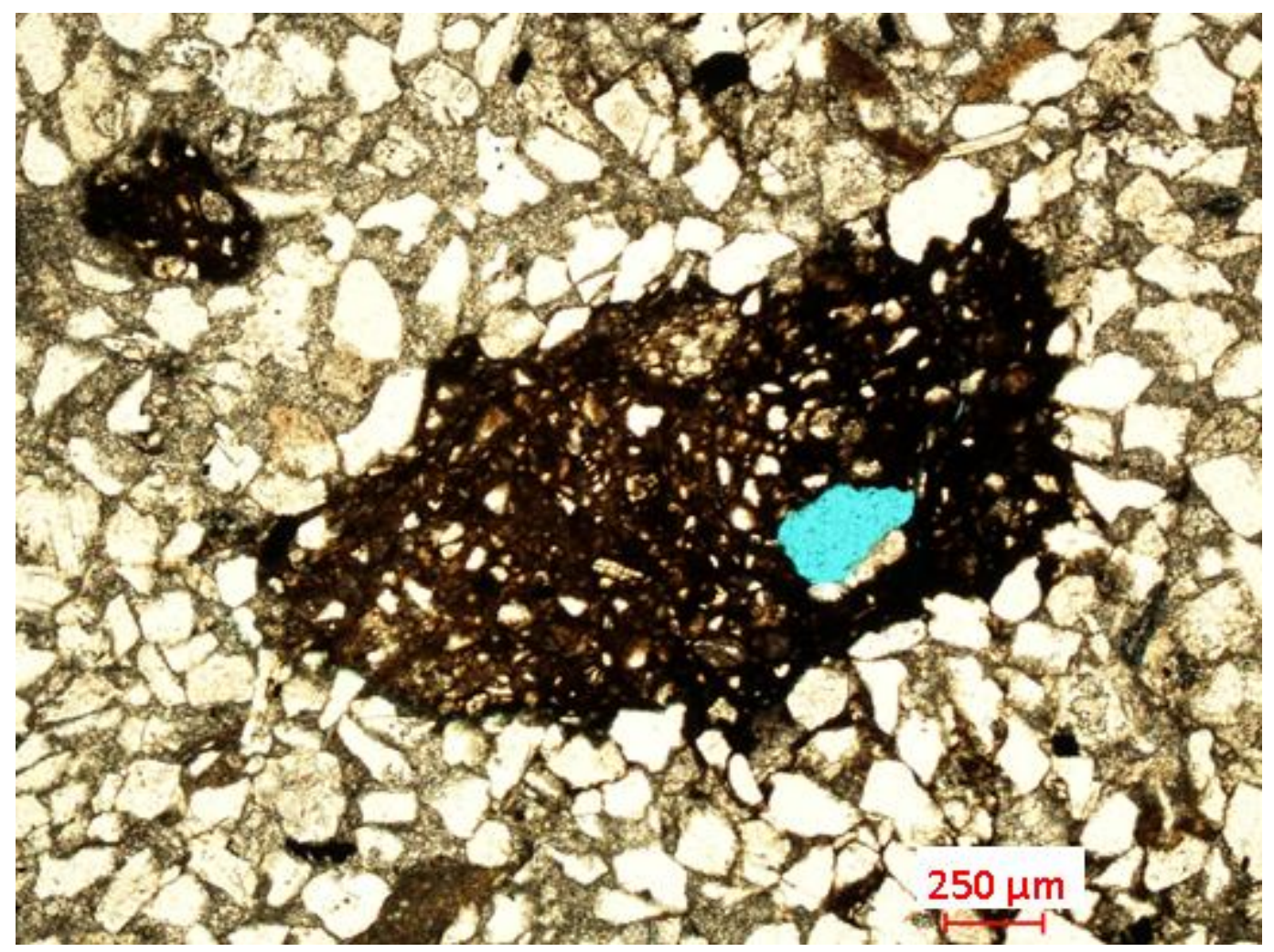

Figure 17. Typical Donovan section subrounded mudstone lithic fragment containing some silt-sized quartz.

Thin section sample 706-10854. Secondary porosity (blue epoxy) is evident within the lithic fragment as well as around the grain edges. Typical Donovan section subrounded mudstone lithic fragment containing some silt-sized quartz.

\section{Cement}

Cement types within the thin sections were typically calcite or dolomite with some minor amounts of silica and hematite cement in some sections. Calcite cement was typically pervasive in sections with very low to no porosity, and localized in sections where there were calcite concretions. In low porosity zone thin sections where grains were altered to the point of physically breaking via alteration or compaction, the cement filled any fractures within the grains that were present. Often in these pervasively-cemented zones there are preserved 
calcite rhombs (see Fig. 20). In higher porosity zones calcite cement is present in the form of localized, spherical diagenetic concretions that likely formed in-situ, judging by their shape and lack of evidence of alteration around their edges.

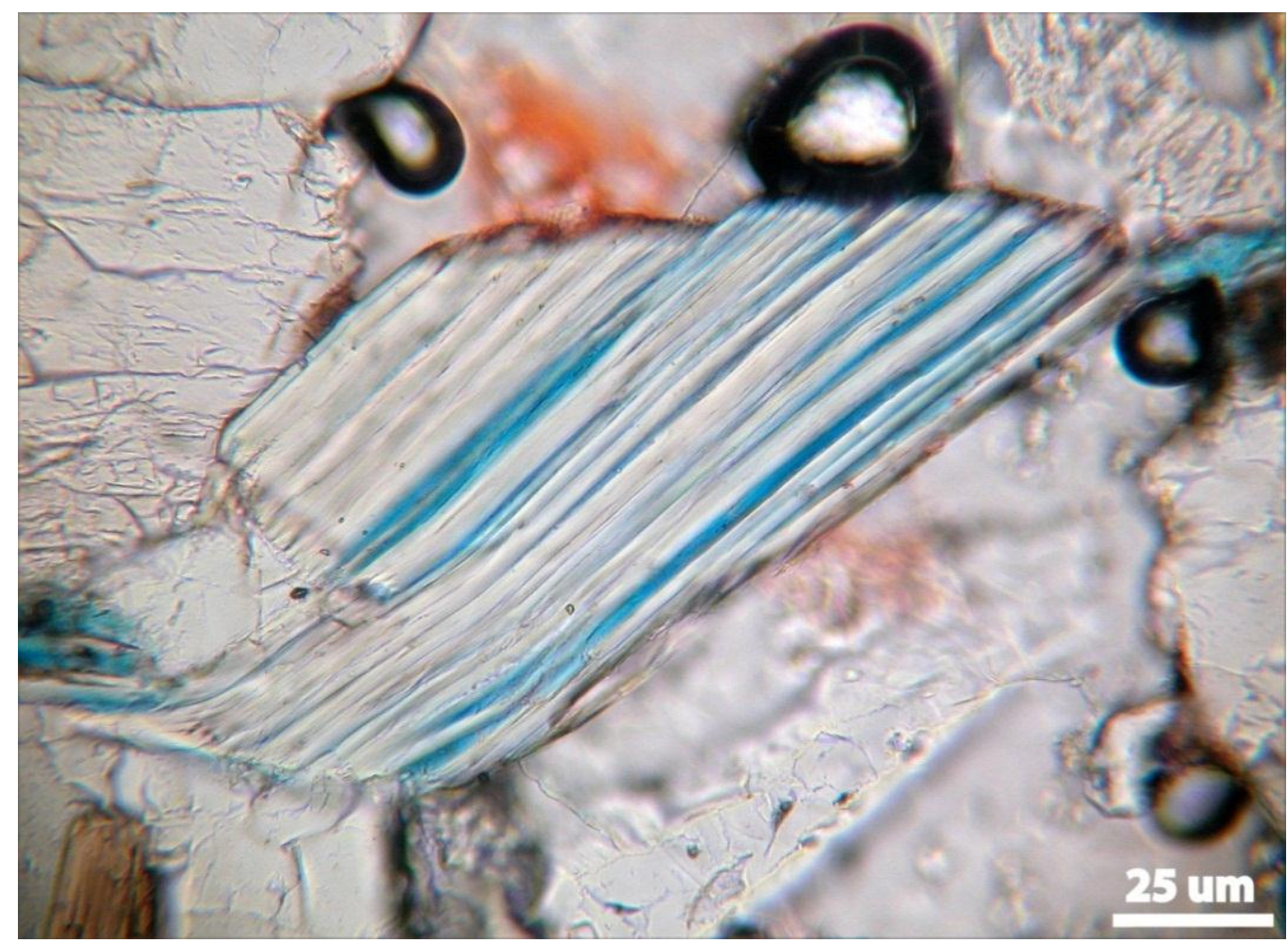

Figure 18. Photomicrograph of an altered mica book within thin section 3086-10941 under plane-polarized light.

Notice the secondary porosity along the cleavage planes of the mica. Photomicrograph courtesy of Geological Survey of Alabama.

Typically, hematite cement was only evident within zones that were also pervasively cemented by calcite or in zones with high matrix content (Fig. 20). Hematite cement is easily distinguished from other cement types by its characteristic red/brown color. 


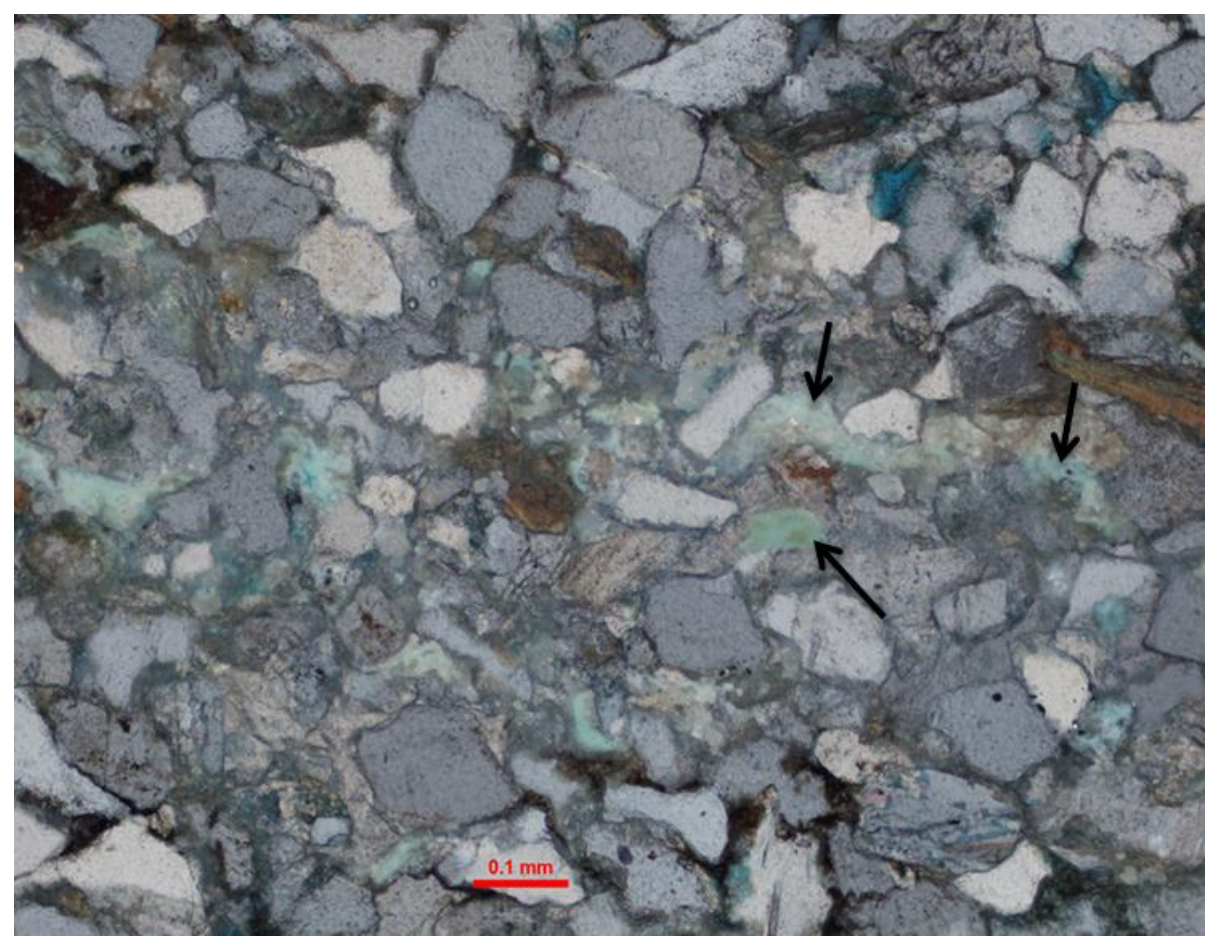

Figure 19. Photomicrograph of thin section 3232-10815 showing the blue titanium oxide mineral under reflected light.

Black arrows point to some of the individual titanium oxide minerals shown in the field of view. Photomicrograph courtesy of George Case.

The majority of the thin sections from well permit numbers $3198,2993,713,633$, and 624 were less porous than those from well permit number 706 or 3232 primarily due to the higher degree of cementation within zones sampled from the 5 wells. Authigenic anhydrite was also seen in some samples (Fig. 21), but was far less abundant than calcite cement. Anhydrite exhibits $5^{\text {th }}$ order birefringence and may be distinguished from other minerals by its characteristic fibrous crystal habit.

\section{Porosity}

Average porosity of the Upper Donovan Sand thin sections is $2.6 \%$, with a maximum value of $\sim 12 \%$ (Appendix Table 1; sample 706-10913) in dataset thin sections. Both primary and 
secondary porosity types were seen in thin section. Usually the dominant pore type in Donovan Sand sections with lower porosity is primary intergranular, and in higher porosity sections there is typically a higher amount of secondary porosity in conjunction with similar amounts of primary porosity that may be seen in lower porosity sections.

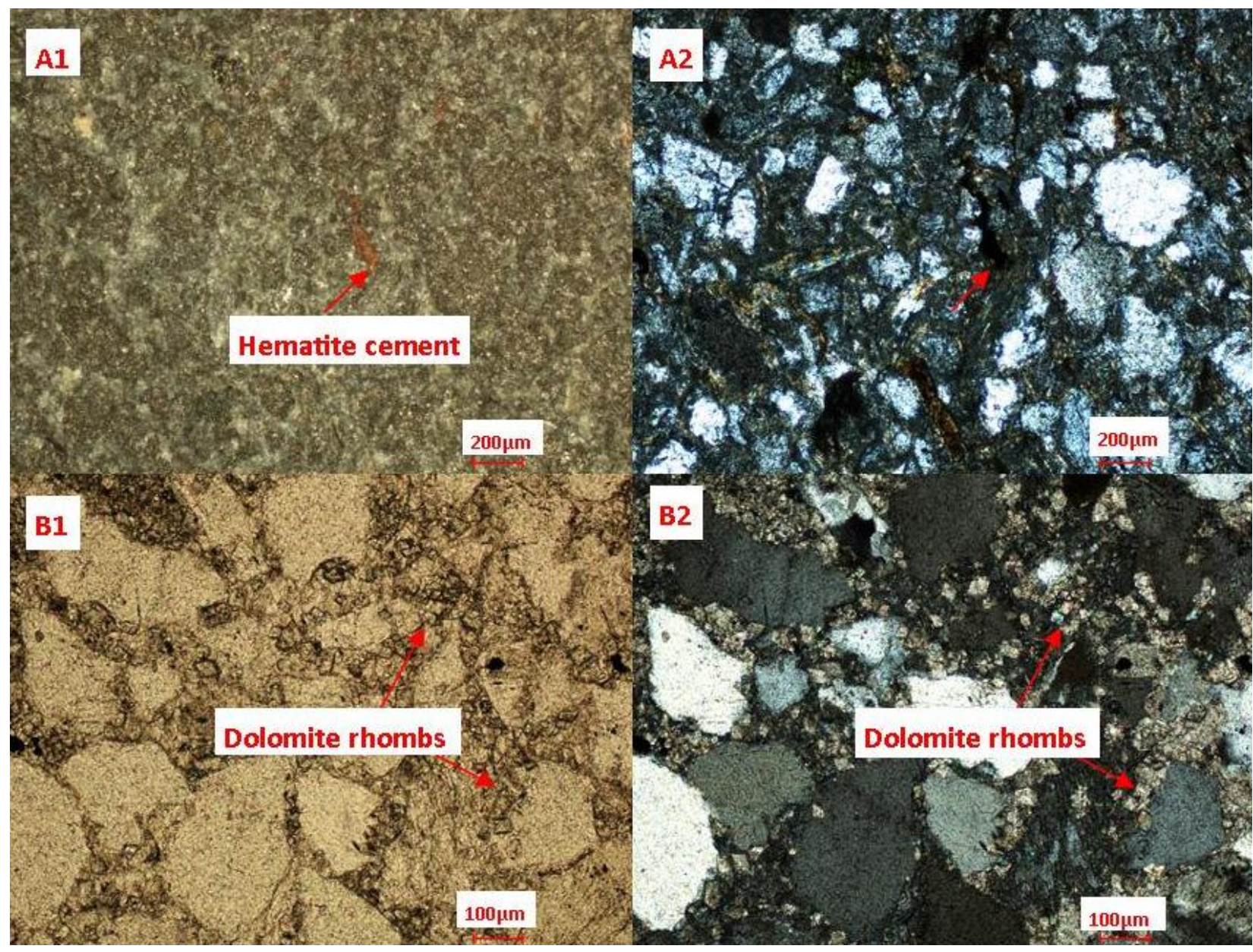

Figure 20. Most common Donovan Sand cement types.

Photomicrographs of the most common cement types within the Donovan Sand. A1 and A2, from sample 713-11347: Hematite cement as seen in PPL (A1) and XPL (A2). B1 and B2, from sample 633-10944.5: Calcite/dolomite cement with dolomite rhomb crystals as seen in PPL (B1) and XPL (B2). 


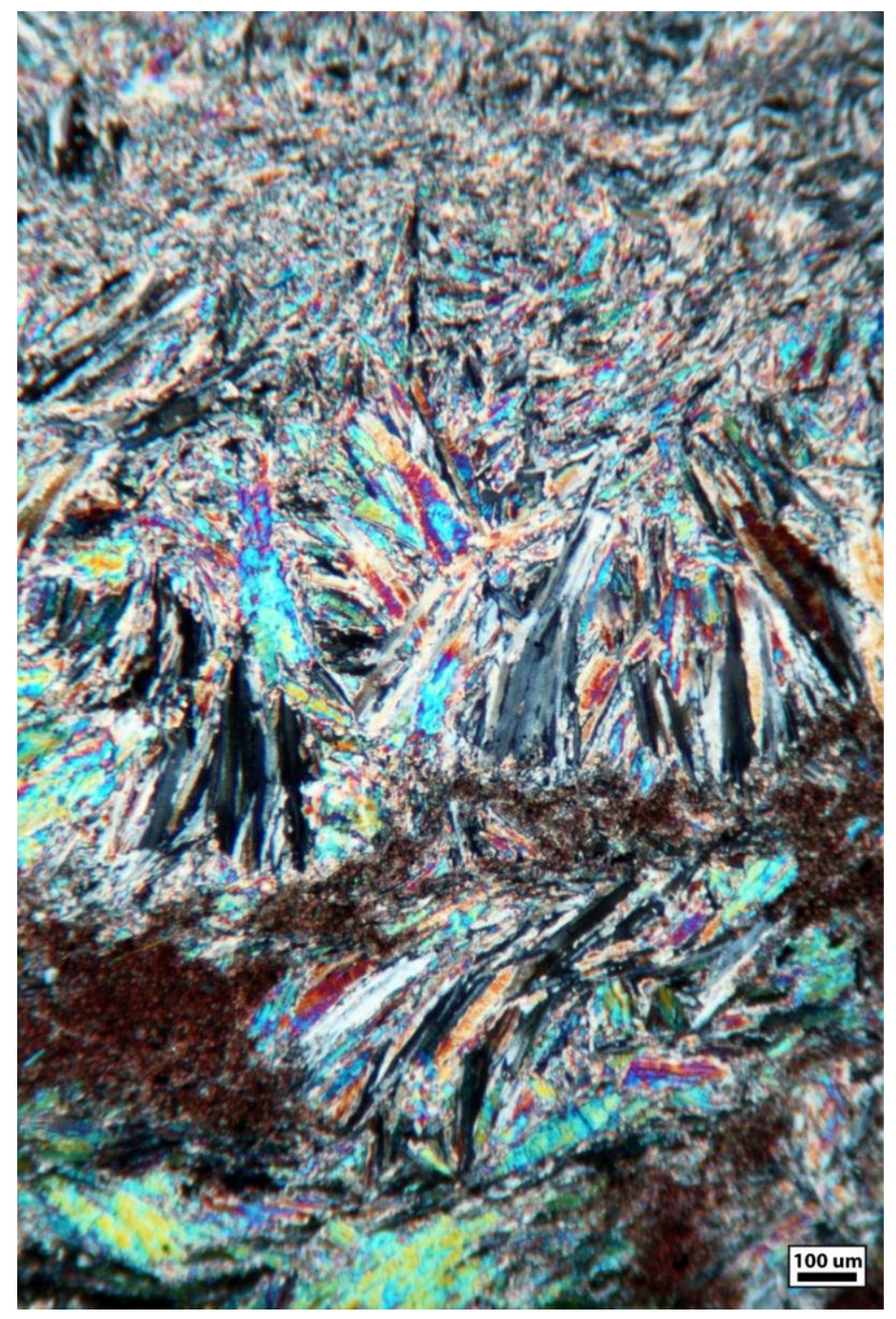

Figure 21. Anhydrite as seen under cross-polarized light.

Sample taken from thin section sample number 2993-10579.5. Photomicrograph courtesy of Geological Survey of Alabama.

Primary pores are typically triangular in shape if the sediment is well-sorted and wellpacked, and secondary pores tend to be more rectangular or grain-shaped, as the void space that is now porosity used to be occupied by a grain of some sort. In sections with higher porosity, there are both primary and secondary pore types. Intragranular porosity is 
uncommon, but there is some minor intragranular porosity in zones where there is also a large amount of secondary porosity. Typically, intragranular porosity is seen within feldspars or lithic grains. No intragranular porosity was seen within quartz grains. There has been no documented fracture porosity within rock samples studied in this research.

\section{Origins of Cement and Porosity}

Pervasive calcite/dolomite cementation is interpreted to have occurred as a product of precipitation in pore spaces from chemically supersaturated formation waters during and after burial. Hematite and silica cement types were likely formed in the same manner. Dissolved constituents necessary for calcite/dolomite cement precipitation include calcium and magnesium, which could be sourced from seawater during deposition of these sediments. Iron in hematite may have been sourced by terrigenous silts and muds that were deposited along with the sand in the early Cretaceous.

Primary pore space was created within the Donovan Sand as the sediment was being deposited. Primary pore space distribution is based upon the grain packing and sorting of the sediment. Most of the Donovan Sand samples are moderately well-sorted to well-sorted, and this has allowed for initial preservation of the triangular shape of the primary pores although they may have been in-filled with cement later in the burial history. Secondary pores within the Donovan were formed by the dissolution of grains or other minerals. Partial alteration of some grain edges and complete dissolution of some grains are both evidence that there has been some interaction between the formation fluid and the reservoir rock.

Secondary porosity mainly forms by dissolution of framework grains or intergranular cement. Due partially to its relative insolubility in acidic waters compared to feldspar (Nesbitt et 
al., 1997), quartz does not often show evidence of chemical alteration via dissolution in thin section (Fig. 13, Fig. 22). However, in arkosic sands framework feldspar grains and lithic fragments are both prone to partially dissolving with the introduction of acidic liquids such as briny formation or injected waters (Nesbitt et al., 1997; Prothero and Schwab, 2003).

Secondary pores are typically one to two times larger than primary pores in well-sorted sands, and may also exhibit the same size and shape of surrounding framework grains (Fig. $23-$ void space; Fig. 24 - filled secondary pore). Primary pores on the other hand, are usually triangular in shape, with overall size and geometry a function of the relative arrangement and degree of packing of the sediment grains.

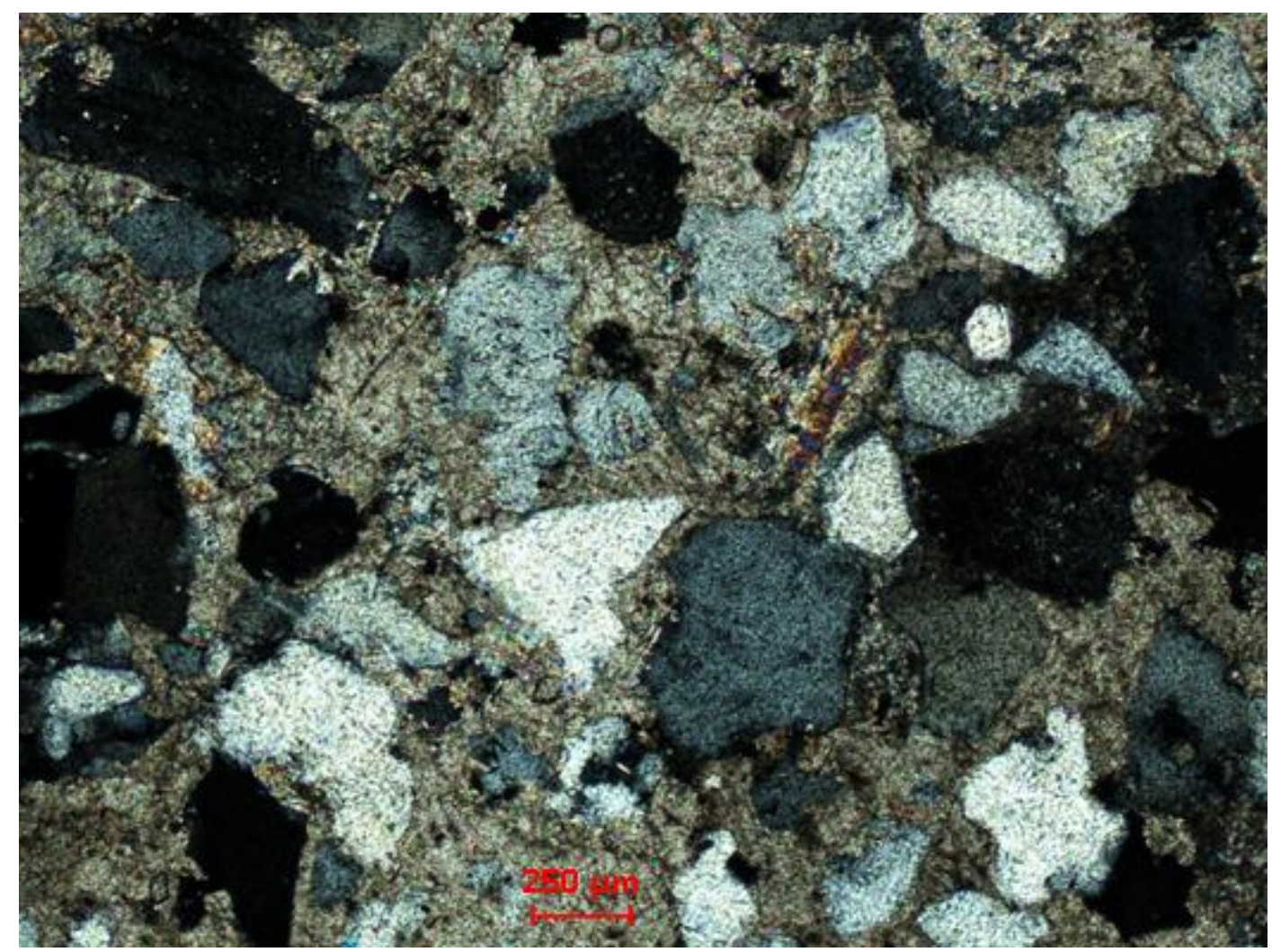

Figure 22. Photomicrograph showing highly-cemented fine-grained sandstone within the Donovan Sand.

Sample number 633-10995.5 under XPL. Notice the grain spacing, perhaps meaning that there was cementation prior to extensive or intense compaction. 


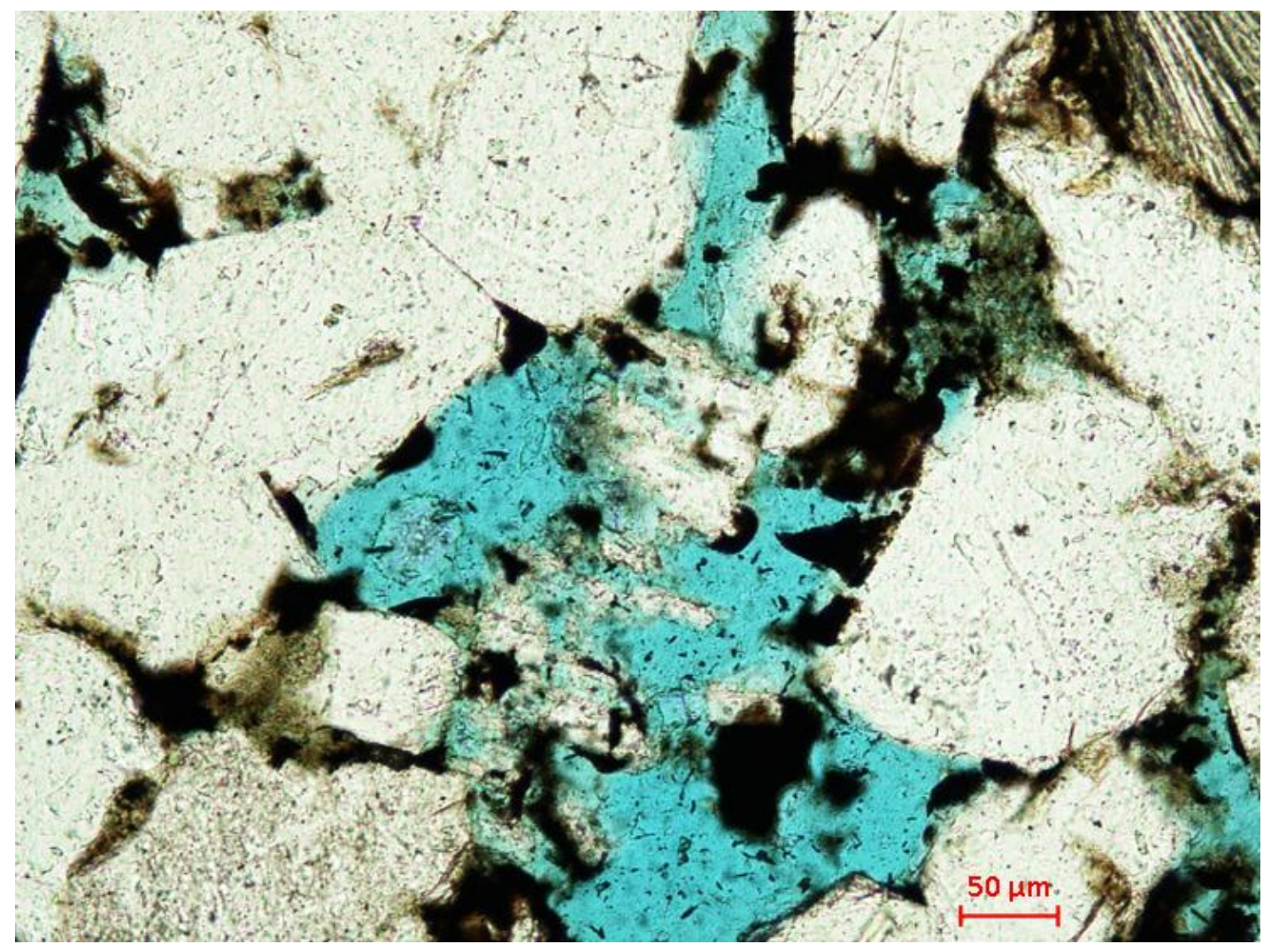

Figure 23. Photomicrograph of a nearly completely dissolved feldspar.

Notice how the creation of secondary porosity results in the creation of a pore in the shape of the grain that formerly occupied that space. Photomicrograph of thin section sample number 3232-11378.

For example, in an idealized diagram of a well-sorted sandstone, perfect spherical grains interlock with one another and are packed in a rhombohedral order (Fig. 25). In this configuration, the pores between the grains are triangular in shape.

\section{Provenance Interpretation}

The petrologic and petrographic data indicate a proximal rather than a distal source for the sediments of the Donovan Sand. The subangular and subrounded framework grain shapes as well as the arkosic composition of the sandstone units both provide evidence for either short transport distance or a very weak chemical weathering system. 


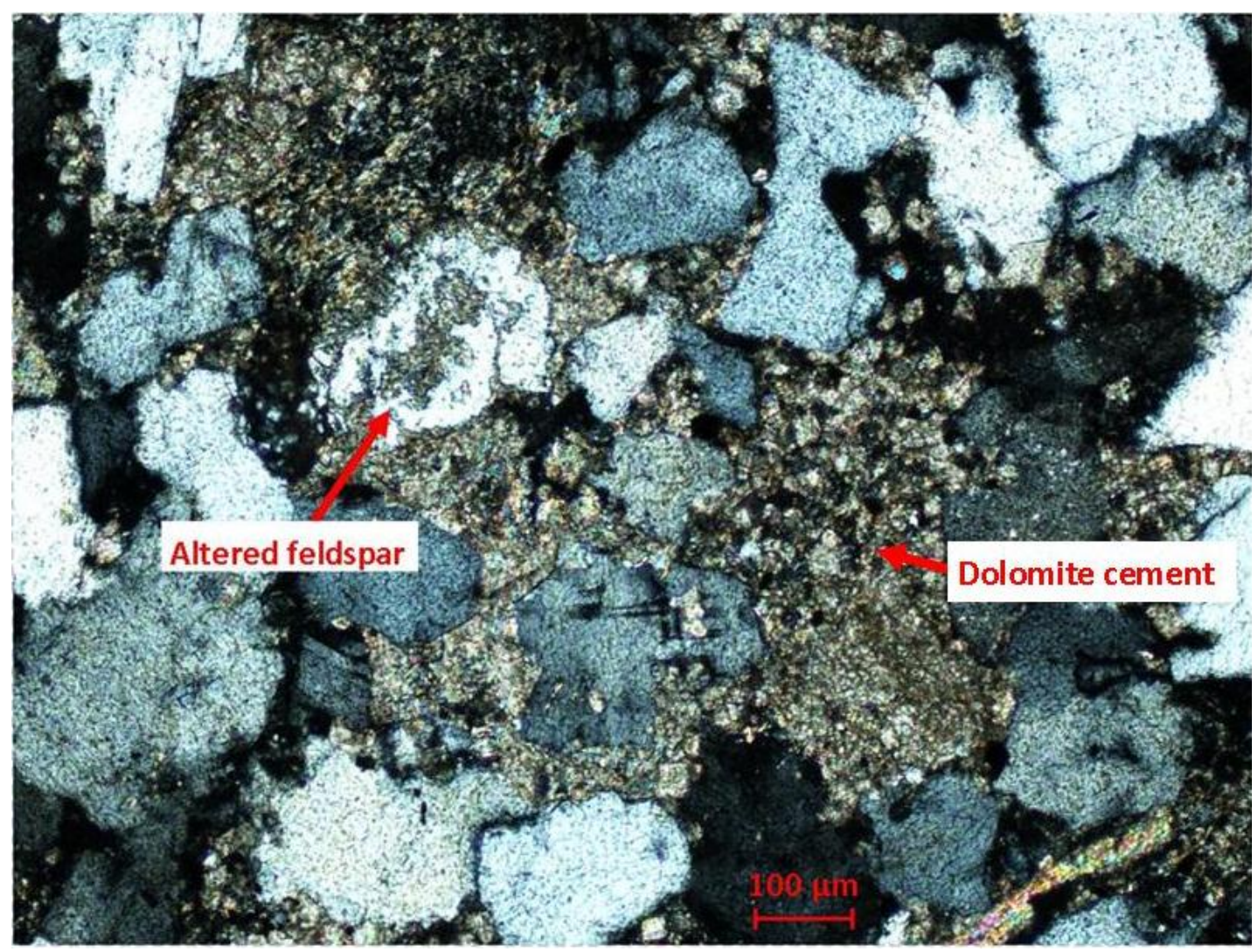

Figure 24. Dolomitic cementation of a secondary pore within the Donovan Sand.

From sample 633-11009.5 as viewed under cross-polarized light. Notice the altered feldspar filled with calcite/dolomite cement.

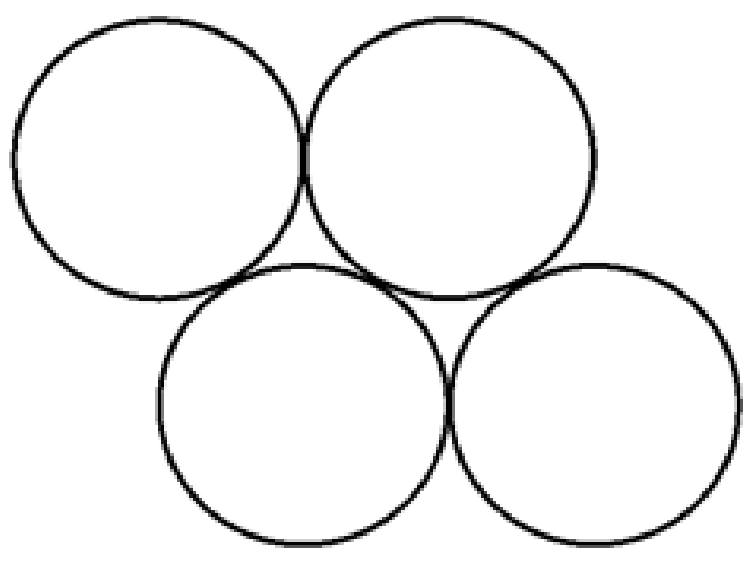

Figure 25. Diagram of rhombohedral packing in an ideal sediment.

Diagram showing rhombohedral packing pattern of ideal, well-sorted sediment with spherical grains and triangular pore spaces. 
Since orthoclase and plagioclase feldspars are susceptible to chemical weathering during sediment transport, and given the high amounts of feldspar within the Donovan sand, chemical weathering processes were not strong during transport and deposition of this sediment. Most of the feldspars seen in thin section maintained a rectangular shape, also indicating that the feldspars had not been transported for a very long distance. As sediments are transported from source to sink, the individual grains abrade against one another as well as other objects along the transport route (e.g., stream or riverbed, debris during floods). During this transport phase, the sediment 'matures' and grains begin to develop rounded edges as they abrade. Had the feldspars been transported over a longer distance, the grain edges would likely be more rounded than the subangular sediments seen in the Donovan Sand. Along with the feldspars, subangular quartz, and lithic grains show signs of only moderate physical abrasion.

Plausible sources for these sediments are the Grenvillian-aged metasedimentary and granitic rocks exposed in the Pine Mountain Window (Fig. 26) within the southern portion of the Piedmont geological province of the Appalachian Mountains (Hooper and Hatcher, 1988; Chalokwu and Hanley, 1990; Steltenpohl et al., 2008). The rocks exposed in the Piedmont province evolved during the Acadian/early Taconic (Bayona, 2003) orogenies as Laurentia collided with Gondwana to produce a fold-thrust belt along the eastern Laurentian margin (Hooper and Hatcher, 1988; Steltenpohl et al., 2008). This fold-thrust belt extended as far south as the present-day state of Alabama (Fig. 27).

Within the tectonically active southern Appalachian Mountains, at the transition from the Acadian orogeny to the Taconic orogeny, metamorphic gneisses and schists of the Uchee terrane were uplifted along with the rest of the now-Pine Mountain Window and any cover 
rock present and immediately began to erode as it was transported to nearby Paleozoic depocenters (Steltenpohl et al., 2008). As uplift continued, this Grenvillian rock was continually exhumed near the Alabama promontory through persistent Neoacadian-Alleghanian orogenic events (Barineau, 2009).

During the Alleghenian orogeny, there were granitic intrusions into the Uchee terrane. They occurred in two phases: 1) exhumation of the Motts Gneiss and 2) intrusion of the Hospilika Granite into the Motts Gneiss. The Motts Gneiss is granodioritic in composition and is up to $3 \mathrm{~km}$ ( 1.864 mi) thick in some locales, and the Hospilika Granite occurs in small $(<\sim 1$ $\mathrm{km}^{2} / 0.386 \mathrm{mi}^{2}$ ) vein-like intrusions within the Motts Gneiss (Steltenpohl et al., 2008). Upon the conclusion of the Alleghenian orogeny, these rocks were exposed directly adjacent to the newly-formed Grenvillian uplift, and their sediments would have been transported towards the nearby newly-forming proto-Gulf of Mexico through the Triassic-Cretaceous periods. Hence, these intruding granites and granitoids are a plausible source for the Donovan Sand sediments because of their composition, proximity to the southern Alabama depocenter, and timing of their exhumation and intrusion. 


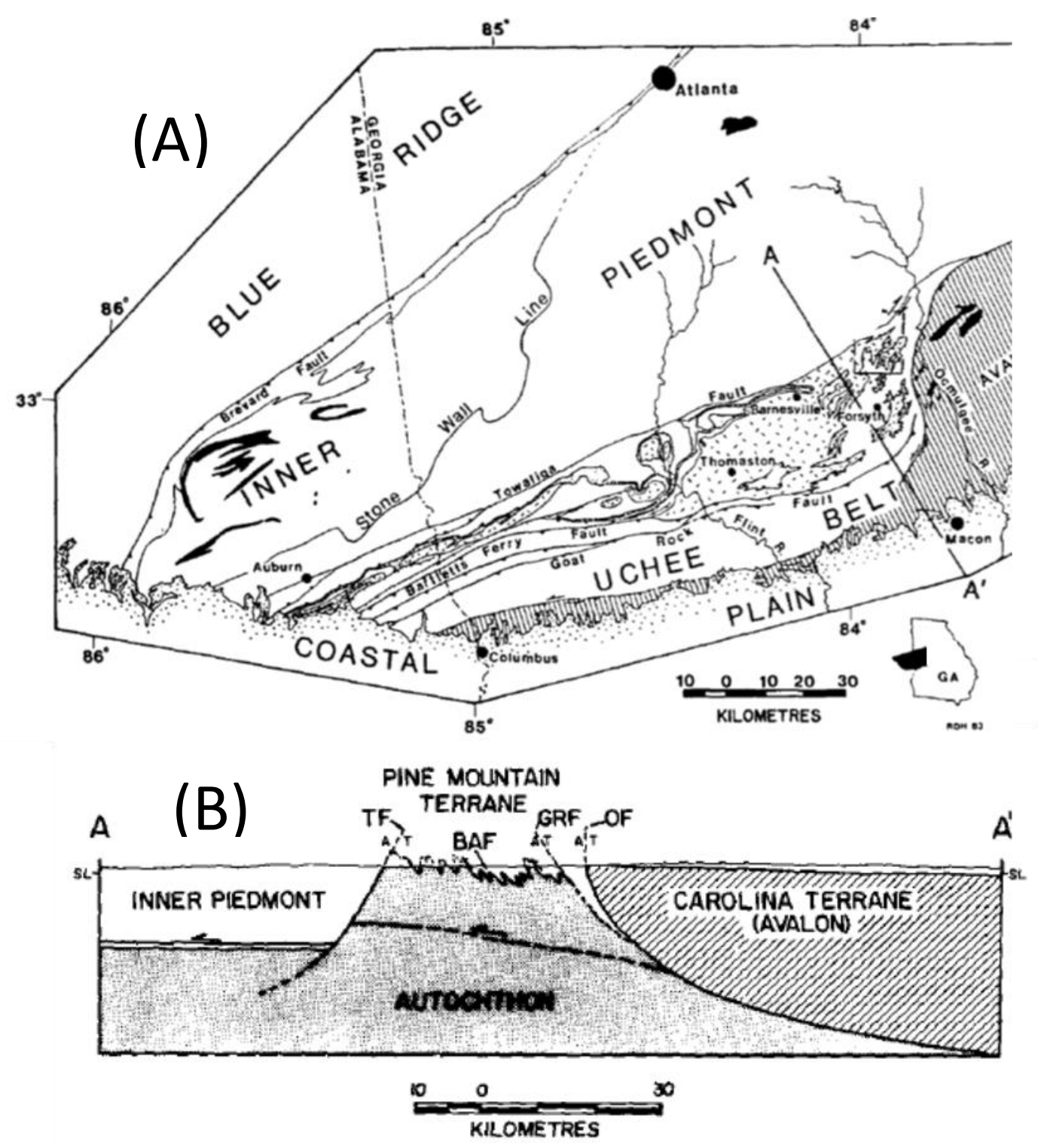

Figure 26. The Pine Mountain Window.

The Pine Mountain Window, shown here between the Inner Piedmont and the Coastal Plain terranes. Cross-section $A-A^{\prime}$ is delineated in map (A) within this figure and shown in part (B). Cross section key: BAF - Box Angle Fault, GRF - Goat Rock Fault, OF - Ocmulgee Fault. (Both figures taken and modified from Hooper and Hatcher (1988).) 


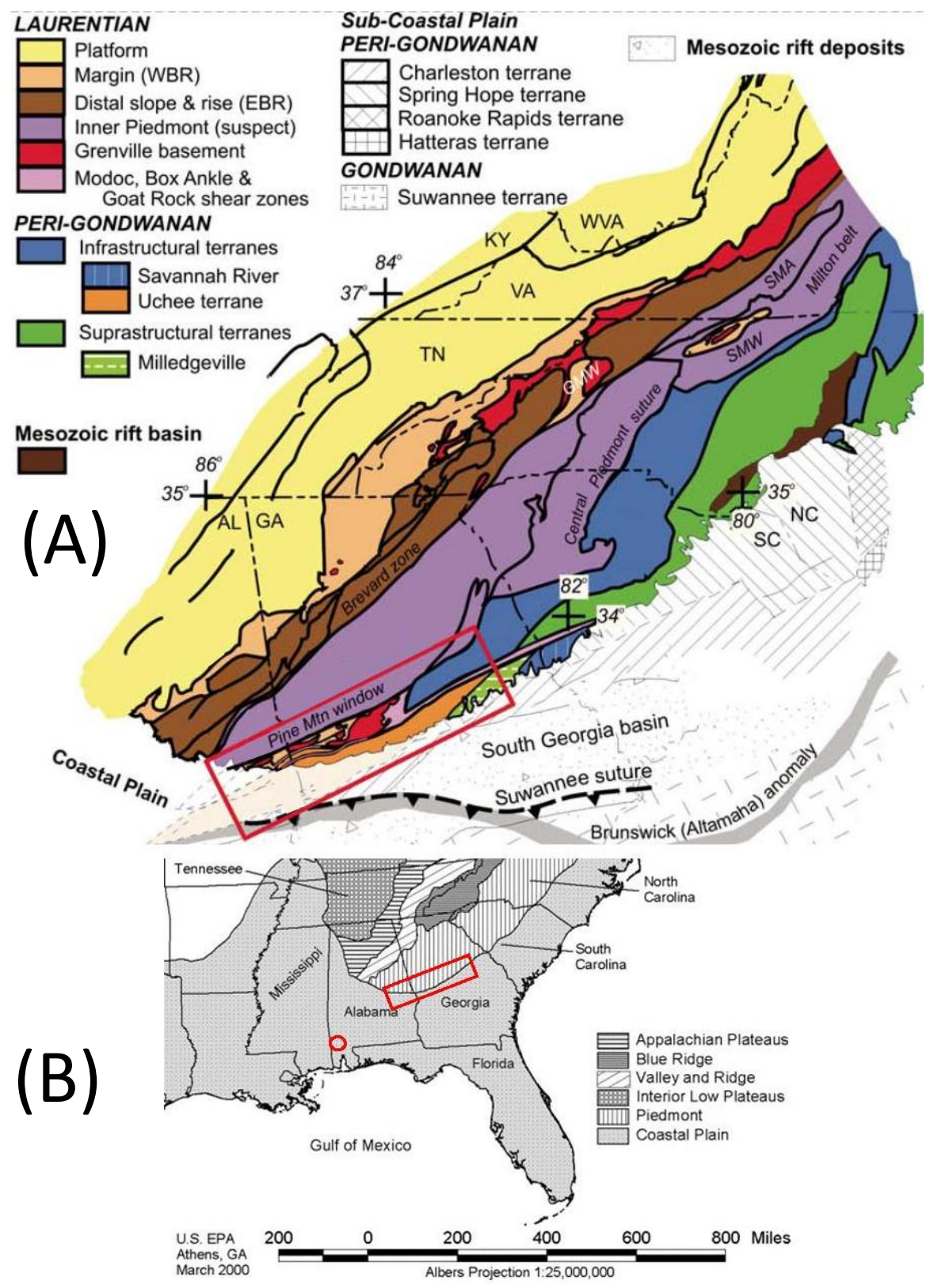

Figure 27. Map of the Piedmont region of the Eastern United States.

(A) - Map of the Piedmont region of the Eastern United States showing the various structural terranes as well as the faults associated with them. Key: GMW-Grandfather Mountain window. SMW-Sauratown Mountains window. SRA-Smith River allochthon (modified from Steltenpohl et al., 2008). (B) - Physiographic province map of the southeastern United States. The red rectangle outlines the Pine Mountain Window's location within the Piedmont province (in accordance with part $(A)$ ), and the red circle indicates the location of the study area (modified from Johnston and Crossley, 2002). 


\section{Petrofacies Identification}

Eight petrofacies were identified in Donovan reservoir sandstones. Because the sands of the Donovan Sand are so compositionally uniform, petrofacies were defined according to grain size distribution, degree of sorting, grain shape, cement type relative abundance, cement volume, and porosity types and amounts. The eight petrofacies defined are listed below:

A. Well sorted, very fine-grained subangular sandstone with $>5 \%$ porosity and minor calcite and/or dolomite cement. Well-developed secondary porosity with grain-shaped void spaces and alteration features evident in feldspars.

B. Well sorted, fine-grained subangular sandstone with $>5 \%$ porosity and minor calcite and/or dolomite cement. Well-developed secondary porosity with grain-shaped void spaces and alteration features evident in feldspars.

C. Moderately well sorted, medium-grained subrounded sandstone with > $5 \%$ porosity and minor calcite and/or dolomite cement. Some evidence of secondary alteration of feldspars via dissolution. There are few completely dissolved grains.

D. Moderately well sorted, very fine-grained subangular sandstone with numerous, small ( $\sim \mathrm{mm}$ ( $\sim 0.314 \mathrm{in})$ diameter) calcite-cemented concretions and 2-5\% porosity. Some evidence of secondary alteration of feldspars via dissolution. There are few completely dissolved grains.

E. Moderately sorted, fine-grained subangular-subrounded sandstone with numerous, small ( $\sim \mathrm{mm}(\sim 0.314 \mathrm{in})$ diameter) calcite-cemented concretions and 
2-5\% porosity. Secondary porosity only is evident in minor alterations and dissolution cavities in some grains, with very few grain-shaped void spaces. F. Moderately sorted, very fine-grained subangular-subrounded sandstone with $<5 \%$ total porosity and abundant calcite/dolomite cementation. Minor amounts of secondary porosity are present in altered calcite cement and altered feldspars.

G. Moderately sorted, fine-grained subangular-subrounded sandstone with $<5 \%$ total porosity and abundant calcite/dolomite cementation. Minor amounts of secondary porosity are present in altered calcite cement and altered feldspars.

H. Poorly sorted, very fine-grained subangular sandstone with $<5 \%$ total porosity due to high matrix content. Some secondary porosity evident due to dissolution of calcite cement and apparent removal of matrix.

Although not typically involved in petrofacies determination, porosity was included due to the low variability in composition of the Donovan Sand samples. Porosity-based petrofacies definitions emphasize the most and least porous zones within a reservoir.

A $5 \%$ porosity cutoff was applied because $5 \%$ was the value separating the relatively few higher-porosity thin sections from the lower-porosity thin sections. The porosity percentage for each thin section was determined by dividing the frequency of pore space counted during point-counting divided by total points counted (grains, matrix, and cement) " $n$ " plus total pore space points counted " $\mathrm{x}$ " $(n+x)$, resulting in some percentage of the total. 


\section{Petrofacies A}

Petrofacies A (Fig. 28) consists of well sorted, very fine-grained subangular sandstone with $>5 \%$ porosity. Calcite and/or dolomite cements within this petrofacies are not so widespread as to severely diminish porosity values, as is the case in petrofacies $F$ or $G$, but rather are present in minor amounts (< 6\% on average, see Table 1 ). There is well-developed secondary porosity within this petrofacies, with grain-shaped void spaces and alteration features evident in feldspars.

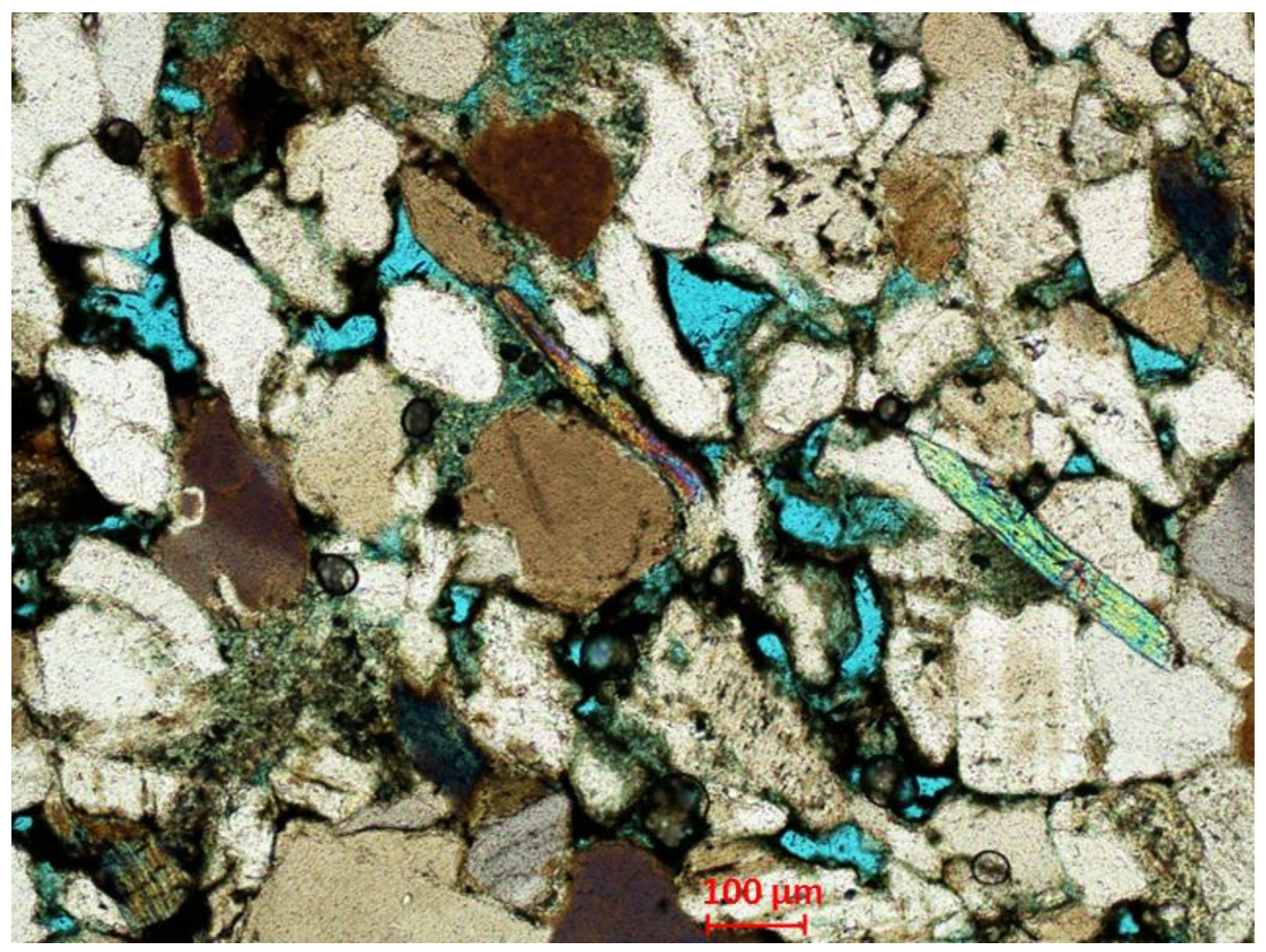

Figure 28. Petrofacies A.

Well sorted, very fine-grained subangular sandstone with $>5 \%$ porosity and minor calcite and/or dolomite cement. Well-developed secondary porosity with grain-shaped void spaces and alteration features evident in feldspars. Some dead oil staining is present within pore spaces in this photomicrograph. (Photomicrograph taken from thin section sample number 3232-10814.) 
The grain-shaped voids are typically the same size as the dominant grain size of the sandstone, because there was an actual sediment grain where the void now exists. These void spaces may connect preexisting primary pores, significantly increasing the overall porosity and permeability. This petrofacies as well as petrofacies B are the highest porosity (up to $\sim 12 \%$ ) petrofacies, with the primary difference between the two being the grain size.

\section{Petrofacies B}

Petrofacies B (Fig. 29) is comprised of well sorted, fine-grained subangular sandstone with $>5 \%$ porosity and minor calcite and/or dolomite cement, as in petrofacies $\mathrm{A}$. This petrofacies is nearly the same as petrofacies $A$ as the porosity, cement, and compositional factors are identical between the two.

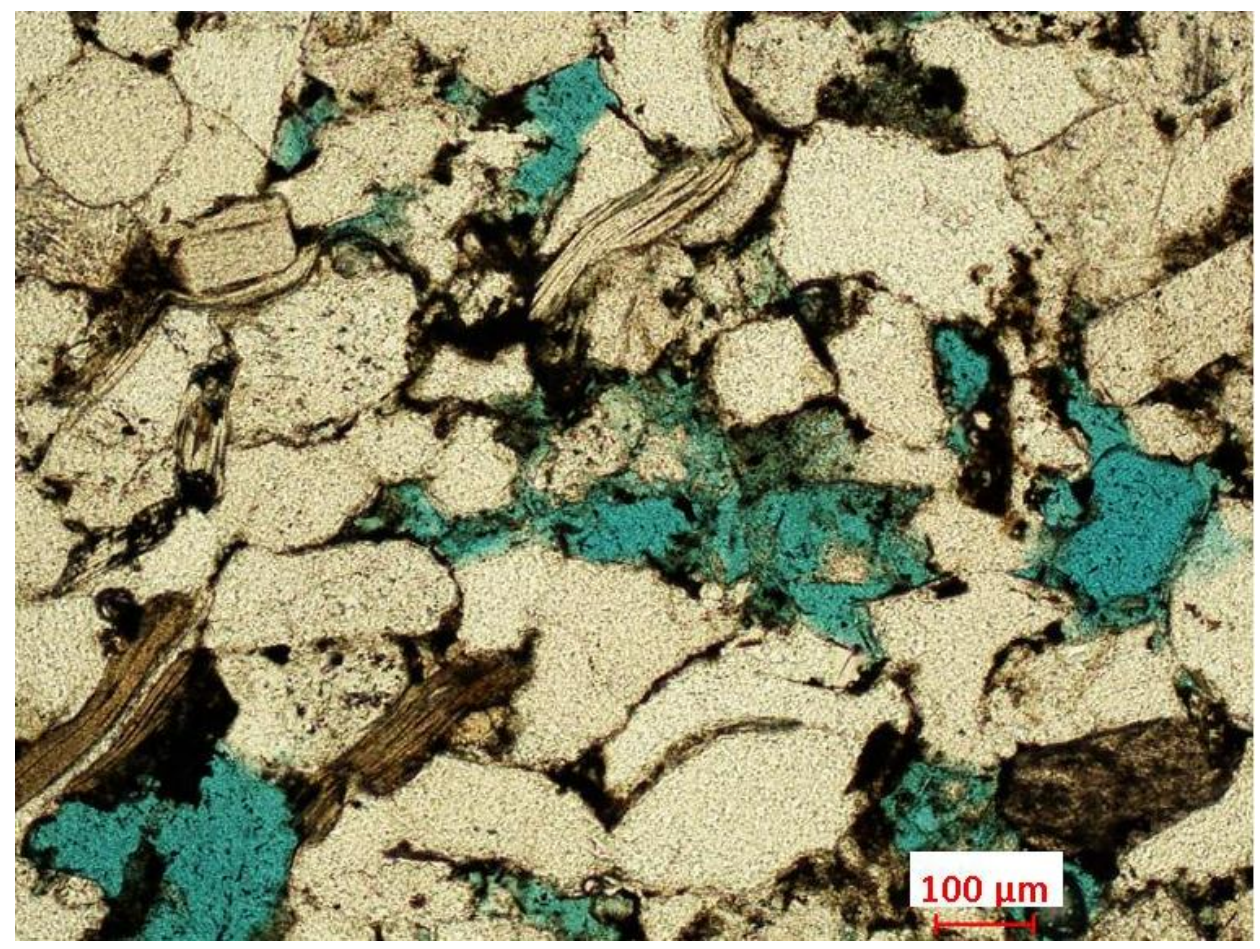

Figure 29. Petrofacies B.

Well sorted, fine-grained subangular sandstone with $>5 \%$ porosity and minor calcite and/or dolomite cement. Well-developed secondary porosity with grain-shaped void spaces and alteration features evident in feldspars. (Photomicrograph of thin section sample number 323211378.) 
The lone distinguishing factor between $A$ and $B$ is the fine grain size of petrofacies $B$ versus the very fine-grained framework of petrofacies $A$.

\section{Petrofacies C}

Petrofacies C (Fig. 30) consists of moderately sorted, fine-grained, subrounded sandstone with $>5 \%$ porosity and minor calcite and/or dolomite cement. Unlike petrofacies A and $B$, there is only moderate evidence of secondary alteration and complete dissolution of feldspars via dissolution within this petrofacies. There is typically still moderately welldeveloped primary as well as secondary porosity within this petrofacies. There may be some silty laminae within this petrofacies, as these sediments were not well-sorted during deposition.

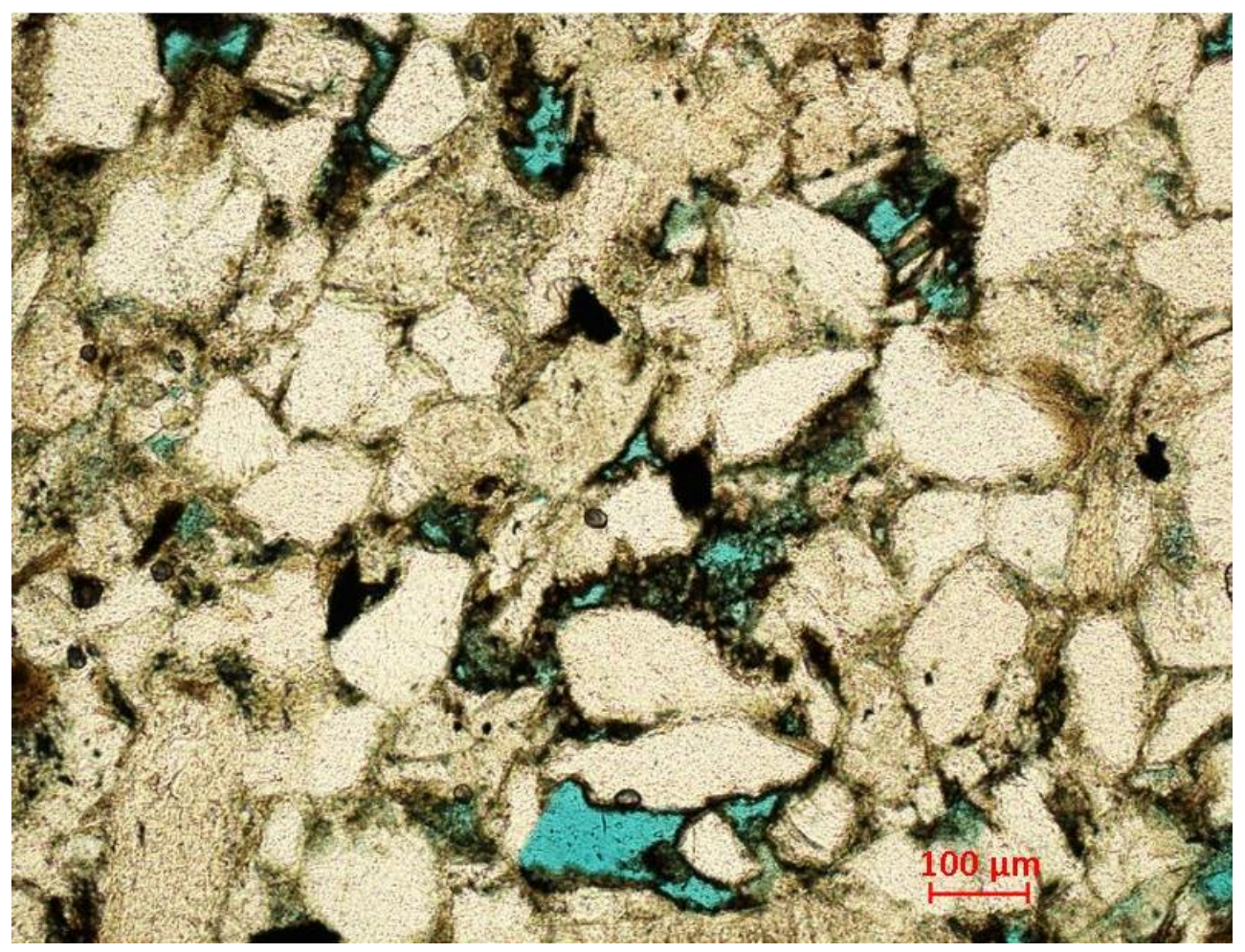

Figure 30. Petrofacies C.

Moderately well sorted, fine-grained, subrounded sandstone with $>5 \%$ porosity and minor calcite and/or dolomite cement. Some evidence of secondary alteration of feldspars via dissolution. There are few completely dissolved grains, however there is evidence that this may have occurred within this thin section. (Photomicrograph of sample number 706-10860.) 


\section{Petrofacies D}

This petrofacies is distinguished from others by its small ( $8 \mathrm{~mm} / 0.314 \mathrm{in}$ ) diameter) and numerous calcite/dolomite concretions and slightly altered pedogenic carbonate fragments amongst moderately well sorted, very fine to fine-grained, subangular sandstone with 2-5\% porosity (Fig. 31). The concretions may be distinguished from the pedogenic carbonate clasts by color in hand sample; concretions are almost purely white in color, while the carbonate fragments are a brown/tan color. There is some evidence of secondary alteration of feldspars and carbonate fragments via dissolution, although there are few completely dissolved grains.

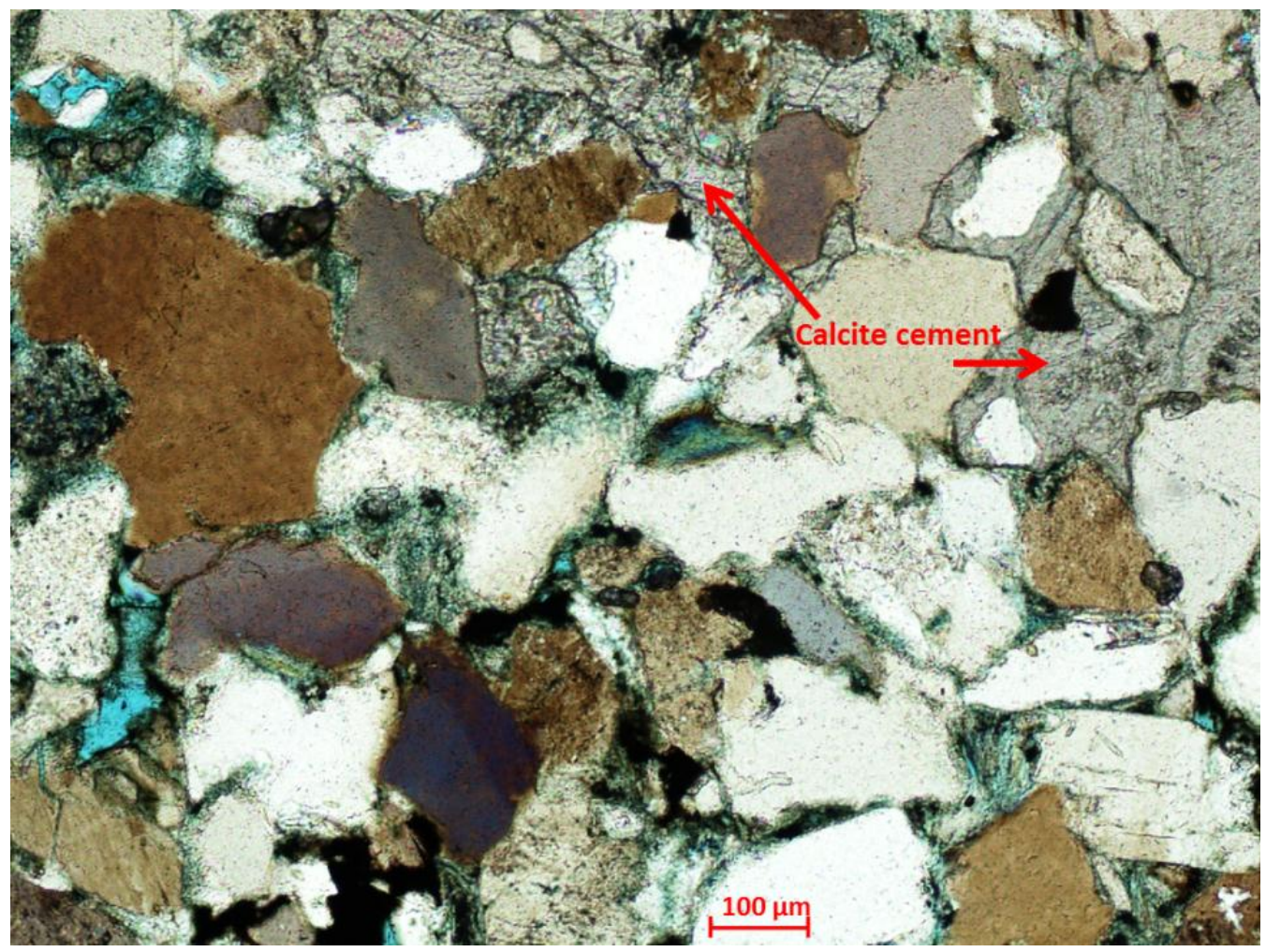

Figure 31. Petrofacies D.

Moderately well sorted, very fine- to fine-grained, subangular sandstone with numerous, small ( $\sim \mathrm{mm}$ ( $~ 0.314 \mathrm{in}$ ) diameter) calcite-cemented concretions and 2-5\% porosity. Some evidence of secondary alteration of feldspars via dissolution. There are few completely dissolved grains. Areas of calcite cement are denoted by red arrows. (Photomicrograph shown as seen in XPL from sample number 3232-10943.) 
Cement is typically localized around the concretions in this petrofacies, however this

petrofacies may be cemented in varying amounts $(0.2-5.5 \%$ cement seen in thin section samples) which can lead to coincidentally variable porosity.

\section{Petrofacies E}

Petrofacies E (Fig. 32) is comprised of moderately sorted, fine-grained subangularsubrounded sandstone often with numerous, small ( $\sim \mathrm{mm} / 0.314 \mathrm{in})$ diameter) calcitecemented concretions and $2-5 \%$ porosity.

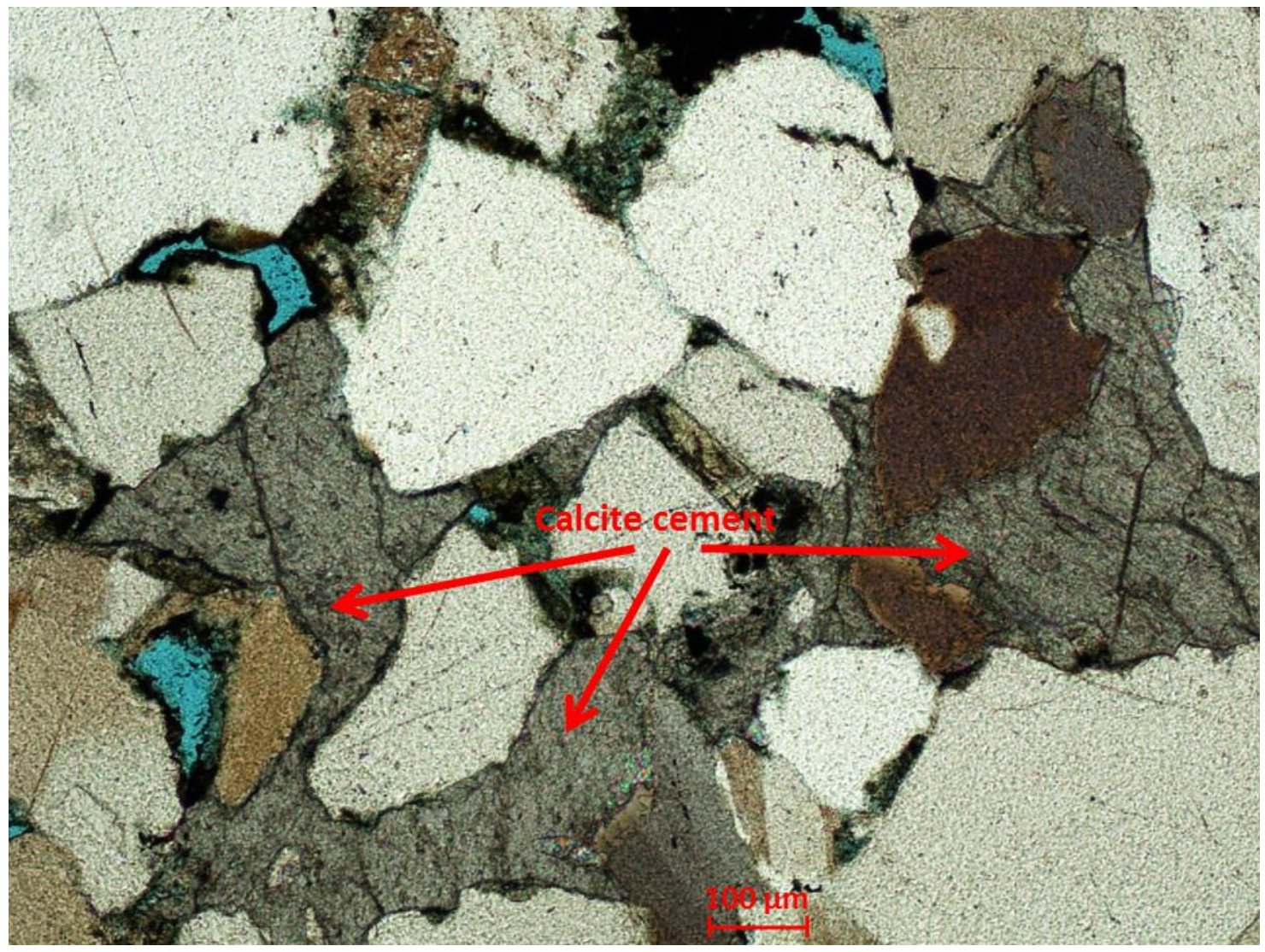

Figure 32. Petrofacies E.

Moderately sorted, fine- to medium-grained, subangular-subrounded sandstone with numerous, small ( $8 \mathrm{~mm}$ (0 .314 in)) diameter) calcite-cemented concretions and 2-5\% porosity. Secondary porosity only is evident in minor alterations and dissolution cavities in some grains, with very few grain-shaped void spaces. Areas of calcite cement are denoted by red arrows. (Photomicrograph of thin section 3232-11023.) 
Secondary porosity only is evident in minor alterations and dissolution cavities in some grains,

with very few grain-shaped void spaces. This petrofacies is essentially a slightly coarser-grained petrofacies $D$, as the only difference is its grain size, and it represents a mid-range porosity petrofacies in the Donovan sand.

\section{Petrofacies F}

Moderately sorted, very fine-grained subangular-subrounded sandstone with $<5 \%$ total porosity and abundant calcite/dolomite cementation defines petrofacies $\mathrm{F}$ (Fig. 33). Minor amounts of secondary porosity are present in altered calcite cement and altered feldspars.

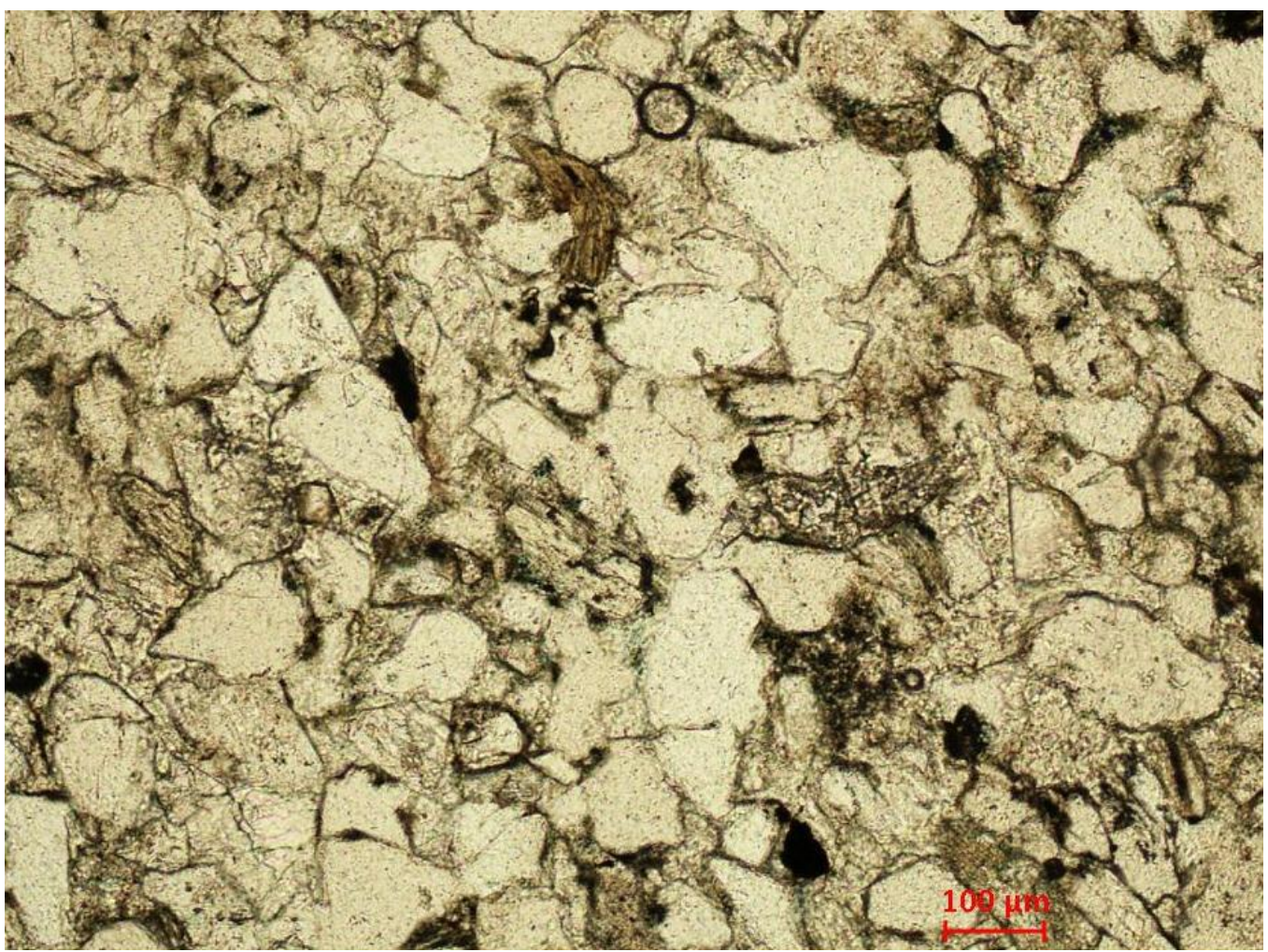

Figure 33. Petrofacies F.

Moderately sorted, very fine-grained subangular-subrounded sandstone with $<5 \%$ total porosity and abundant calcite/dolomite cementation. Minor amounts of secondary porosity are present in altered calcite cement and altered feldspars. Calcite cement pervades this section, and is evident between the grains in this photomicrograph from thin section sample number 706-10865. 
This petrofacies is one of the three lowest porosity petrofacies, with petrofacies $\mathrm{G}$ and $\mathrm{H}$ making up the other 2 low porosity petrofacies. The abundant cementation within this petrofacies has occluded pore space to the degree that some sections that this petrofacies may not possess any porosity at all. This zone is compositionally the same as the previously discussed petrofacies but the grain size, abundant calcite cementation, and resultant low porosity characterize petrofacies $\mathrm{F}$.

\section{Petrofacies G}

Petrofacies G (Fig. 34) is characterized by moderately sorted, fine-grained subangularsubrounded sandstone with $<5 \%$ total porosity and abundant calcite/dolomite cementation.

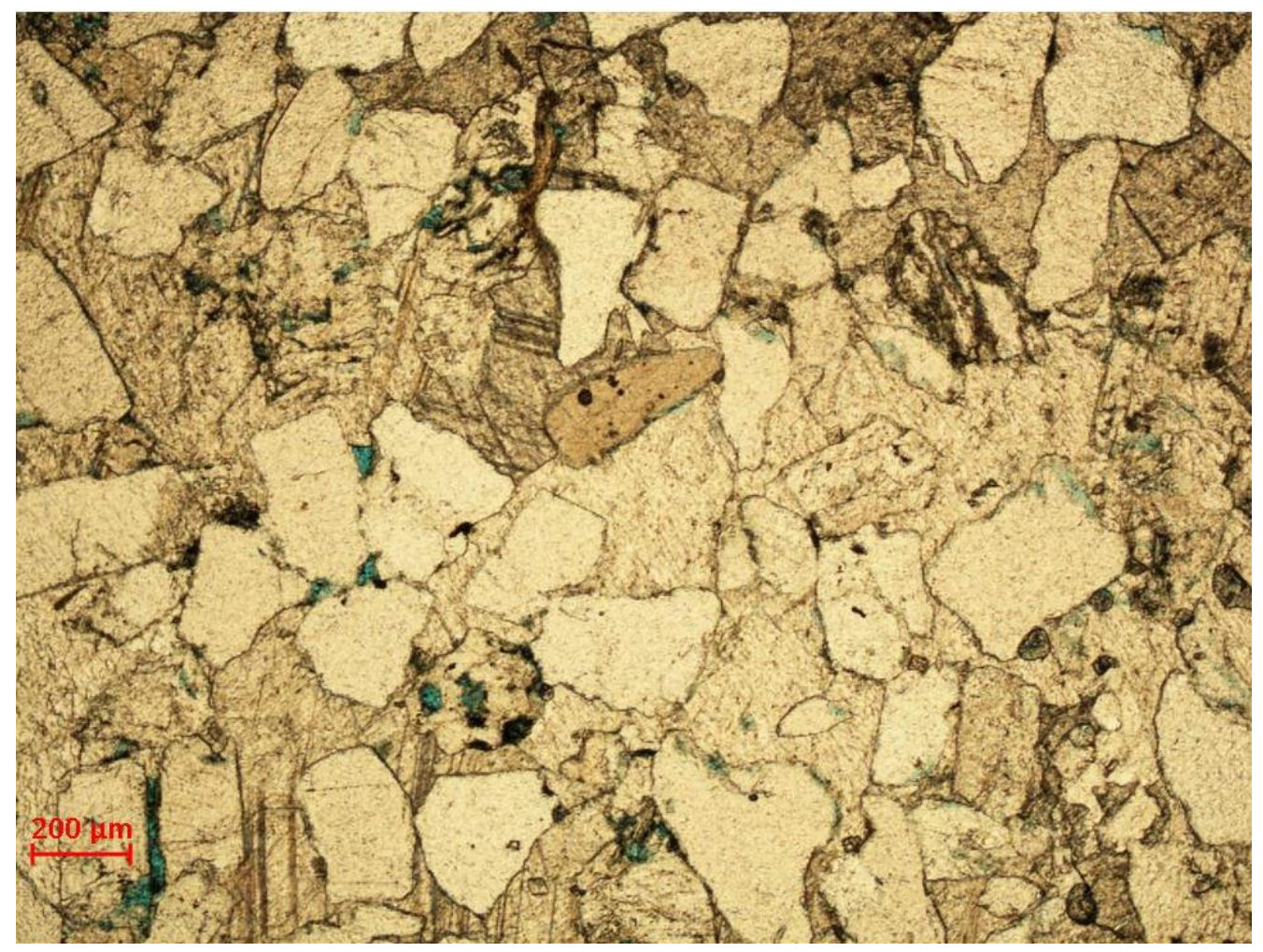

Figure 34. Petrofacies G.

Moderately sorted, fine-grained subangular-subrounded sandstone with $<5 \%$ total porosity and abundant calcite/dolomite cementation. Minor amounts of secondary porosity are present in altered calcite cement and altered feldspars in this photomicrograph (taken from thin section sample number 3232-11018.5). 
Much like petrofacies F, minor amounts of secondary porosity are present in altered calcite cement and altered feldspars, however the large volume of cement in this petrofacies occludes large amounts ( $>5 \%)$ of intergranular space. The sole difference between this petrofacies and petrofacies $F$ is the grain size.

\section{Petrofacies H}

This petrofacies is comprised of poorly sorted, very fine-grained subangular sandstone with $<5 \%$ total porosity due to high matrix content (Fig. 35 ). Some secondary porosity is evident due to dissolution of calcite cement and apparent removal of matrix, but given the large matrix volume within this petrofacies there is an overall very low amount of porosity. While this petrofacies is like petrofacies $F$ and $G$ in that it possesses very minor amounts of porosity, this petrofacies is not thoroughly cemented. There may be some dissolution surfaces within the matrix, but these are not numerous and do not seem to be interconnected in most cases.

\section{Petrofacies Discussion}

Petrofacies A through E are stained by dead oil in some cases, meaning that they were porous enough to allow for hydrocarbon storage and possibly migration in the past. However it is worth mentioning that when encountered in thin section, dead oil was counted as intergranular matrix and not porosity. Thus, petrofacies with dead oil are slightly more porous than their porosity values calculated from open pores represent, but not by more than $2-3 \%$.

These petrofacies (A-E) are conceivably still conducive to fluid storage due to their relatively higher porosities although where there is dead oil in the section, the rock will not be able to store as much fluid as easily because the dead oil is occupying the pore space as a 
hardened substance. Dead oil-bearing petrofacies may be seen in the graphic logs (Plate 2), and are denoted by two asterisks in the left-most column.

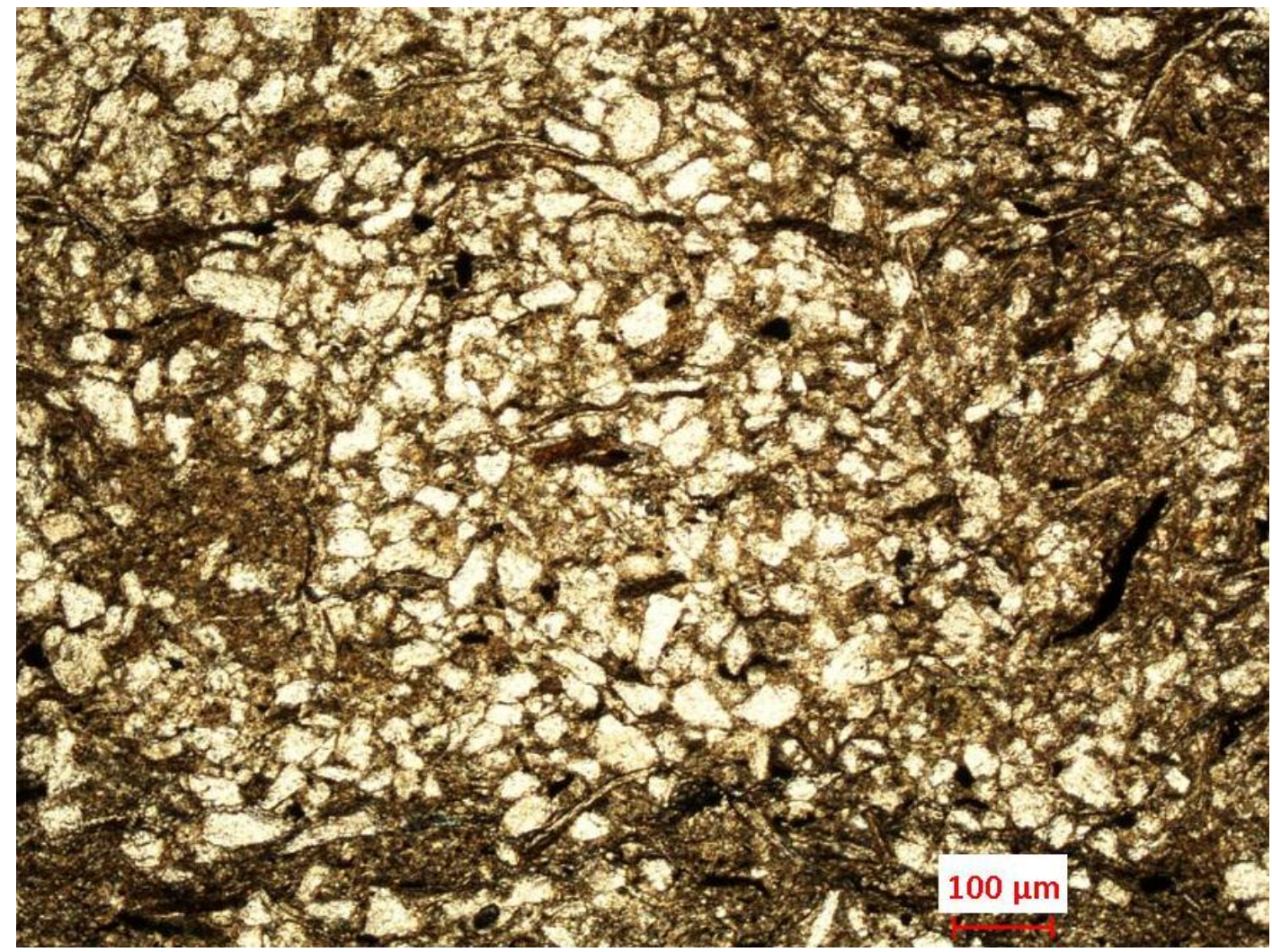

Figure 35. Petrofacies $\mathrm{H}$.

Poorly sorted, very fine-grained subangular sandstone with $<5 \%$ total porosity due to high matrix content. There is very little porosity within this section due to the high matrix content. (Photomicrograph of thin section 713-11347.)

Many of the sandstone thin sections taken from wells 713, 2993, 3198, and 624 also did not have high amounts ( $>5 \%)$ of porosity because they were nearly completely cemented. Typical porosity values for these low porosity sections were 1-3\%. Petrofacies $F$ and $G$ represent these sandstone units with very little to no porosity due to pervasive cementation, and there would not be fluid migration through these tightly cemented zones. Petrofacies $\mathrm{H}$ also is not a 
candidate for fluid transmission, but due to the high volumes of pore-filling silty matrix, not cement. In some instances there are micropores have formed within these three petrofacies due to mineral or matrix dissolution, but these zones are few and the micropores are not significant enough in number to develop connective networks for transmission of fluid.

\section{Diagenesis Interpretation}

Petrofacies A-C are inferred to share a similar diagenetic history, because their porosity type distribution and porosity volumes are similar. After the Donovan sediments were deposited during the early Cretaceous, they began to compact. After some moderate compaction, cementation processes began. Moderate amounts of calcite cementation, driven by mineral precipitation from supersaturated calcium-rich formation water, occurred before there was extensive compaction. This resulted in the preservation of wide grain spacing. By occupying the available primary pore spaces, the early cementation slowed the effects of compaction on the sediment, and the grain spacing was preserved. As cementation was occurring, there was intermittent dissolution of grains or cement, judging by some cases of filled intragranular and intergranular porosity within these petrofacies (e.g., Figs. 15, 22, and 24). This was likely driven by the lower degree of calcium saturation of formation waters during some portions of the reservoir's diagenetic history.

Petrofacies D and E likely share the same diagenetic history, as both of these petrofacies contain calcite/dolomite concretions and have similar porosity distributions. These sediments were likely buried and compacted in the same manner as petrofacies A-C, but were not as drastically affected by secondary porosity creation processes as the higher porosity petrofacies. Cementation within petrofacies $\mathrm{D}$ and $\mathrm{E}$ likely initially began as small patches as calcite cement 
precipitated out of solution from supersaturated formation waters, with some patches growing faster than others. Eventually, small concretions began to form and served as the main sites for cementation within these petrofacies. Some slight alteration via fluid interaction with minerals may have occurred afterward, but the effect of the interaction would be minimal, as these petrofacies have only $2-5 \%$ porosity.

Petrofacies $\mathrm{F}$ and $\mathrm{G}$ were buried similarly to the previously discussed petrofacies, however these petrofacies did not undergo as much compaction as the others because of nearly immediate cementation after burial due to immediate introduction of calcitesupersaturated formation waters to the reservoir, preserving the wider grain spacing within the cement. Some grains may not be touching all of their surrounding grains, and this is an indicator that cementation occurred very early on in the diagenetic history because otherwise the grains would likely be forced to share edge contacts with one another due to compaction. Primary pores are all filled with calcite/dolomite cement, and secondary pores are not present within these petrofacies. However, there may be filled secondary pores within this petrofacies which may indicate alternating periods of cementation and fluid dissolution after the beginning of initial cementation.

Petrofacies $\mathrm{H}$ was deposited along with an abundance of silt and mud, and as a result, the sediments within this petrofacies were compacted until the matrix and framework grains were so tightly packed together that most (if not all) porosity was occluded by the pore space-filling muds. There may have been some minor calcite cementation after compaction due to temporary interaction of the reservoir with calcite-supersaturated fluids; however the majority of the pore-filling constituency is matrix within this petrofacies. 


\section{Chapter 6: Geophysical Well Log Analysis}

\section{Formation Top Signatures}

Formation tops were picked by comparison with a type log based on SP and resistivity log curves from Pashin et al. (2007, see Fig. 4). The uppermost formation top picked was the Mooringsport Formation, and it was picked at the base of the Paluxy Formation which typically has a pronounced log signature of low ( $20 \mathrm{mV})$ SP and mid-range ( $100-200$ ohm-m) resistivity values. The Ferry Lake Anhydrite immediately underlies the Mooringsport Formation. This formation top exhibits a sharp decrease in SP as well as a pronounced resistivity increase immediately downhole of the Mooringsport Formation mudstone. Resistivity values within the Ferry Lake are typically the highest of any formation in the section (average $130-150$ ohm-m), and this pick is laterally extensive and continuous across the area. The top of the Upper Donovan Sand was identified as the base of the Ferry Lake Anhydrite, based upon the sharp increase in SP and decrease in resistivity as the top mud layer of the Upper Donovan is encountered downhole. This 10-to-20-foot (3-6 m) thick mudstone signature should overly a zone with decreased SP and increased resistivity once more as the section transitions into the first Upper Donovan sand body.

The top of the Middle Donovan Sand was identified based on the sharp deflection of SP toward the more negative end of the track and coinciding resistivity decrease from the bottom mudstone of the Upper Donovan to the sands of the Middle Donovan. The Middle Donovan is water-bearing, but both the Upper and Lower are oil-bearing. This is a key difference in interpreting the sand layers and different Donovan formations in the log signature. The Lower Donovan Sand formation top was picked based upon the sharp increase in the SP curve as it 
transitioned downward from the overlying water-bearing sandstone of the Middle Donovan to the upper mudstone layers of the Lower Donovan. Generally, this pick was made at the base of the last extremely negatively-deflecting sand layer, because the Lower Donovan sandstone signatures tended to seem dampened or not as pronounced. Lastly, the Pine Island formation top exhibits a larger negative deflection of the SP and resistivity curves than the Lower Donovan. This is likely due to the sorting difference as well as the fluid type difference between the formations. Formation tops were correlated across all 47 wells in the dataset and then checked for quality control. The resultant data was used to produce a series of cross-sections

(Fig. 36; also Plate 1).

\section{Structure Map}

The Upper Donovan Sand structure map was generated and hand-contoured using formation top depths. The study area is situated on the northeastern flank of the Citronelle Dome, and the structure map (Fig. 37) shows that the slope of the top of the Upper Donovan begins at its highest in the southwest and gently dips away from the dome. There are no major faults within the study area which would disrupt this structural pattern.

\section{Upper Donovan Sand Isochore}

Much like the Upper Donovan Sand structure map, the isochore map was created in GeoGraphix GeoAtlas module using the formation top picks made within GeoGraphix CrossSection module. The formation tops used to measure the thickness of the formation were the Upper Donovan Sand and the Middle Donovan Sand tops as the top and bottom, respectively. This isochore map shows the total thickness of the formation, not solely the thickness of the sand bodies within the Upper Donovan. However it does seem to match the 
shape of a fluvial channel system, with the brighter-colored portions of the isochore representing the thickest accumulations of total Upper Donovan thickness and then thinning towards the edges of the map (Fig. 38).

\section{Upper Donovan Net Sand Map}

The Upper Donovan Sand net sand map (Fig. 39) was created by applying gamma ray and SP cutoffs of $90 \mathrm{API}$ units and $30 \mathrm{mV}$, respectively, to the Upper Donovan Sand interval within GeoGraphix. These cutoffs allow differentiation between sand and shale layers within the two logs. SP-related net sand values were used where there was not gamma ray log control. Some portions of the Upper Donovan Sand were not logged in some wells. In these cases, the well log cross-sections that contained the Upper Donovan were reviewed and a value for the net sand was assumed based on interpretation by the author.

The areas within the Upper Donovan Sand with the thickest total amount of sand are indicated by the red and orange areas denoted in the net sand map (Fig. 39). Aside from the northern and far western/southwestern portions of the map, the areas with the thickest overall section are not necessarily the areas with the thickest accumulations of sandstone (Fig. 38). 


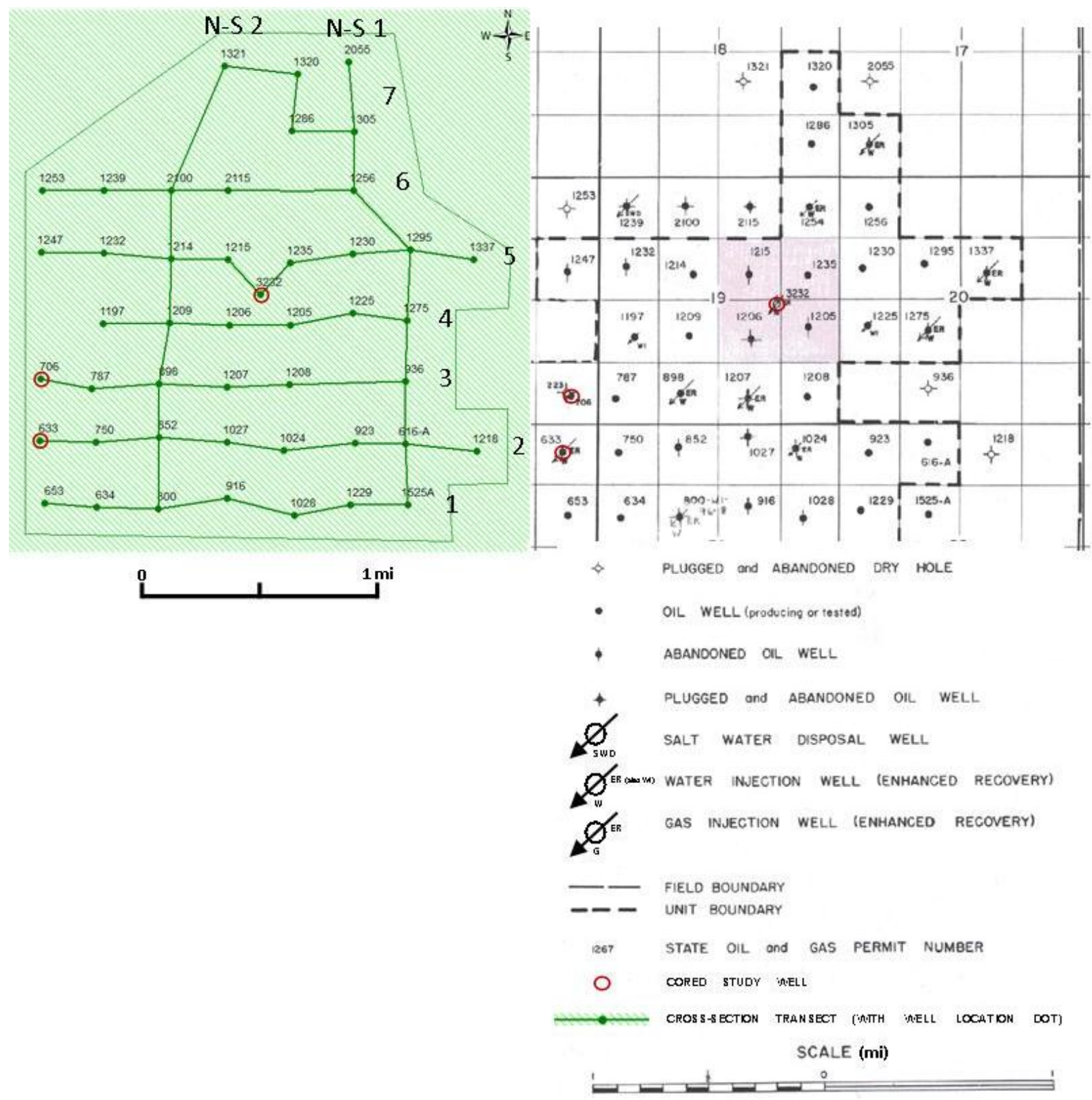

Figure 36. Cross-section location map for all dataset wells.

The transects of all cross-sections made within the GeoGraphix module, GeoAtlas, are shown here. In total there are nine cross-sections, with number one beginning at the bottom with well permit number 1525A and ending at well permit number 653. Each of the horizontal crosssections followed this pattern except for the north-south ( $\mathrm{N}-\mathrm{S}$ )-oriented cross-sections which began in the northern portion of the study area and progressed southward. Northeastern portion of Citronelle field landgrid may be seen in the right-hand portion of this figure, outlining the study area. Cored study wells are outlined in red. 


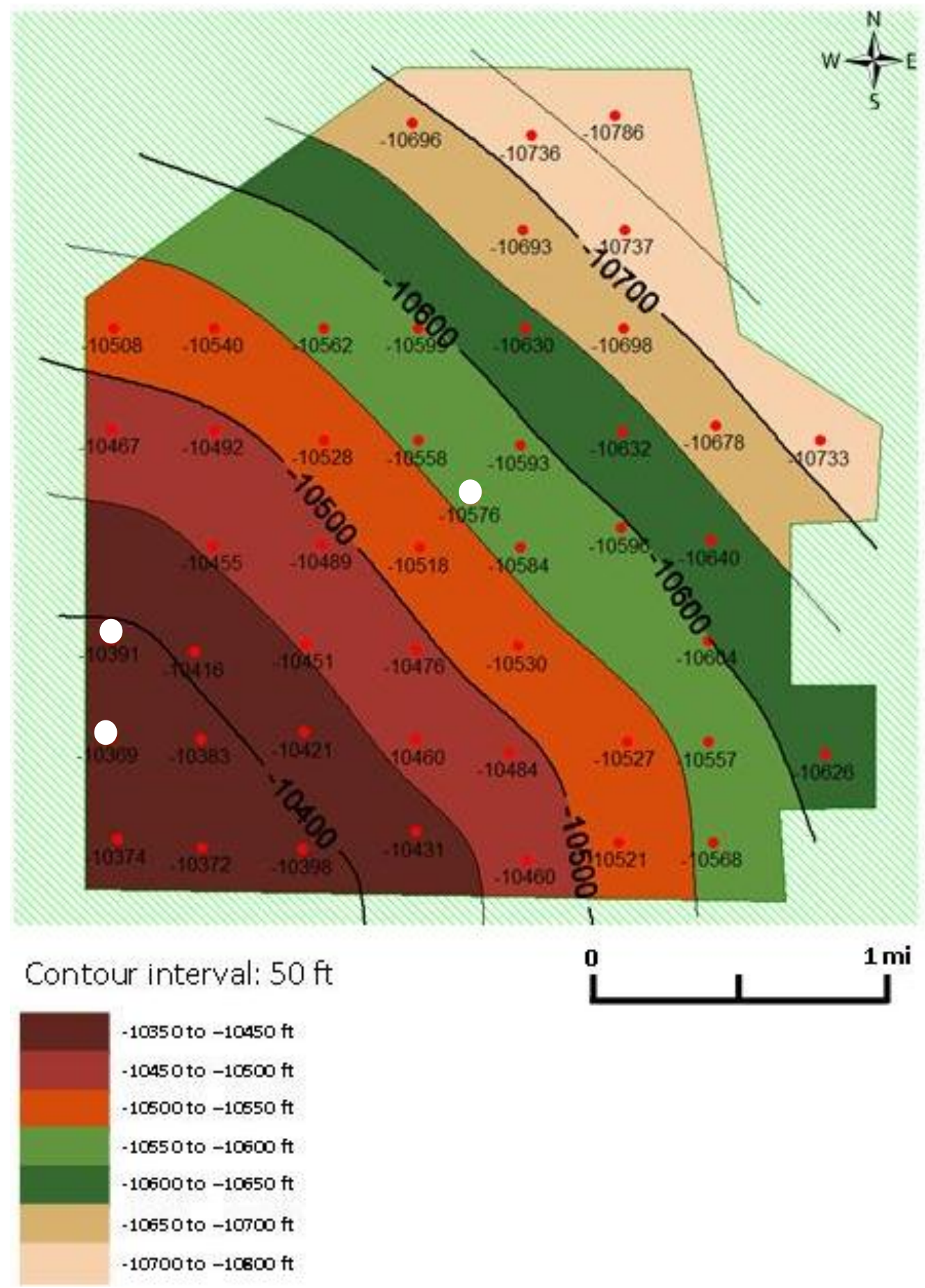

Figure 37. Upper Donovan structure map.

The structure is gently sloping away from the Citronelle Dome, which is to the southwest of this study area. Study well locations are shown as red dots, with the Upper Donovan formation top depth listed below each respective well location. Cored well locations are shown as white ovals. (Metric contour interval is $15.24 \mathrm{~m}$.) 


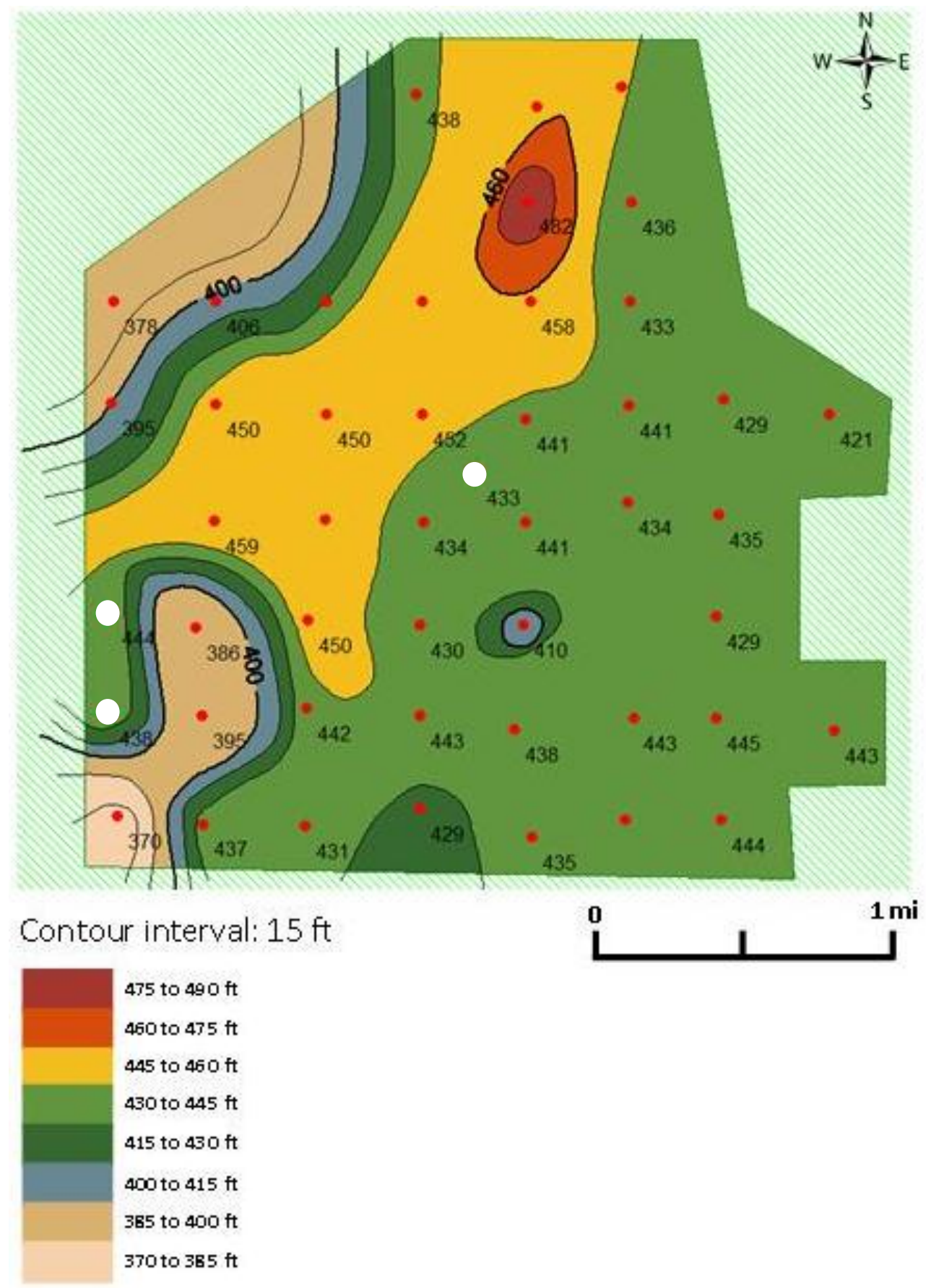

Figure 38. Upper Donovan isochore map.

Map showcasing the thickness of the entire Upper Donovan interval. Study well locations are shown as red dots, with the total Upper Donovan Sand thickness listed below each respective well location. Cored well locations are shown as white ovals. (Metric contour interval is $\sim 4.572$ m.) 


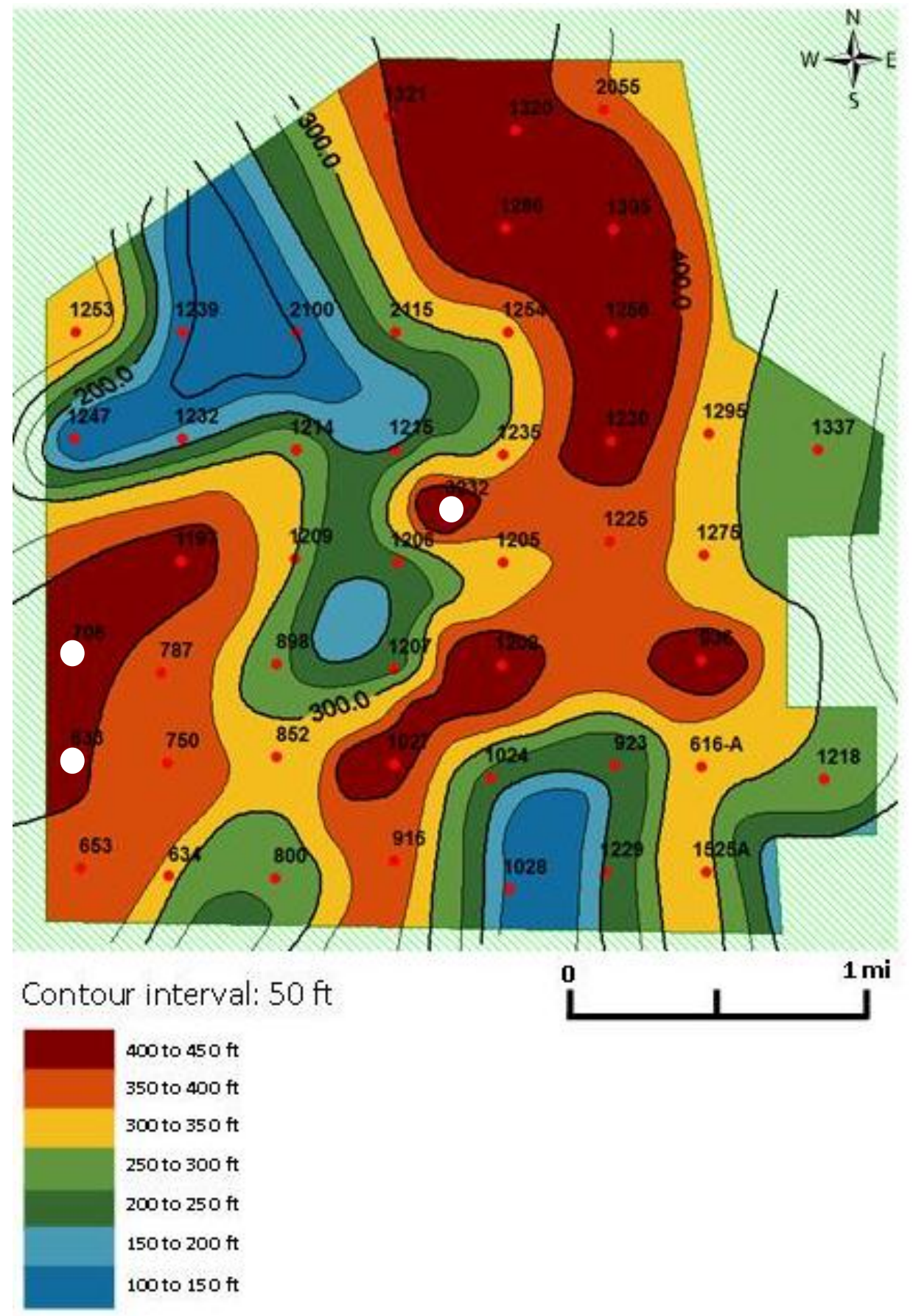

Figure 39. Upper Donovan net sand map.

Map showing the areas of the Upper Donovan Sand with the most total sand. Red and orange colors indicate the areas with the most sand, while the blue color denotes an area with relatively thin $(<200 \mathrm{ft})$ total sand accumulation. Well permit numbers are shown next to their respective locations (marked with red dots). Cored well locations are shown as white ovals. Map was hand-contoured by the author within GeoGraphix. (Metric contour interval is 15.24 m.) 


\section{Chapter 7: Petrology-Log Ties}

\section{Petrofacies Distribution within Petrophysical Logs}

Petrofacies were defined in all seven cored wells (Plate 2) and then identified in respective well logs. These petrofacies were then transferred from graphic logs (Plate 2) to cross-section well logs in order to test for a relationship between the geophysical log character and petrofacies. The 3 available well logs from the 7 cored wells were gathered into a single cross-section (Fig. 40) and then the most porous petrofacies ( $A$ through $\mathrm{C}$ ) were denoted on the well log (see Plate 3). The results depict zones within the Donovan sand that contain widespread cementation and other zones in which some factor has precluded widespread cementation, leaving open pore space. Most of these porous petrofacies are distributed within the middle portion of the Upper Donovan Sand. This zone has been identified as a high porosity zone and will be discussed later in this chapter.

\section{Porosity Distribution}

The PHID curve, generated within the geologic software program GeoGraphix via methods outlined in Chapter 3, was averaged over the entire thickness of the Upper Donovan Sand interval (Fig. 38) using operations within the PRIZM module within GeoGraphix and then posted as a single value on the wellbore location (red dots in Fig. 41). Because PHID values were generated in decimal form, the points on the porosity map are also in decimal form. Negative values posted in Figure 41 represent a denser matrix than the 70/30 feldspar to quartz ratio sandstone that the PHID curve was generated for, possibly indicating that the material was slightly more dense than this approximation. This may mean that more quartz (density: 2.64

$\mathrm{g} / \mathrm{cm}^{3}$ ) or calcite cement (density: $2.71 \mathrm{~g} / \mathrm{cm}^{3}$ ) rather than orthoclase feldspar (density: 
$2.52 \mathrm{~g} / \mathrm{cm}^{3}$ ) was present within the averaged interval. Wells that are not shown did not have adequate log control for a formation top pick of the Middle Donovan Sand to constrain the bottom of the Upper Donovan Sand, and as such the average porosity for the Upper Donovan could not be generated. After the average porosity data had been posted to the well location within the GeoGraphix module GeoAtlas, the values were then hand-contoured to create the porosity map (Fig. 41). Two higher porosity zones are present within this map, and are denoted by the yellow and green portions. The area with the highest average porosity is located in the western portion of the porosity map, with another area of relatively high porosity at the central-eastern portion. When the porosity distribution (Fig. 41) is compared with the total Upper Donovan interval thickness map (Fig. 38), the western high porosity zone does fit within an area of relatively thicker Donovan section, but there does not seem to be a direct relationship between porosity and overall formation thickness within this study area.

\section{High Porosity Zone \& $\mathrm{CO}_{2}$ Storage}

The three most porous petrofacies occur in the same stratigraphic zone within the three cored wells (well permit numbers 3232, 706, and 633; Fig. 40). The 'high porosity zone' is defined as a zone in the Donovan Sand that possesses $>5 \%$ porosity according to thin section point counts and correlation of porous petrofacies based on well logs signature for wells with no thin section control. The high porosity zone is represented in log as a relatively clean sand body with a depressed gamma, EstRHOB, and resistivity signature, while the PHID curve usually exhibits higher values. This zone represents a preferential migration pathway of fluids. 

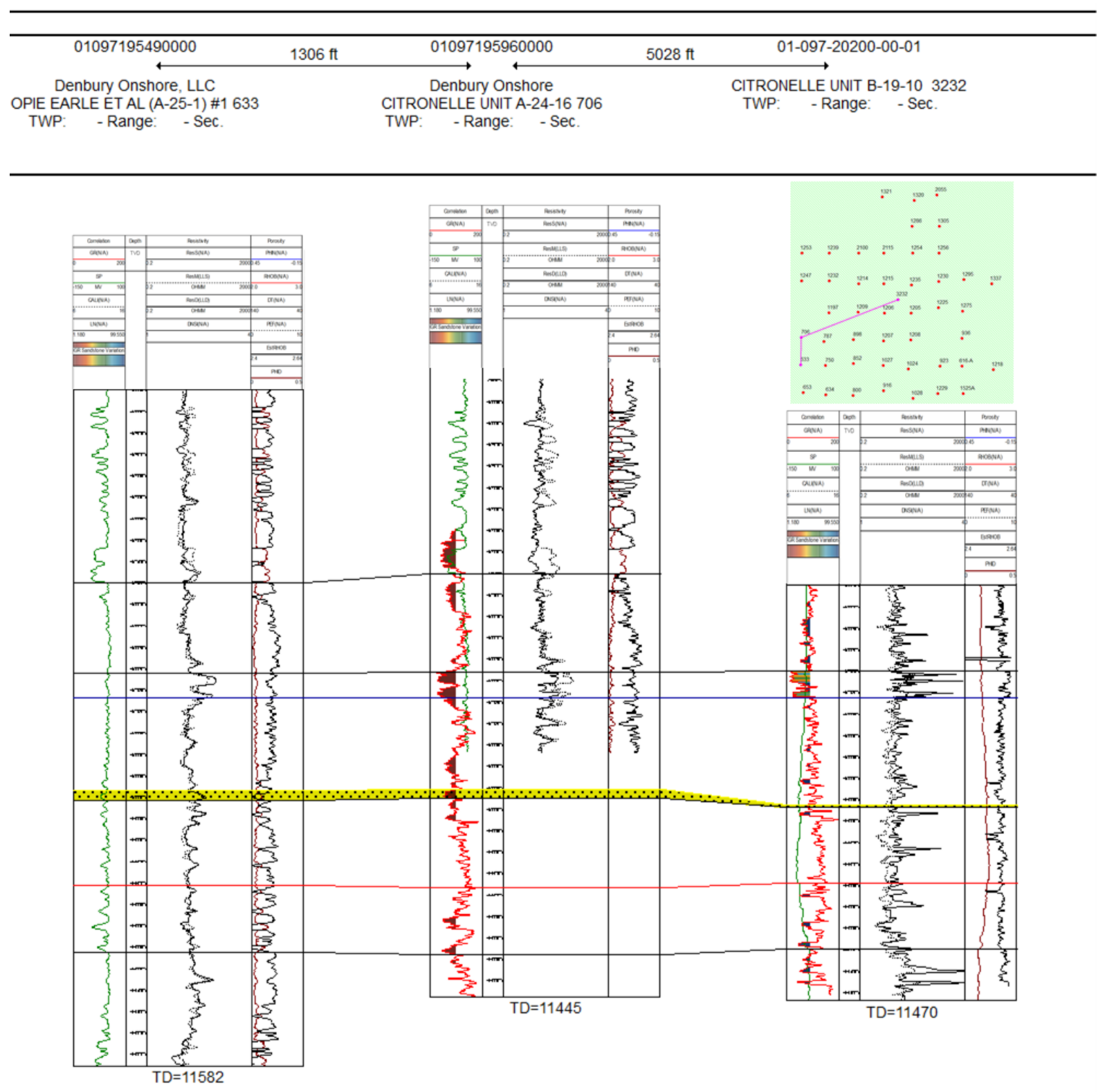

Figure 40. Cored wells cross-section

Cross-section showing well permit numbers 635, 706, and 3232 from left to right. Formation tops are shown as colored lines, and the high porosity zone (yellow fill) lies within the Upper Donovan Sand portion of the log. The cross-section is flattened stratigraphically on the Upper Donovan Sand (blue) formation top in order to show the correlation of the high porosity zone. The red formation top line is the Middle Donovan Sand formation top, which is included for reference. Map of the study area (top right, inset) outlines the cross-section (pink line). 


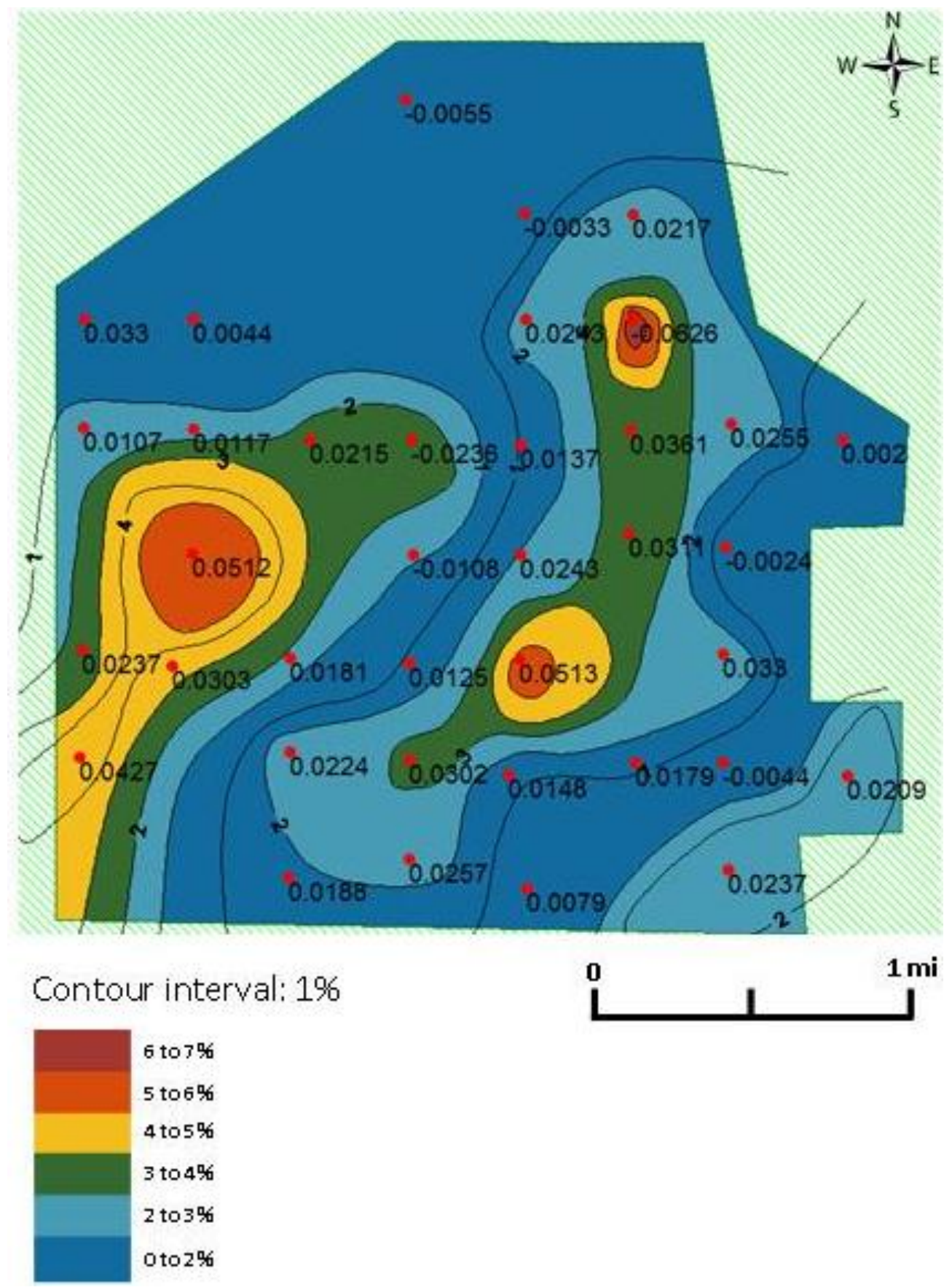

Figure 41. Upper Donovan Sand porosity distribution map.

Average porosity values are shown as they were calculated: minus-cement taken from the PHID curve generated during log analysis. Minus-cement means that these values were calculated as if there was no cement present within the reservoir. Note the red, orange, and yellow higher porosity areas. 
Due to the high feldspar content and moderate amount of calcite and dolomite cement in this zone, minerals could be subject to further dissolution given reservoir conditions and fluid geochemistry. The pressure and temperature within an underground reservoir is much different than at the surface, and depending upon these conditions $\mathrm{CO}_{2}$ behaves differently with regards to $\mathrm{CO}_{2}$-mineral interaction.

The current temperature of the Donovan Sand at depth is $\sim 98.9^{\circ} \mathrm{C}\left(210^{\circ} \mathrm{F}\right)$, and although depleted since initial production within Citronelle Field, the formation pressure is $\sim 20.7 \mathrm{MPa}$ (3000 psi) (Esposito, 2010). In past studies concerning the interaction of formation fluid and injected $\mathrm{CO}_{2}$, there has been evidence for alteration/dissolution of feldspars and carbonate mineral phases in both experimental (Fischer et al., 2011) and naturally-occurring (Emberley et al., 2004; Rosenbauer et al., 2005) settings. The Donovan Sand within Citronelle Field is thus prone to dissolution of calcite phases and creation of secondary porosity within the reservoir with the injection of $\mathrm{CO}_{2}$. Given that the high porosity zone could_delineate a fluid migration pathway if the pores are well-connected within the Upper Donovan prior to injection, it is logical that the $\mathrm{CO}_{2}$ will also migrate along this pathway. Secondary porosity creation along this pathway will then be accentuated as the $\mathrm{CO}_{2}$ interacts with and likely alters the formation minerals.

$\mathrm{CO}_{2}$ injected during EOR operations likely would have had an effect similar to that just described, with the $\mathrm{CO}_{2}$ being forced through the reservoir and temporarily interacting with the reservoir minerals it contacted. With long-term storage operations however, the $\mathrm{CO}_{2}$ will be left within the reservoir for a longer period of time and will interact with the reservoir longer than in EOR operations. This prolonged interaction between the sequestered $\mathrm{CO}_{2}$ and the reservoir 
minerals could have a drastic effect on the reservoir quality, either enhancing or diminishing the porosity. Introduction of the $\mathrm{CO}_{2}$ may initially lead to an increase in secondary porosity amounts as susceptible mineral phases are altered, but over time the fluid may equilibrate with the reservoir rock as it becomes more saturated with ions derived from mineral dissolution in the reservoir rock. If the fluid becomes supersaturated with respect to these minerals, the same minerals that were initially dissolving may precipitate out of solution once more resulting in a decrease in overall porosity. 


\section{Chapter 8: Discussion}

The data that has been gathered over the course of this study show that there is a high porosity zone within the Upper Donovan Sand that is correlatable from well to well within the study area. This zone could be a fluid migration pathway, such that as $\mathrm{CO}_{2}$ is injected into the reservoir, $\mathrm{CO}_{2}$ flow will preferentially follow this zone. The $\mathrm{CO}_{2}$ could interact with the reservoir minerals themselves just as formation fluids have over geologic time to create secondary pore space and fill pore space with authigenic cement. However, it is difficult to ascertain the exact timing of these reactions, be it immediately with introduction of $\mathrm{CO}_{2}$ to the reservoir or sometime in the distant future. It is also difficult to predict the exact reactions that may occur within the reservoir, however experimental results all point to the conclusion that silicate and carbonate minerals are prone to dissolution when $\mathrm{CO}_{2}$ is introduced and the $\mathrm{pH}$ of the formation waters is lowered as a result (e.g., Emberley et al., 2004; Rosenbauer et al., 2005; Strazisar et al., 2006; Fischer et al., 2011). This is not to say that there will necessarily be a net increase in the total porosity within the formation or even within the zone of interest within the formation when long-term storage is further pursued within the Donovan, because diagenetic porosity development may also be redistributional in closed systems such as a long-term geologic storage reservoir. Redistributional porosity is secondary porosity that results in the dissolution of minerals and/or cement in one portion of a reservoir and the precipitation of some mineral out of supersaturated formation fluid in another part of the reservoir (Bloch, 1994).

The composition of the Donovan Sand is very consistent within the upper portion and presumably the Middle and Lower members as well, and this bodes well for secondary porosity 
creation via mineral dissolution given that the sands are arkosic. However, heterogeneity can present itself on such a scale that it may not be noticeable in the data given the spatial log control and the scarcity of log data.

The petrofacies analysis has demonstrated that the porosity distribution is almost, if not entirely dependent upon diagenetic processes. That is, cementation occurred in some zones but not uniformly across the basin during and after deposition. The petrofacies outline the zones in which there has and has not been abundant cementation, which further reinforces the need for better logs and geophysical data because the Upper Donovan Sand is highly compartmentalized not only lithologically, but reservoir sandstones themselves are compartmentalized by diagenetic alteration as well. However, core descriptions, thin section compositional analysis, or depofacies correlations do not fully capture the heterogeneous nature of the Upper Donovan Sand reservoir for a few reasons:

1. The core descriptions do not allow for a thin-section analysis of every compartment within the reservoir because not every well has had core sampled.

2. Thin-section compositional analysis is not very useful in trying to plot compositional heterogeneity of framework grains in these rocks because of the essentially uniform framework composition throughout the Donovan. However, thin section-derived porosity counts are important because there are porosity differences within the Donovan Sand. 
3. Petrofacies seem to have been formed independently of depositional environment, meaning that we cannot accurately trace degrees of cementation to depofacies outlined in this thesis.

Hence in order to accurately ascertain the location of compartmentalized deposits, the petrofacies outlined in this thesis and the subsequent high porosity zones may act as boundaries which may define fluid flow pathways within the reservoir.

With the petrofacies tied to a log character and the correlation of that log signature across the field (Plate 1; high porosity zone is outlined in yellow), the sand unit that has been correlated is composed of the same three most porous petrofacies. However the possibility exists that the cementation of that unit is variable. This possibility could be tested through other logs, such as gamma ray and density logs, if these logs were available. The process involved in the determination of petrofacies as well as the high porosity zones is repeatable, and can be applied to any area in which adequate log control exists and where core samples have been taken from the intended study target at depth.

The amount of secondary porosity that is evident within the Upper Donovan Sand, specifically within the high porosity zone outlined in the cross-sections, is direct proof that this zone has been affected by diagenetic porosity enhancing processes in the past. While connate water moving through a porous zone can dissolve minerals over geologic time, the introduction of $\mathrm{CO}_{2}$ into the reservoir could drastically increase the rate of dissolution by lowering the formation water $\mathrm{pH}$ (Strazisar et al, 2006) and create porosity more quickly within the unit. 


\section{Chapter 9: Conclusions}

The Citronelle Field in southwestern Alabama is a longstanding oil and gas producing field with over $168 \mathrm{MMbbl}$ of oil and $15 \mathrm{Bcf}$ of natural gas produced from the Donovan Sand within the Rodessa Formation (Pashin et al., 2007). The Donovan Sand has undergone $\mathrm{CO}_{2}$ injection for EOR purposes in the past, and the Upper Donovan Sand is currently undergoing $\mathrm{CO}_{2}$ injection as a test for long-term storage in mature oil and gas reservoirs.

The Cretaceous-aged Donovan Sand is arkosic, with most of its sediments likely having been sourced from granites and granitoids within the Motts Gneiss and the Hospilika Granite intrusions of the Uchee terrane of Georgia and Alabama (Steltenpohl et al., 2008). The Upper Donovan Sand a heterogeneous reservoir with variable porosity but relatively consistent composition. In order to better understand the subsurface migration pathway as well as the potential fluid-rock interactions that may occur as a result of the introduction of the $\mathrm{CO}_{2}$ into a mature hydrocarbon reservoir, core, thin section, and petrophysical log data have been gathered and cross-referenced. An estimation of bulk density based upon SP log values was generated using the geologic software package GeoGraphix and then applied to every well with well logs. From this approximation of bulk density (EstRHOB) another log was generated using the EstRHOB curve in order to approximate the porosity. A structure map, isochore map, and an average porosity map of the Upper Donovan Sand were created using publicly available well logs from the Geological Survey of Alabama and the user-generated EstRHOB and estimated porosity curves.

Seven cores were described and thin sections were taken from the cores in order to sample each representative sandstone facies. Data from the cores and thin sections were 
compiled into graphic log form (Plate 2) and the 8 depofacies and 8 petrofacies were outlined from the cores and thin sections, respectively. Depositional environments of the 8 depofacies were interpreted to be as follows: depofacies 1 - incised valley fill, depofacies 2 - channel thalweg sandstone, depofacies 3 - braided stream channel sandstone, depofacies 4 - tidallyinfluenced deltaic distributary channel, depofacies 5 - floodplain, depofacies 6 - estuary, depofacies 7 - prodelta, and depofacies 8 - carbonate shelf.

Petrofacies were unconventionally defined, due in large part to the consistent composition of the Donovan Sand. Petrofacies were defined based upon their porosity and cement percentages according to point-counted values from thin sections. The petrofacies were then tied to their depth-calibrated signature on the well log based upon porosity and cement percentages. The most porous petrofacies $(A-C)$ happen to occur within the same stratigraphic zone in the Upper Donovan Sand, and this zone has been dubbed a 'high porosity zone'. Correlation of this high porosity zone from well to well results in the delineation of a fluid migration pathway that the sequestered $\mathrm{CO}_{2}$ may follow in the subsurface.

There are higher amounts of secondary porosity within the high porosity zone than in other portions of the reservoir, indicating that there has already been some sort of fluid-rock interaction within the high porosity zone prior to injection of the $\mathrm{CO}_{2}$ for long-term storage purposes. Experimental and field data both provide evidence of feldspar and carbonate mineral dissolution with the introduction of $\mathrm{CO}_{2}$ (Emberley et al., 2004; Rosenbauer et al., 2005; Strazisar et al., 2006; Fischer et al., 2011), and these mineral phases are present within the high porosity zone. In delineating and understanding the fluid migration pathway, the reservoir 
composition, and the possible mineral reactions to introduction of $\mathrm{CO}_{2}$, the possible effects that sequestered $\mathrm{CO}_{2}$ could have upon the reservoir rock may also be better understood. 


\section{References}

Allen, J.R.L., and Collinson, J.D., 1974, The superimposition and classification of dunes formed by unidirectional aqueous flows: Sedimentary Geology, v. 12, no. 3, p. 169-178.

Allison, M.A., 1998, Geologic framework and environmental status of the Ganges-Brahmaputra Delta: Journal of Coastal Research, v. 14, no. 3, p. 826-836.

Ashley, G.M., Southard, J.B., Boothroyd, J.C., 1982, Deposition of climbing-ripple beds: a flume simulation: Sedimentology, v. 29, p. 67-79.

Bachu, S., 2001, Screening and ranking of hydrocarbon reservoirs for $\mathrm{CO}_{2}$ storage in the Alberta Basin, Canada: Proceedings from the First National Conference on Carbon Sequestration Poster Presentations.

Bachu, S., 2002, Sequestration of CO2 in geological media: criteria and approach for site selection in response to climate change: Energy Conversion and Management, v. 41, p. 953-970.

Barineau, C.I., 2009, Superimposed fault systems of the southernmost Appalachian Talladega Belt: implications for Paleozoic orogenesis in the southern Appalachians (PhD Dissertation): Tallahassee Florida, Florida State University.

Bayona, G., 2003, Controls on middle to late Ordovician synorogenic deposition in the southeastern corner of Laurentia (PhD Dissertation): Lexington, Kentucky, University of Kentucky, p. 75-77, 139-142.

Bird, D.E., Burke, K., Casey, J.F., and Hall, S.A., 2005, Gulf of Mexico tectonic history: Hotspot tracks, crustal boundaries, and early salt distribution, v. 89, no. 3, p. 311-328.

Blakey, R., 2010, Paleogeographic Reconstruction of North America, http://www2.nau.edu/rcb7/namJ180.jpg. Accessed 28 October, 2011.

Bloch, S., 1994, Secondary porosity in sandstones: significance, origin, relationship to subaerial unconformities, and effect on predrill reservoir quality prediction: Reservoir Quality Assessment and Prediction in Clastic Rocks, Society for Sedimentary Geology, v. 30, p. 137-159.

Caldwell, C.D., 1983, Kansas-Type Cyclothems and Porosity Development in Middle Pennsylvanian Marmaton Group, Dirks Field, Logan County, Kansas: AAPG Bulletin, v. 67, p. 1315-1323. 
Chalokwu, C.I. and Hanley, T.B., 1990, Geochemistry, petrogenesis, and tectonic setting of amphibolites from the southernmost exposure of the Appalachian Piedmont: Journal of Geology, v. 98 , no. 5, p. 725-738.

Dobson, L.M., and Buffler, R.T., 1997, Seismic stratigraphy and the geologic history of Jurassic rocks, northeastern Gulf of Mexico: AAPG Bulletin, v. 81, p. 100-120.

Droser, M.L., and Bottjer, D.J., 1986, A semiquantitative field classification of ichnofabric: Journal of Sedimentary Research, v. 56, p. 558-559.

Drummond, M.S., Weselowski, D.J., and Allison, D.T., 1988, Generation, diversification, and emplacement of the Rockford Granite, Alabama Appalachians; mineralogic, petrologic, isotopic (C\&O), and P-T constraints: Journal of Petrology, v. 29, No. 4, p. 869-897.

Emberley, S., Hutcheon, I., Shevalier, M., Durocher, K., Gunter, W.D., and Perkins, E.H., 2004, Geochemical monitoring of fluid-rock interaction and $\mathrm{CO}_{2}$ storage at the Weyburn $\mathrm{CO}_{2}$-injection enhanced oil recovery site, Saskatchewan, Canada: Energy, v. 29, p. 1393-1401.

Esposito, R.A., 2010, Business models for commercial-scale carbon dioxide sequestration; with focus on storage capacity and enhanced oil recovery in Citronelle Dome (PhD Dissertation): Birmingham, Alabama, University of Alabama at Birmingham, p. 1-103.

Esposito, R.A., Pashin, J.C., and Walsh, P.M., 2008, Citronelle Dome: A Giant Opportunity for Multi-Zone Carbon Storage and Enhanced Oil Recovery in the Mississippi Interior Salt Basin of Alabama: Environmental Geosciences, v. 15, no. 2, p. 53-62.

Esposito, R.A., Pashin, J.C., Hills, D.J., and Walsh, P.M., 2010, Geologic assessment and injection design for a pilot $\mathrm{CO} 2$-enhanced oil recovery and sequestration demonstration in a heterogeneous oil reservoir: Citronelle Field, Alabama, USA: Environmental Earth Sciences, v. 60, p. 431-444.

Fischer, S., Zemke, K., Liebscher, A., Wandrey, M., and the $\mathrm{CO}_{2} \mathrm{SINK}$ Group, 2011, Petrophysical and petrochemical effects on long-term $\mathrm{CO}_{2}$-exposure experiments on brine-saturated reservoir sandstone: Energy Procedia, v. 4, p. 4487-4494.

Galloway, W.E., Ganey-Curry, P.E., Li, X., and Buffler, R.T., 2000, Cenozoic depositional history of the Gulf of Mexico basin: AAPG Bulletin, v. 84, no. 11, p. 1743-1774.

Goodbred, S.L. Jr., Kuehl, S.A., Steckler, M.S., and Sarker, M.H., 2003, Controls on facies distribution and stratigraphic preservation in the Ganges-Brahmaputra delta sequence: Sedimentary Geology, v. 155, p. 301-316. 
Godínez-Urban, A., Geissman, J.W., Molina Garza, R.S., and Wawrzyniec, T., 2011, Paleomagnetism of the Todos Santos and La Silla Formations, Chiapas: Implications for the opening of the Gulf of Mexico: Geosphere, v. 7, no. 1, p. 145-158.

Google Earth, 2012. Google Inc. www.google.com. Accessed 24 May, 2012.

Graham, D.J., and Midgley, N.G., 2000, Graphical representation of particle shape using triangular diagrams: an Excel spreadsheet method: Earth Surface Processes and Landforms, v. 25, no. 13, p. 1473-1477.

Hatcher, R.D. Jr. and Bream, B.R., 2002, Inner Piedmont geology in the South Mountains-Blue Ridge Foothills and the southwestern Brushy Mountains, central-western North Carolina: Carolina Geological Society.

Hooper, R.J. and Hatcher, R.D. Jr., 1988, Pine Mountain terrane, a complex window in the Georgia and Alabama Piedmont; evidence from the eastern termination: Geology, v. 16, p. 307-310.

Hudson, P.F., 2005, Natural Levees: Encyclopedia of Water Science, p. 1-4.

Johnston, J.M. and Crossley, D.A. Jr., 2002, Forest ecosystem recovery in the southeast US: soil ecology as an essential component of ecosystem management: Forest Ecology and Management, v. 155, no. 1-3, p. 187-203.

Kovscek, A.R., 2002, Screening criteria for CO2 storage in oil reservoirs: Petroleum Science and Technology, v. 20, no. 7-8, p. 841-866.

Mancini, E.A., and Puckett, T.M., 2002, Transgressive-Regressive Cycles: Application to Petroleum Exploration for Hydrocarbons Associated with Cretaceous Shelf Carbonates and Coastal and Fluvial-Deltaic Siliciclastics, Northeastern Gulf of Mexico: Gulf Coast Section SEPM Foundation Bob F. Perkins Research Conference Transactions, p. 173200.

Mancini, E.A. and Scott, R.W., 2006, Sequence Stratigraphy of Comanchean Cretaceous Outcrop Strata of Northeast and South-Central Texas: Implications for Enhanced Petroleum Exploration: Gulf Coast Association of Geological Societies Transactions, v. 56, p. 539550.

Martin, C.A.L., and Turner, B.R., 1998, Origins of massive-type sandstones in braided river systems: Earth Science Reviews, v. 44, no. 1-2, p. 15-38.

Meyer, J.P., 2007, Summary of carbon dioxide enhanced oil recovery $\left(\mathrm{CO}_{2} \mathrm{EOR}\right)$ injection well technology: American Petroleum Institute, p.54. 
Myer, L.R., 2008, Carbon Capture and Geologic Storage: Proceedings from American Institute of Physics Conference, p. 366-375.

Nesbitt, H.W., Fedo, C.M., and Young, G.M., 1997, Quartz and Feldspar Stability, Steady and Nonsteady State Weathering, and Petrogenesis of Siliciclastic Sands and Muds: The Journal of Geology, v. 105, no. 2, p. 173-192.

Nichols, M.M., and Biggs, R.B., 1985, Geomorphology: Springer-Verlag, New York. Second ed., v. 23, p. 77-186.

Pashin, J.C., and Esposito, R.A., 2007, Citronelle Dome: A Giant Opportunity for Multi-Zone Carbon Storage and Enhanced Oil Recovery in the Mississippi Interior Salt Basin of Alabama, Presented at the Annual Convention and Exhibition of the American Association of Petroleum Geologists, Long Beach, CA, April 1-4, 2007.

Pindell, J. and Kennan, L., 2001, Kinematic Evolution of the Gulf of Mexico and Caribbean: GCSSEPM Foundation $21^{\text {st }}$ Annual Research Conference Transactions, Petroleum Systems of Deep-Water Basins, p. 193-220.

Prothero, D.R. and Schwab, F., 2003, Sedimentary Geology : an introduction to sedimentary rocks and stratigraphy: W.H. Freeman and Company, New York. Second ed., p. 21.

Raymond, D.E., Osborne, E.W., Copeland, C.W., and Neathery, T.L., 1988, Alabama Stratigraphy, Geological Survey of Alabama, Circular 140, p. 16-18.

Rosenbauer, R.J., Koksalan, T., and Palandri, J.L., 2005, Experimental investigation of $\mathrm{CO}_{2}$-brinerock interactions at elevated temperature and pressure: Implications for $\mathrm{CO}_{2}$ sequestration in deep-saline aquifers: Fuel Processing Technology, v. 86, p. 1581-1597.

Salvador, A., 1987, Late Triassic-Jurassic paleogeography and origin of Gulf of Mexico Basin: American Association of Petroleum Geologist Bulletin, v. 71, p. 419-451.

Salvador, A., 1991, Triassic-Jurassic: in, Salvador, A., ed., The Gulf of Mexico Basin: The Geology of North America, v. J, p. 131-180.

Steltenpohl, M.G., Mueller, P.M., Heatherington, A.L., Hanley, T.B., and Wooden, J.L., 2008, Gondwanan/peri-Gondwanan origin for the Uchee terrane, Alabama and Georgia: Carolina zone or Suwannee terrane (?) and its suture with Grenvillian basement of the Pine Mountain window: Geosphere, v.4, no.1, p.131-144.

Stern, R.J., and Dickinson, W.R., 2010, The Gulf of Mexico is a Jurassic backarc basin: Geosphere, v. 6, no. 6, p. 739-754. 
Strazisar, B.R., Zhu, C., and Hedges, S.W., 2006, Preliminary modeling of the long-term fate of $\mathrm{CO}_{2}$ following injection into deep geological formations: Environmental Geosciences, v. 13 , no. 1 , p. $1-15$.

United States Department of Energy, 2007, Carbon dioxide-enhanced oil production from the Citronelle oil field, DE-FC26-06NT43029, http://www.docstoc.com/docs/37878997/Carbon-Dioxide-Enhanced-Oil-Productionfrom-the-Citronelle-Oil-Field . Accessed 24 March, 2012.

United States Department of Energy, Enhanced Oil Recovery/CO2 Injection, http://fossil.energy.gov/programs/oilgas/eor/. Accessed 15 November, 2011.

Weislogel, A.L., and Donahoe, R., 2011, Technical Annual Report for the Year Ending December 31, 2010 DE-FOA-0000032 GEOLOGIC SEQUESTRATION TRAINING AND RESEARCH, Submission to U.S. Department of Energy and National Energy Technology Laboratory, p. 2-11.

Zervas, D., Hall, R., Lüthje, C., Murtagh, F., Nichols, G.J., and Smyth, H.R., 2009, SedLog: a shareware program for drawing graphic logs and log data manipulation", Computers \& Geosciences, v. 35, p. 2151-2159. 
Plate 1. Cross-sections 1-7 and N-S cross-sections 1-2 showing the formation top picks (labeled) and the high porosity zone (yellow-filled horizon) within the Upper Donovan Sand.

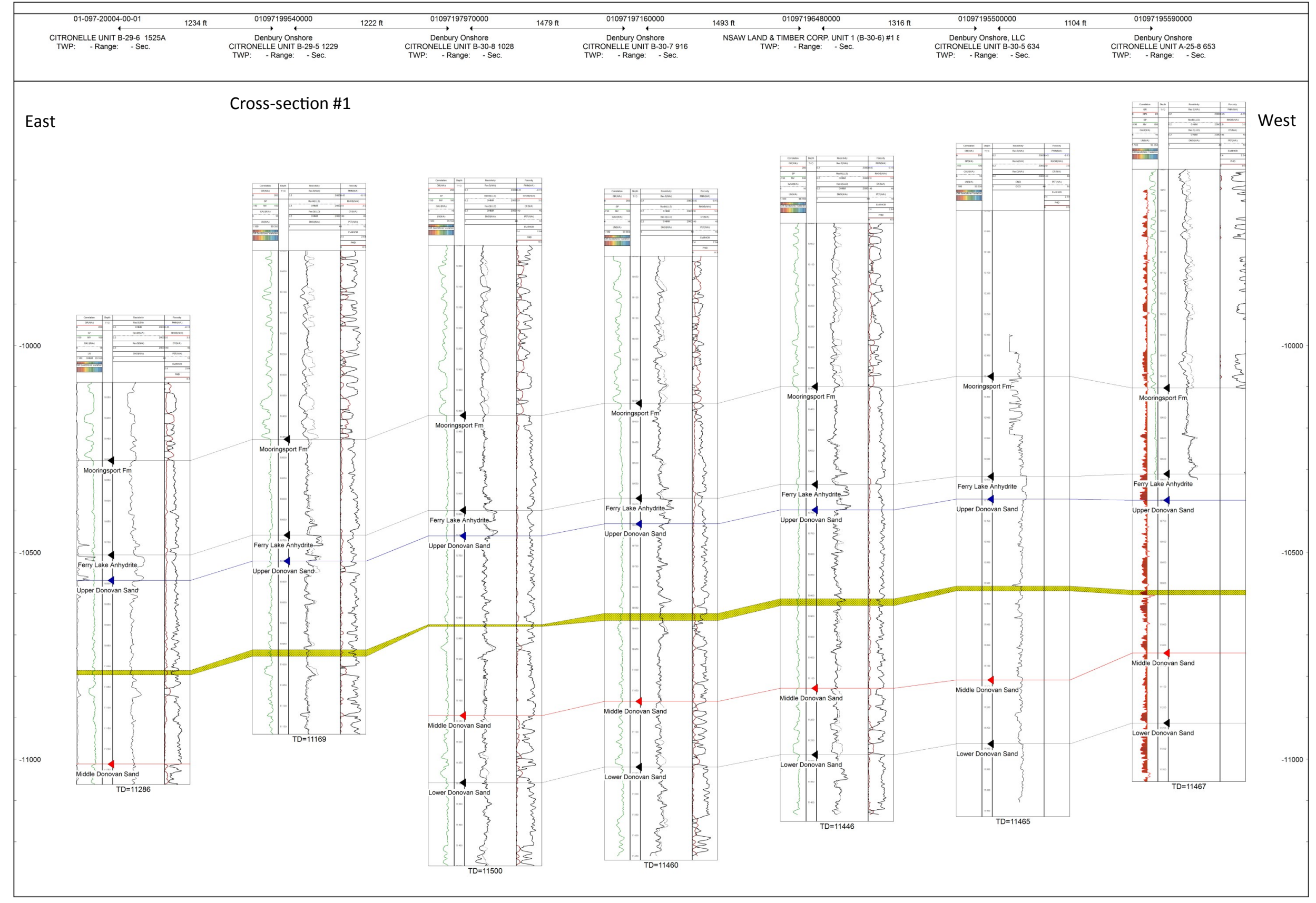




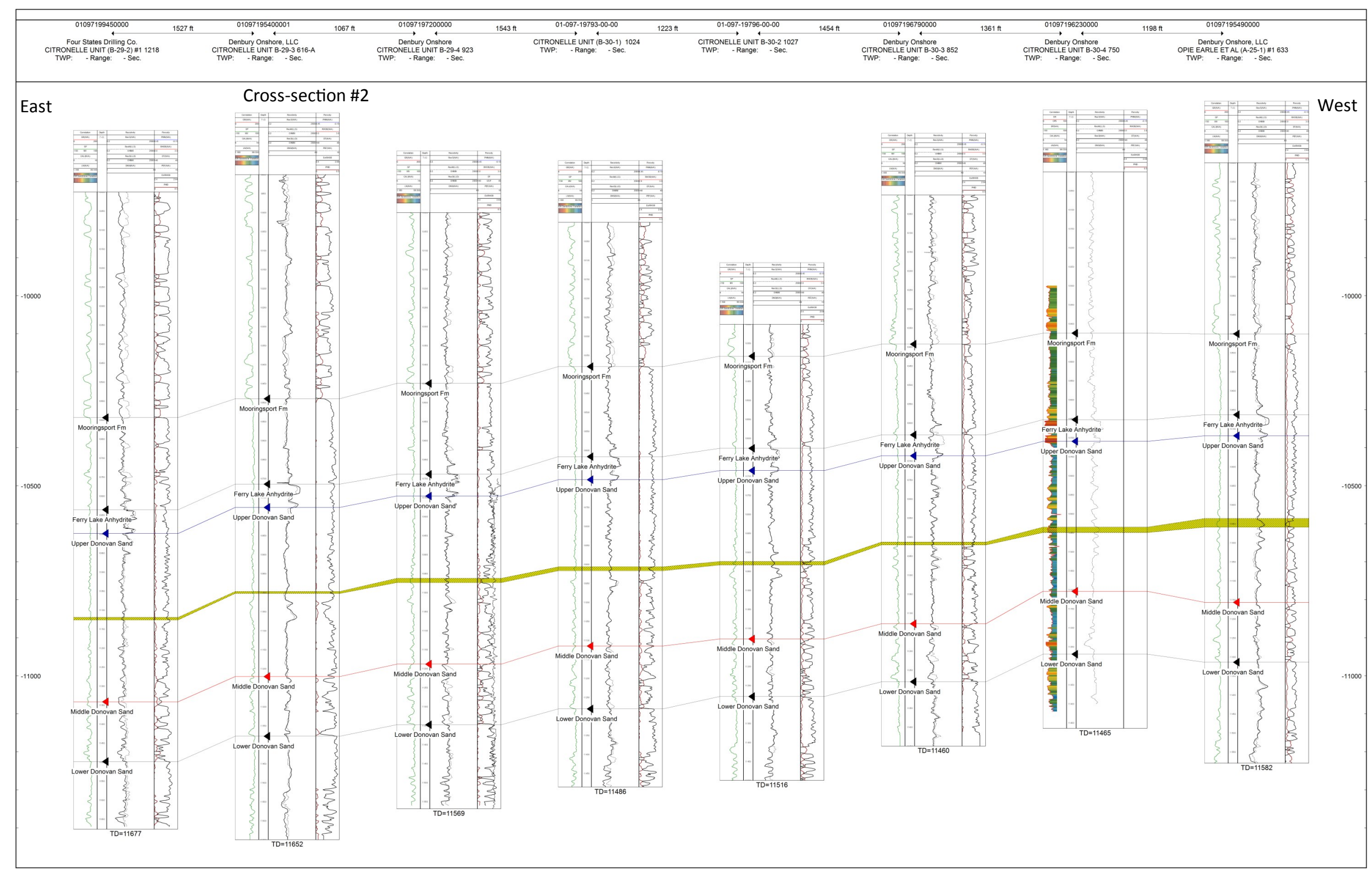




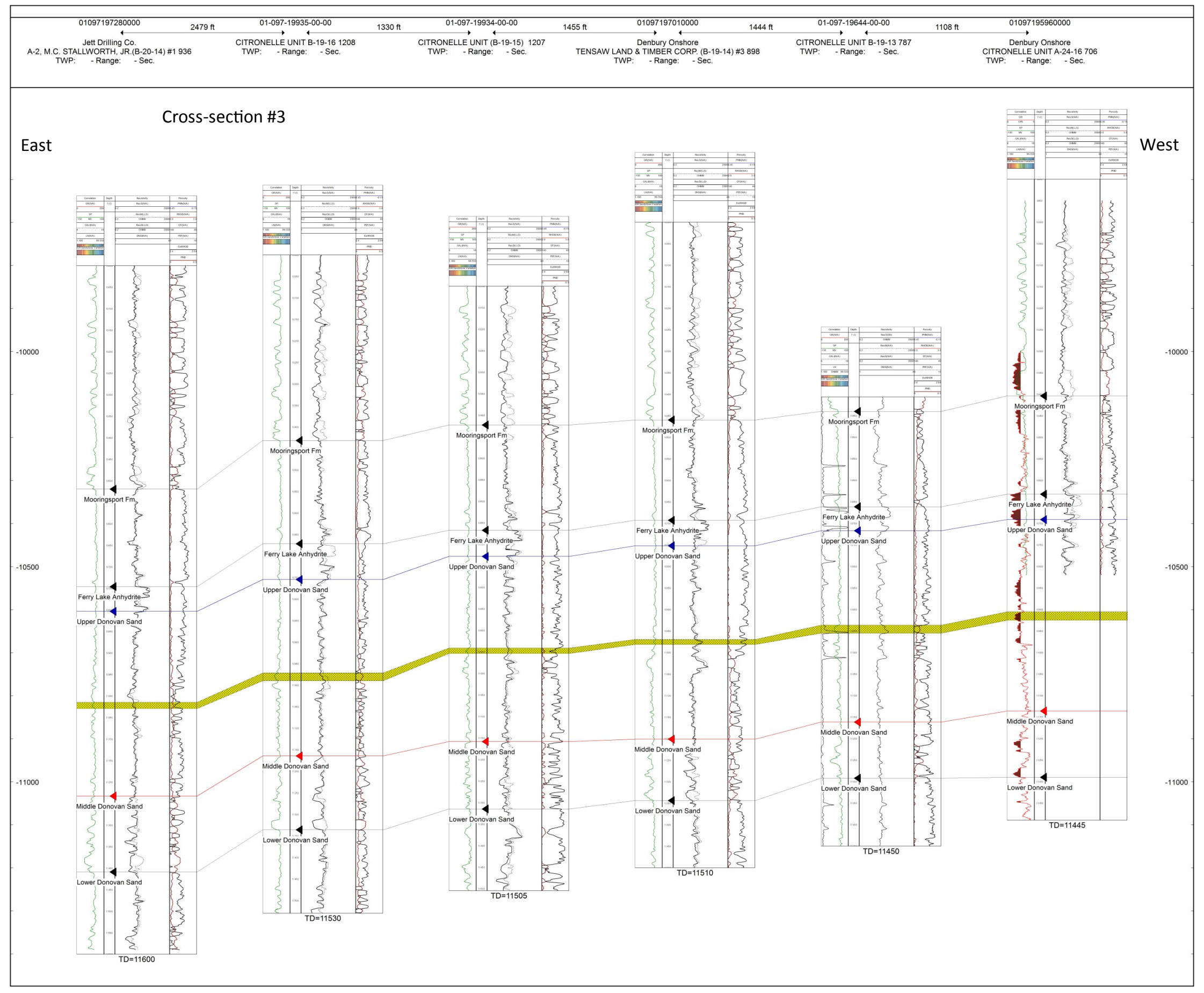




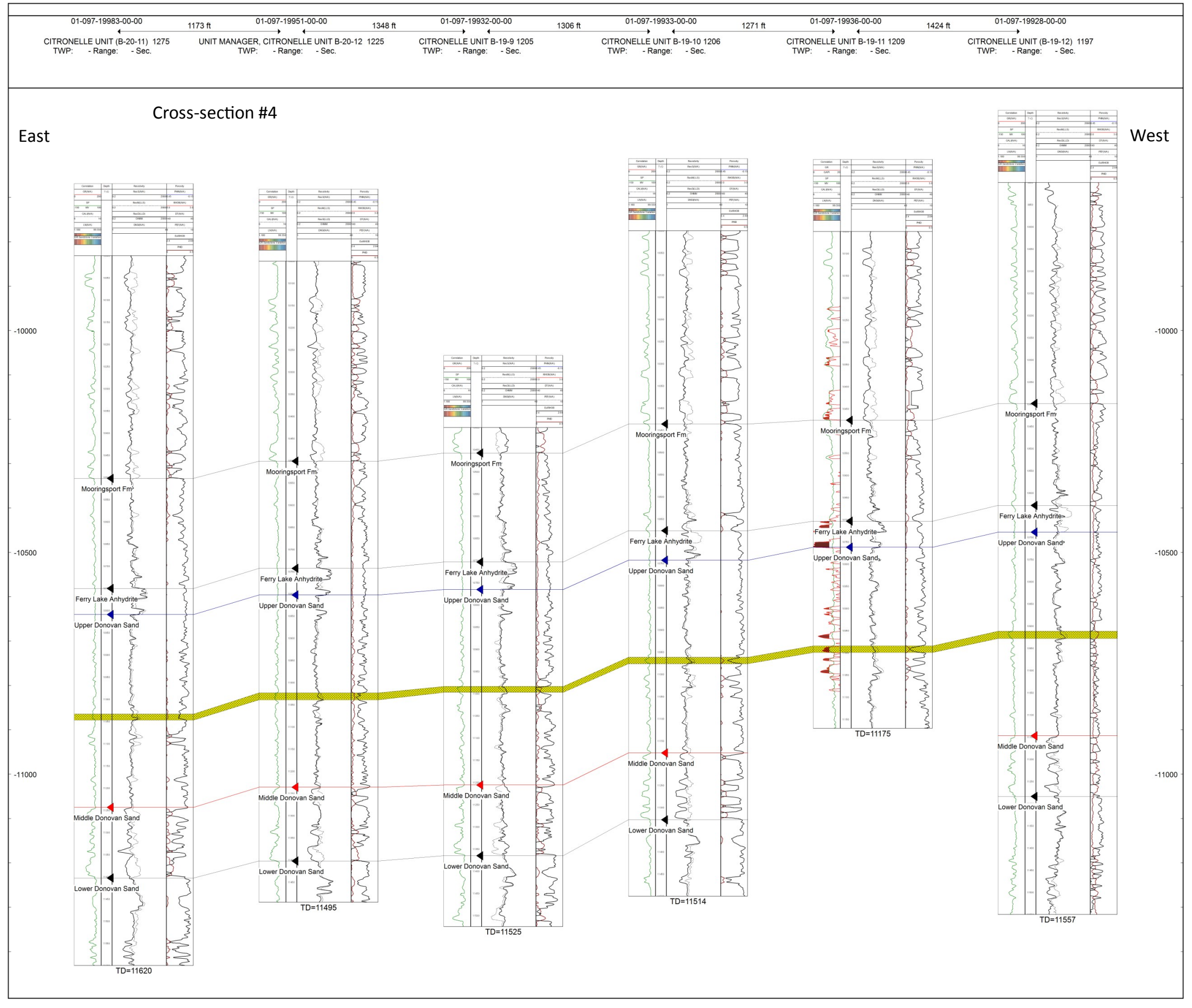




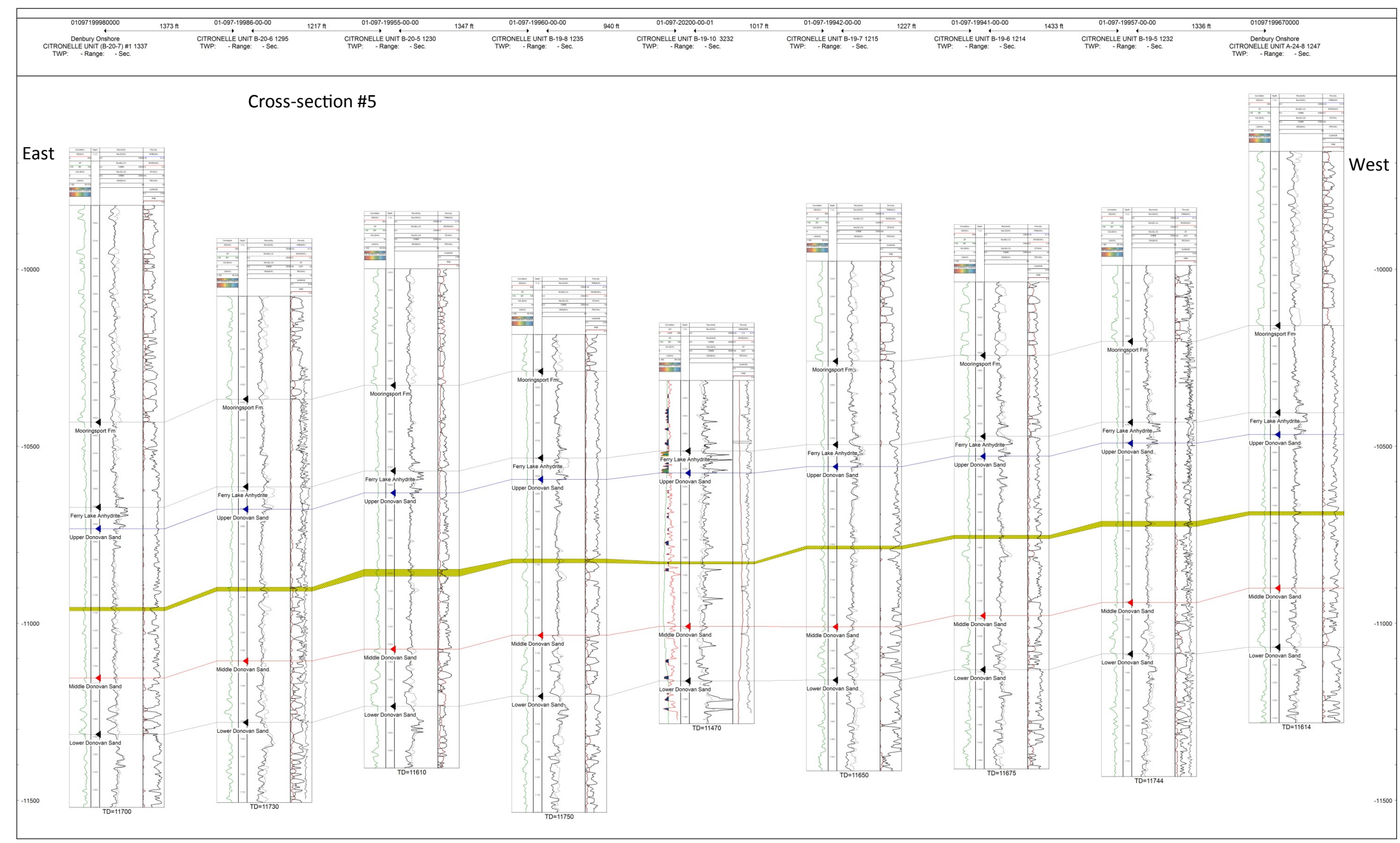




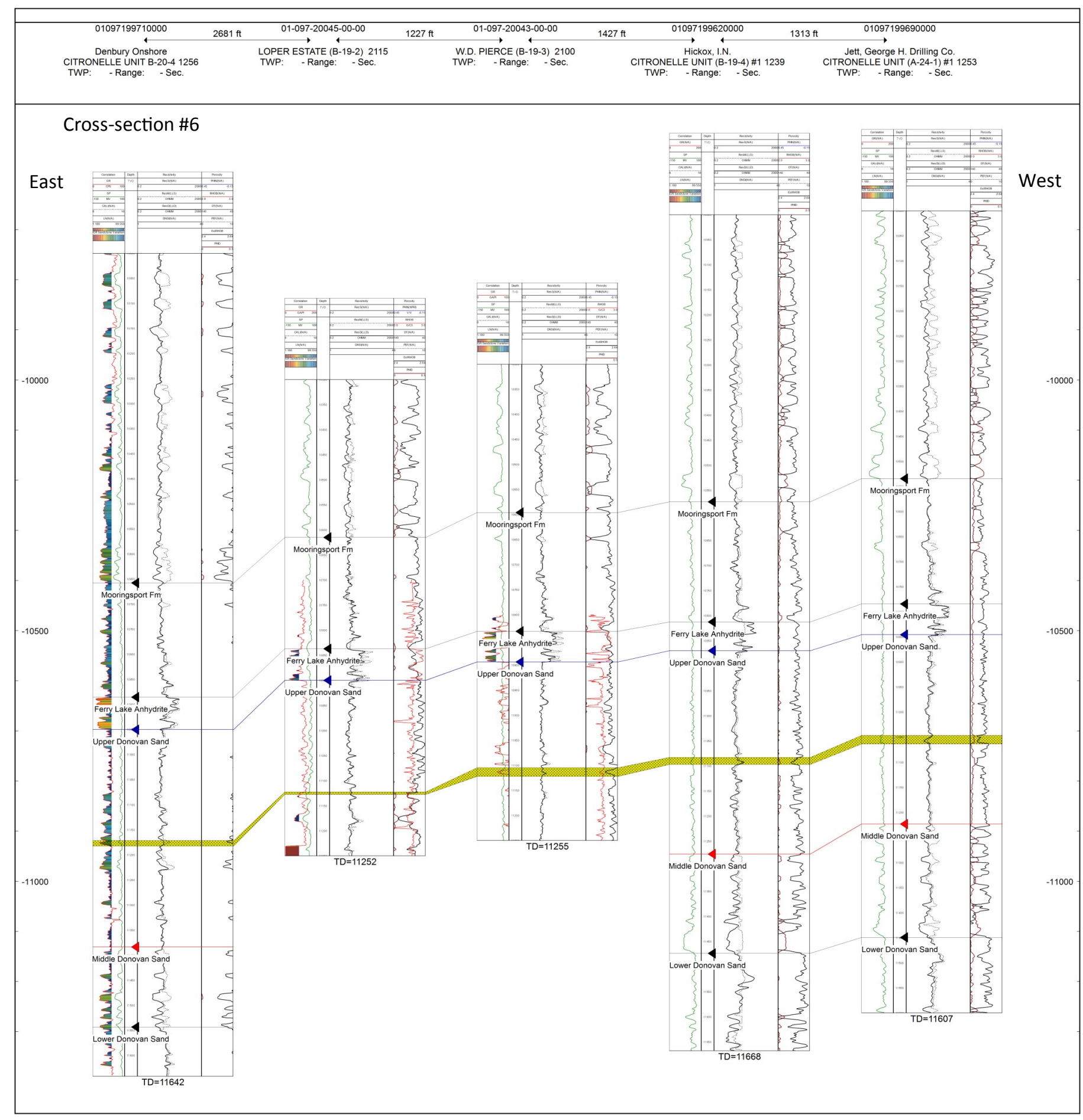




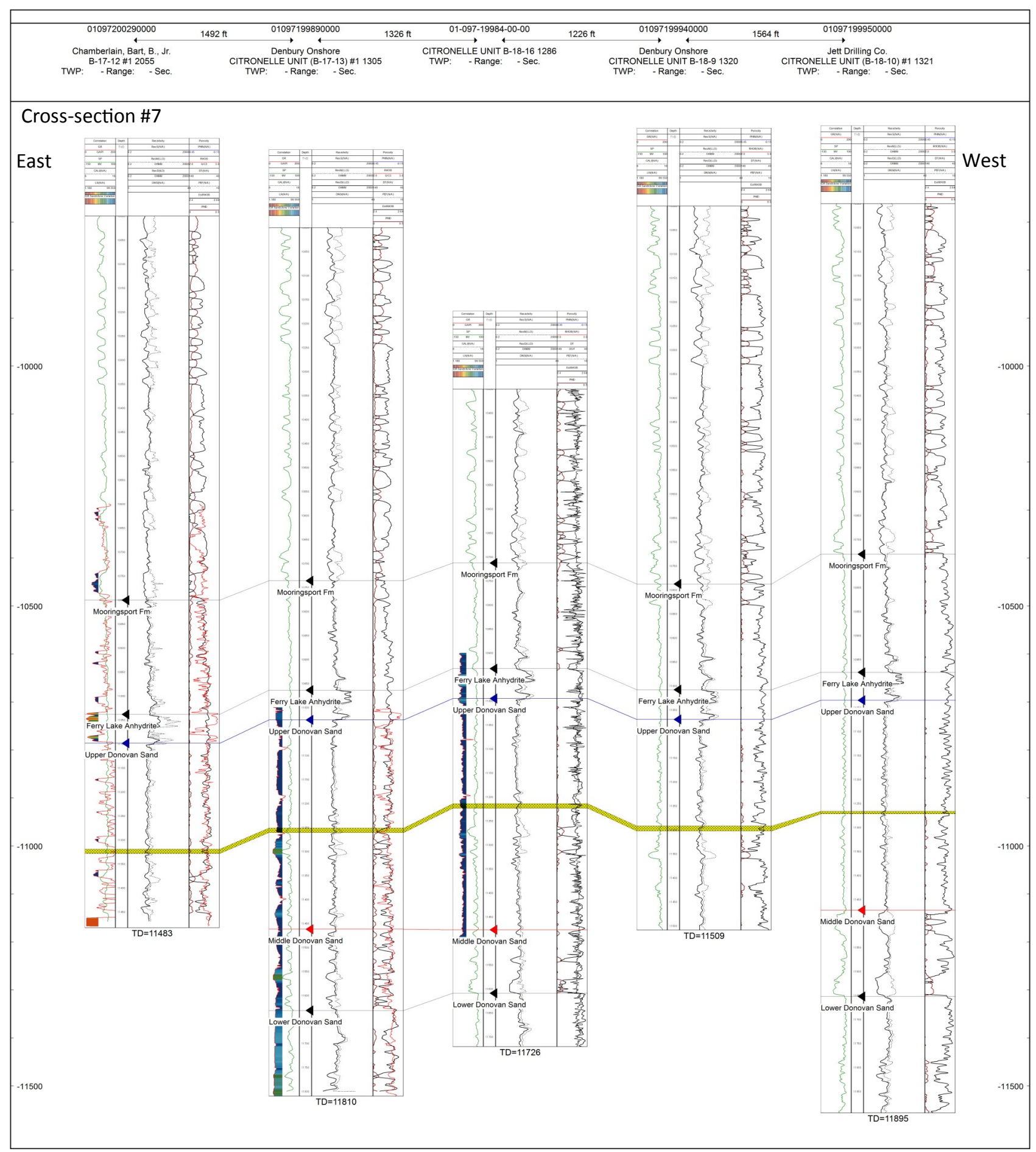




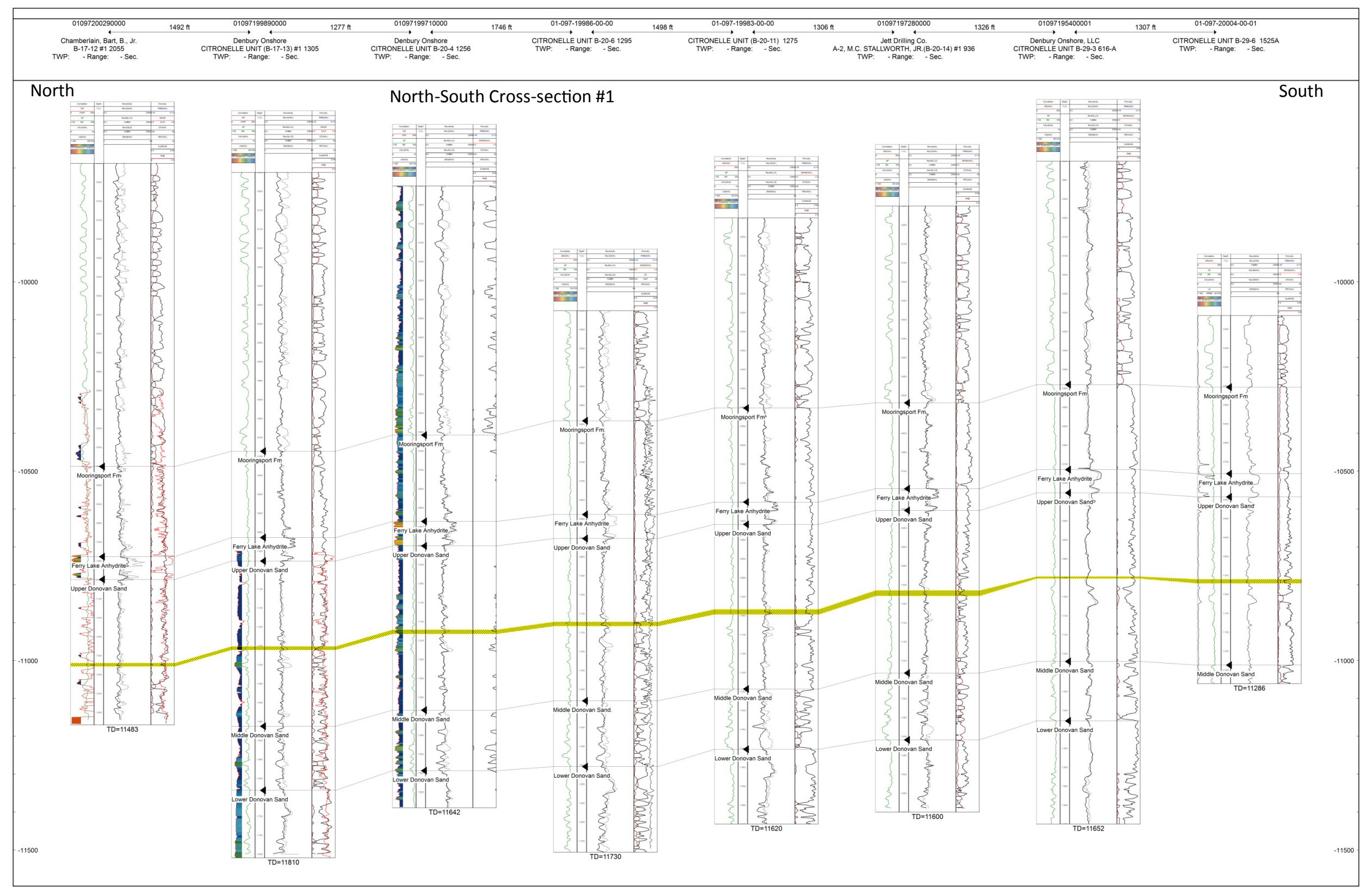




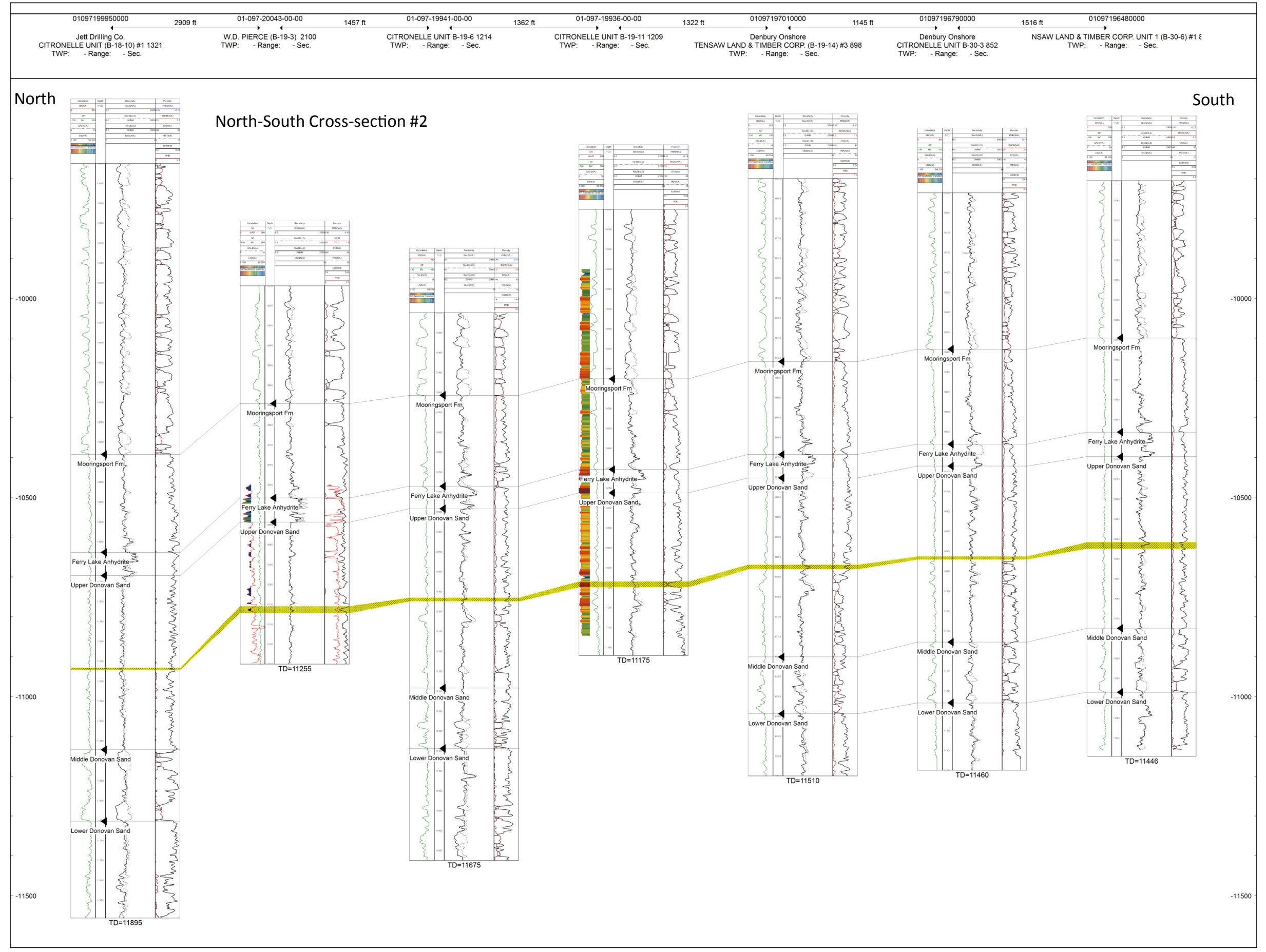




\section{Plate 2. Graphic logs from 7 cored study wells.}

Legend: Lithologies
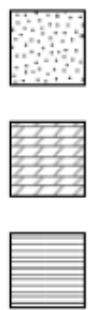

Shale Sandstone

Dolomite

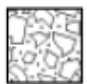

Conglomerate

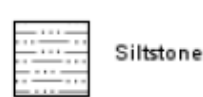

Symbols

808 Intraclasts

If Vertical burrows

* Hydrocarbon staining

Horizontal planar lamination

scours

$\square$

Nodules and concretions

モ

Horizontal burrrows

Mudclasts

Current ripple cross-lamination

Trough cross bedding
Base Boundaries

Sharp

Gradational

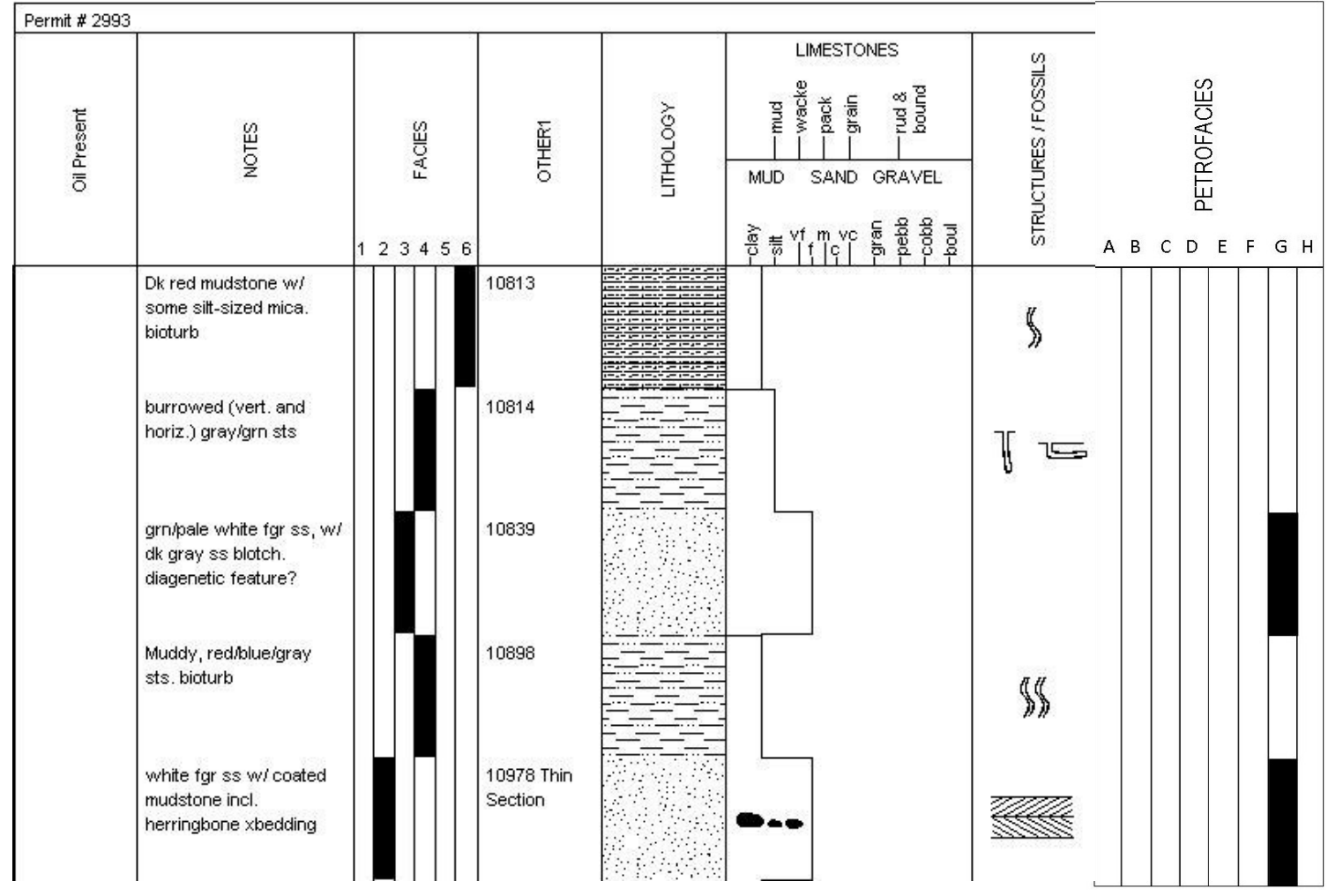




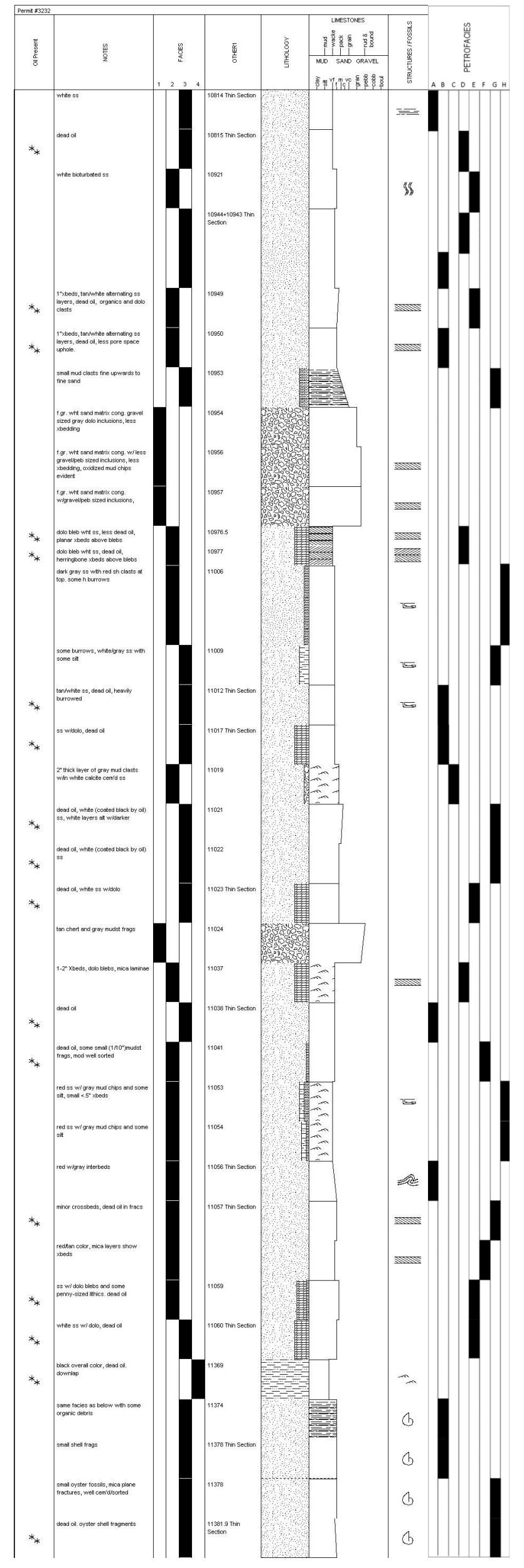




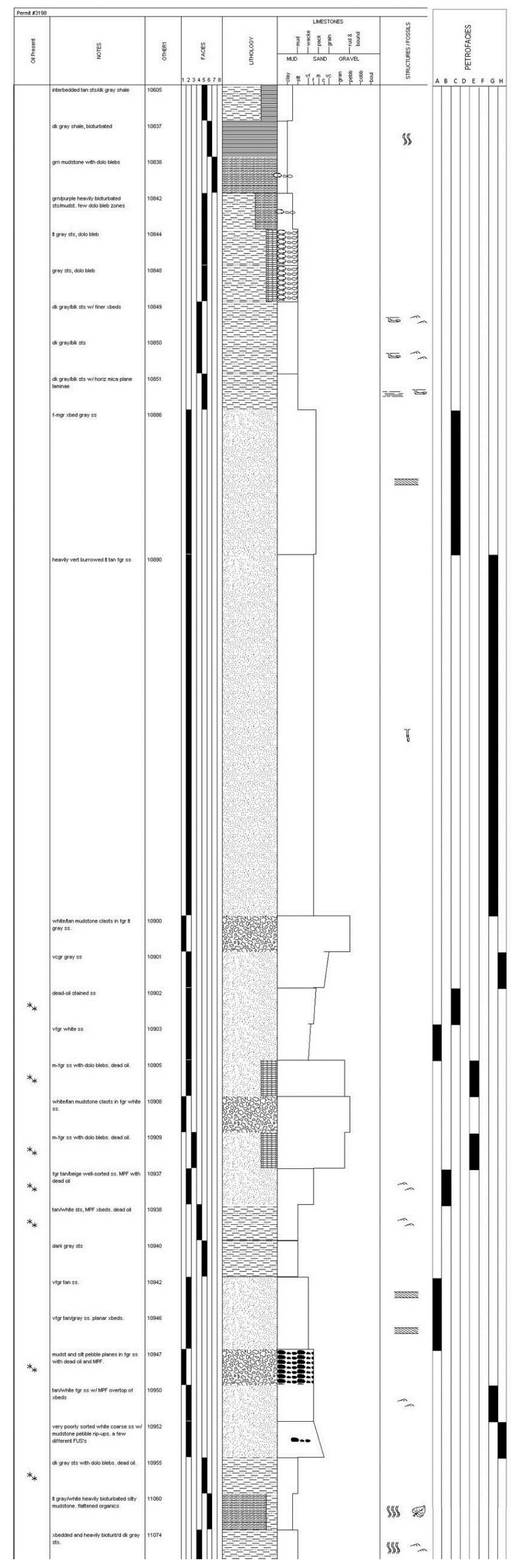




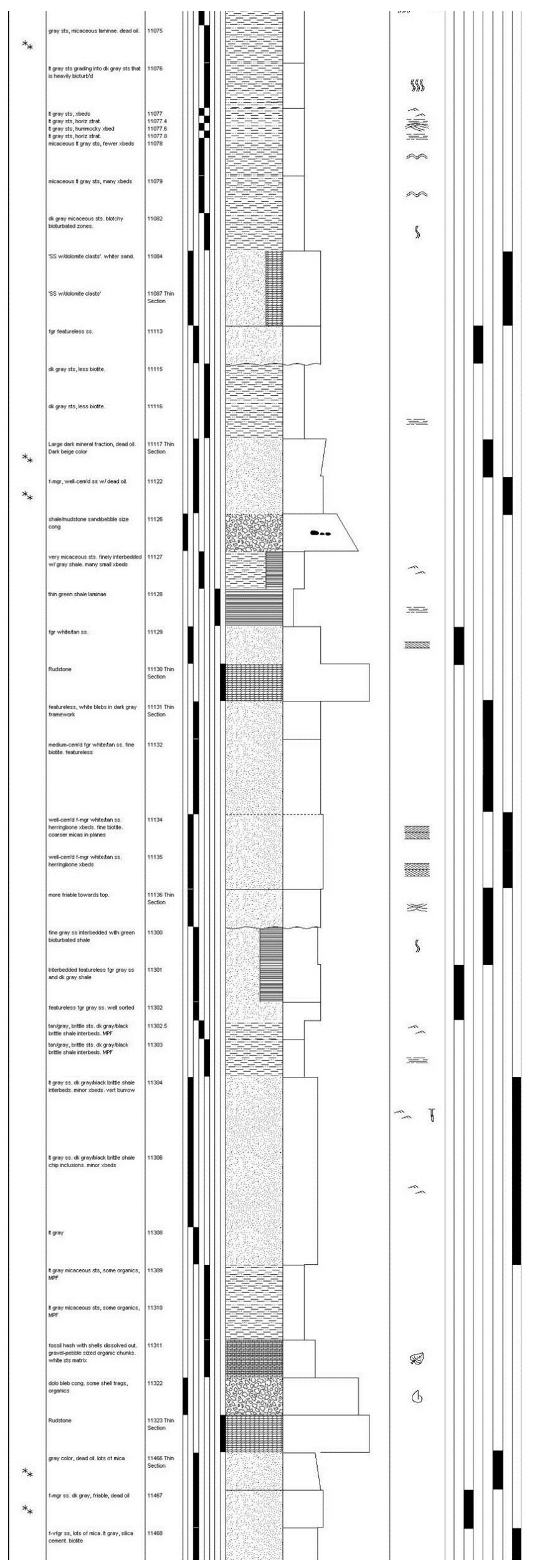




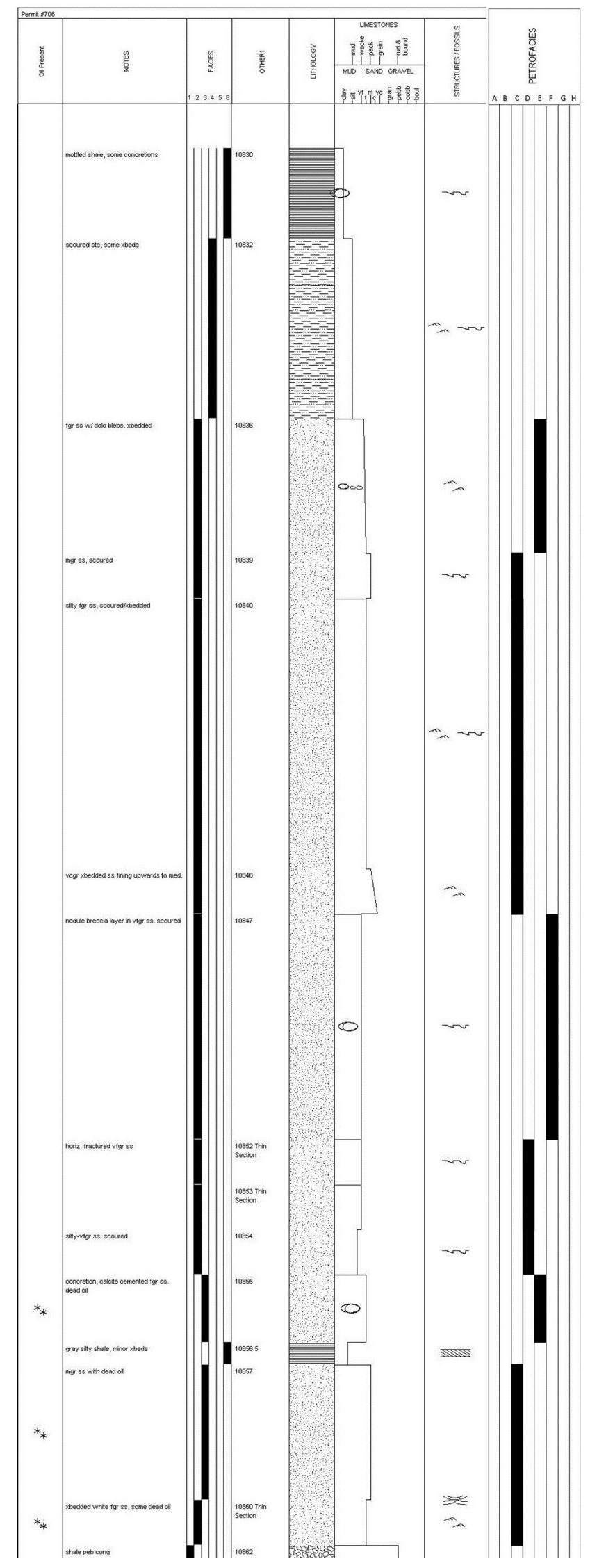




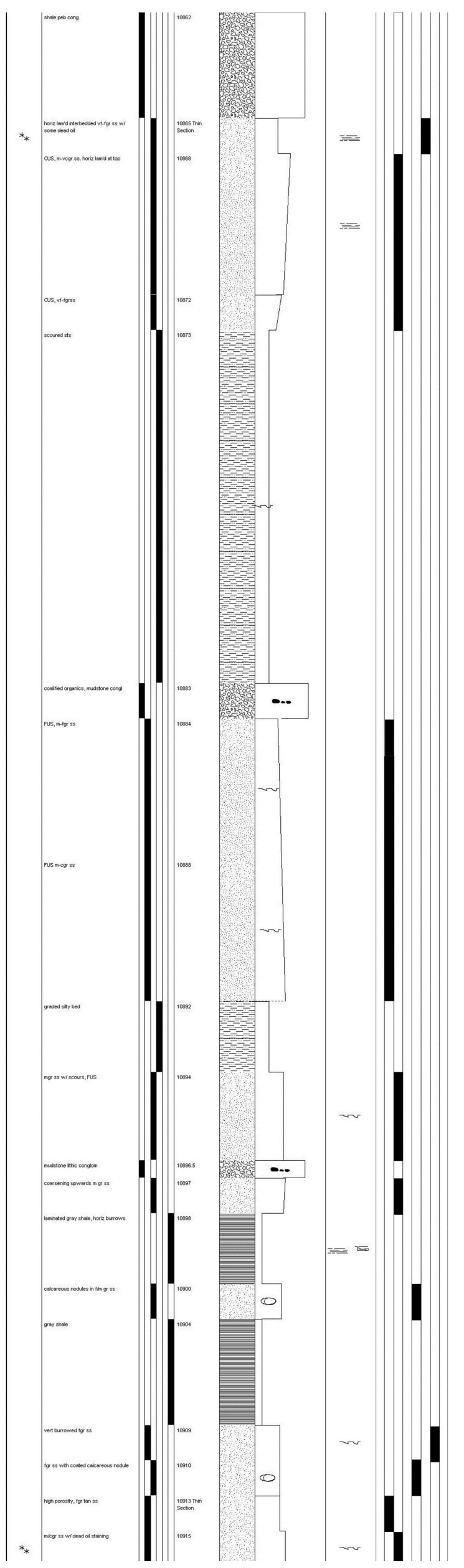




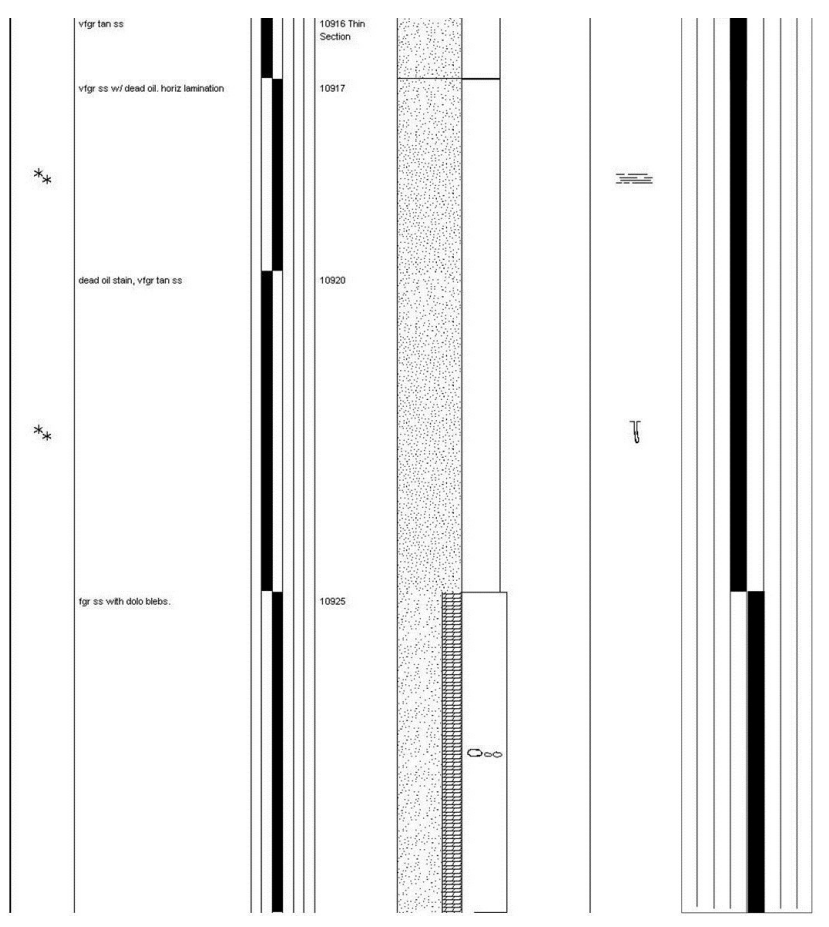




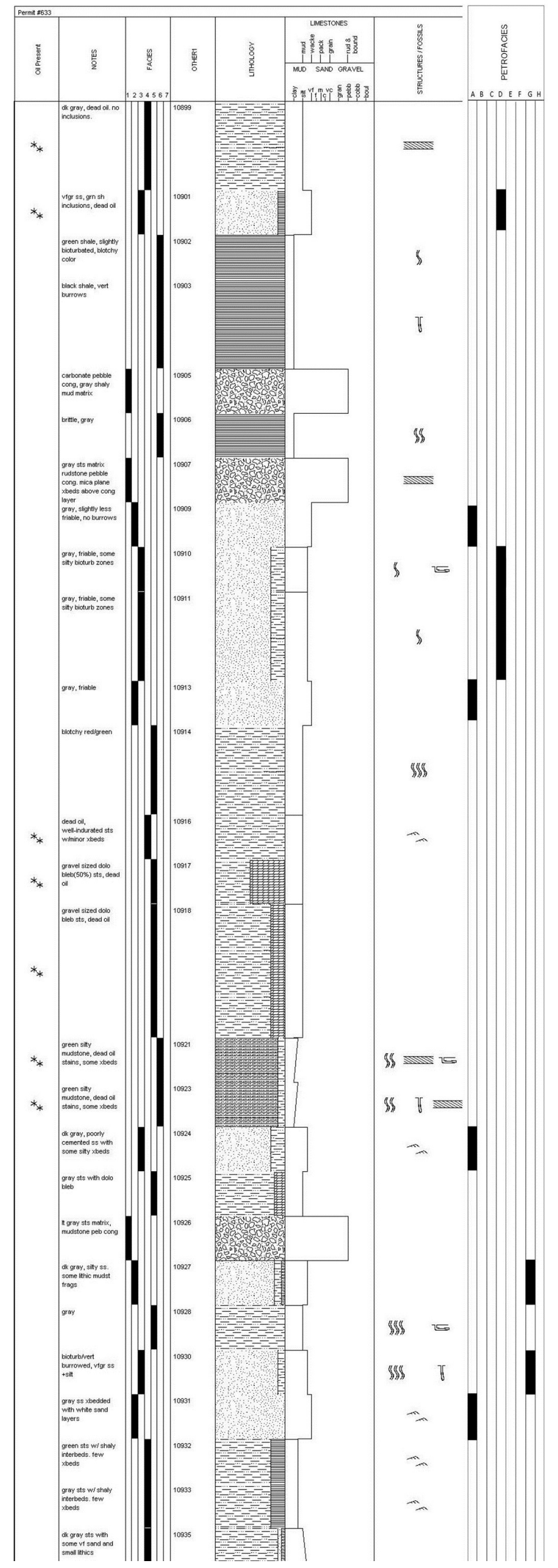




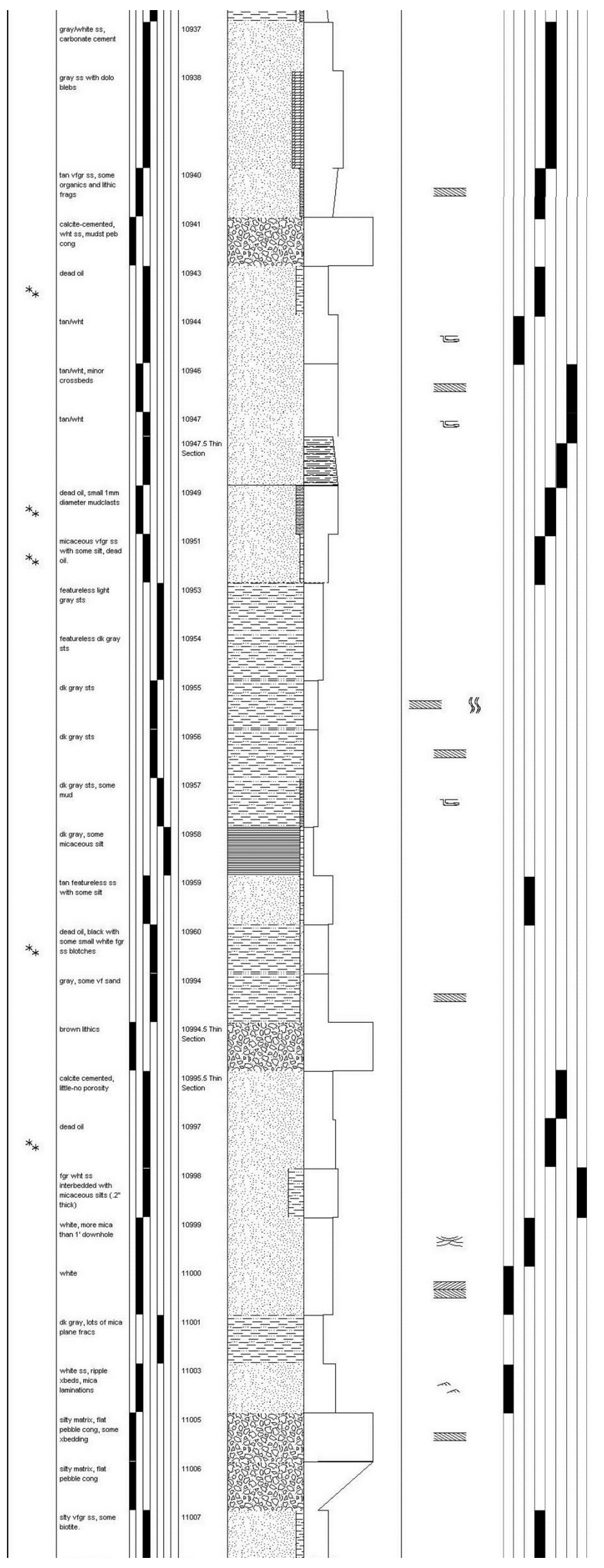




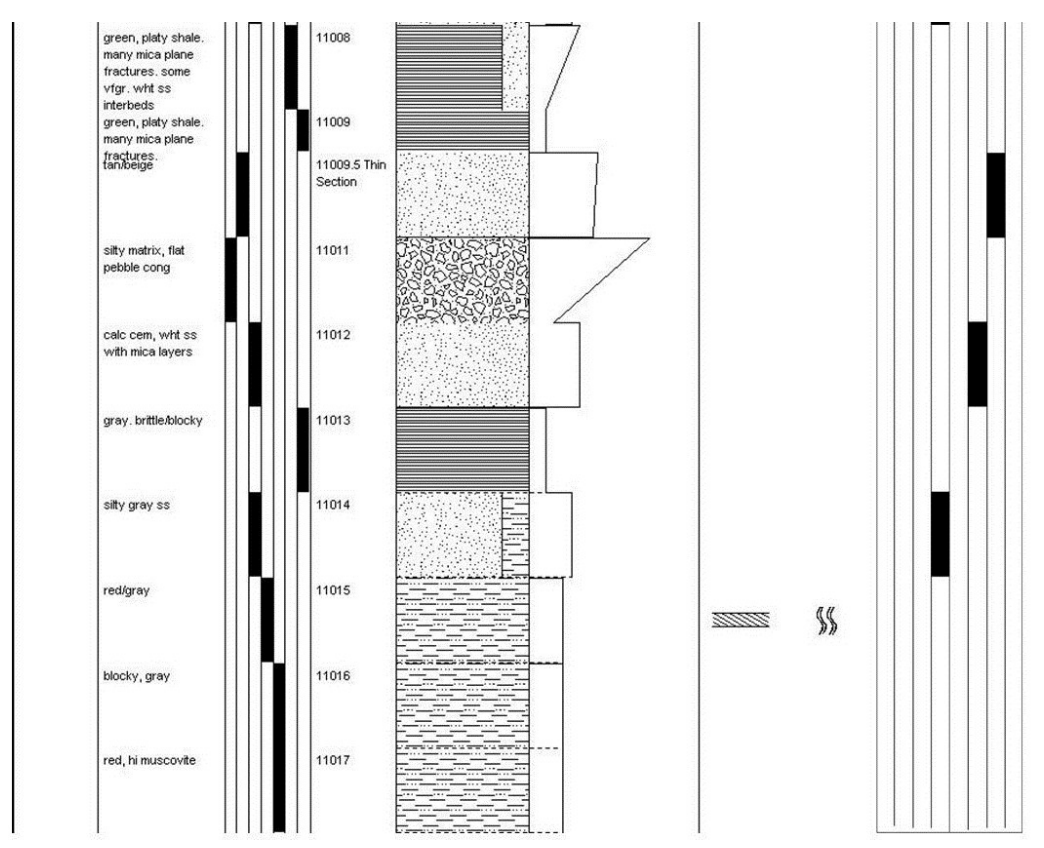




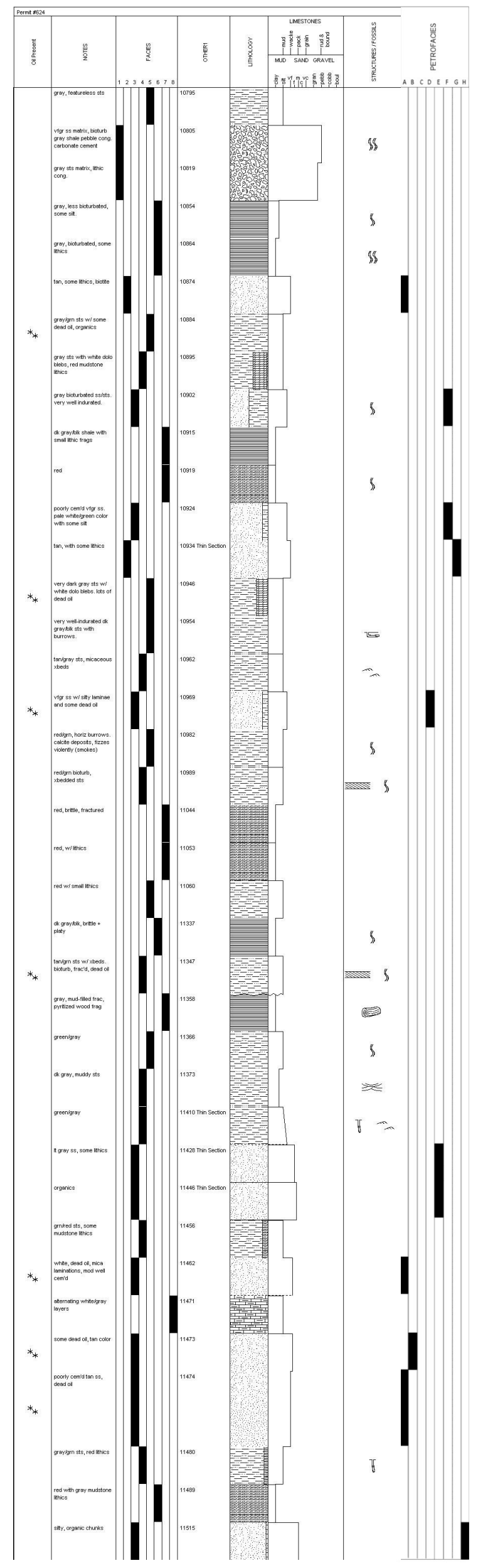




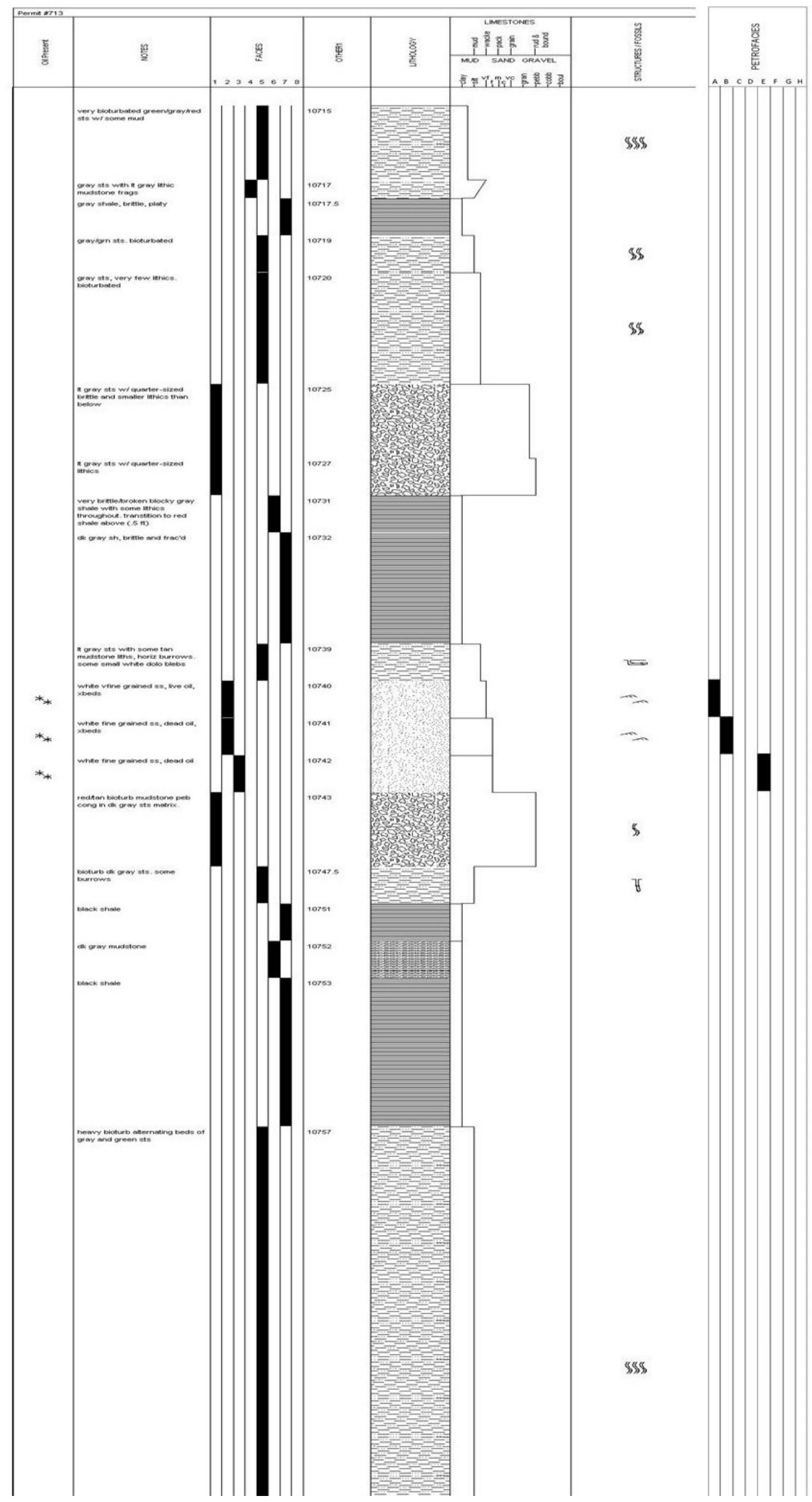




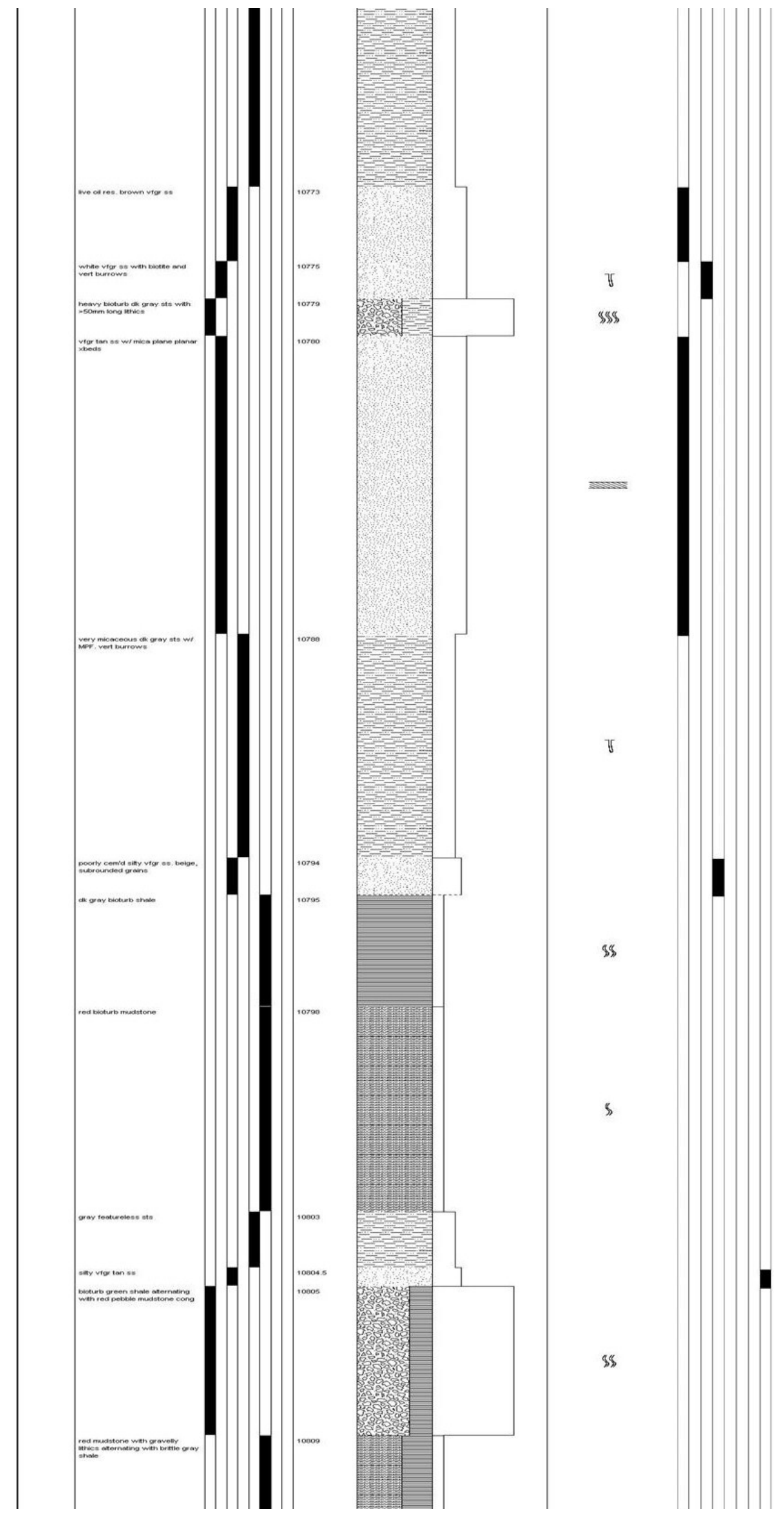




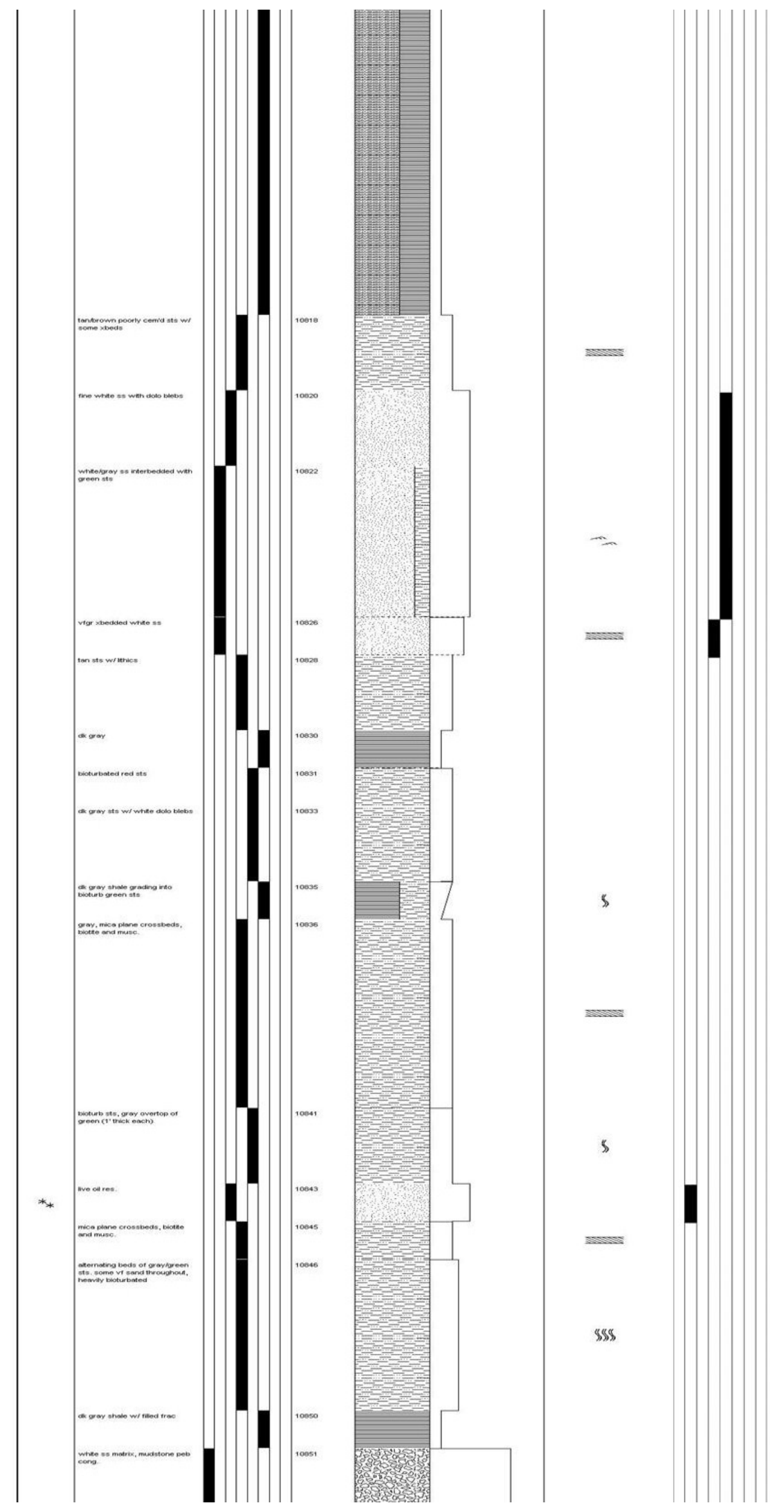




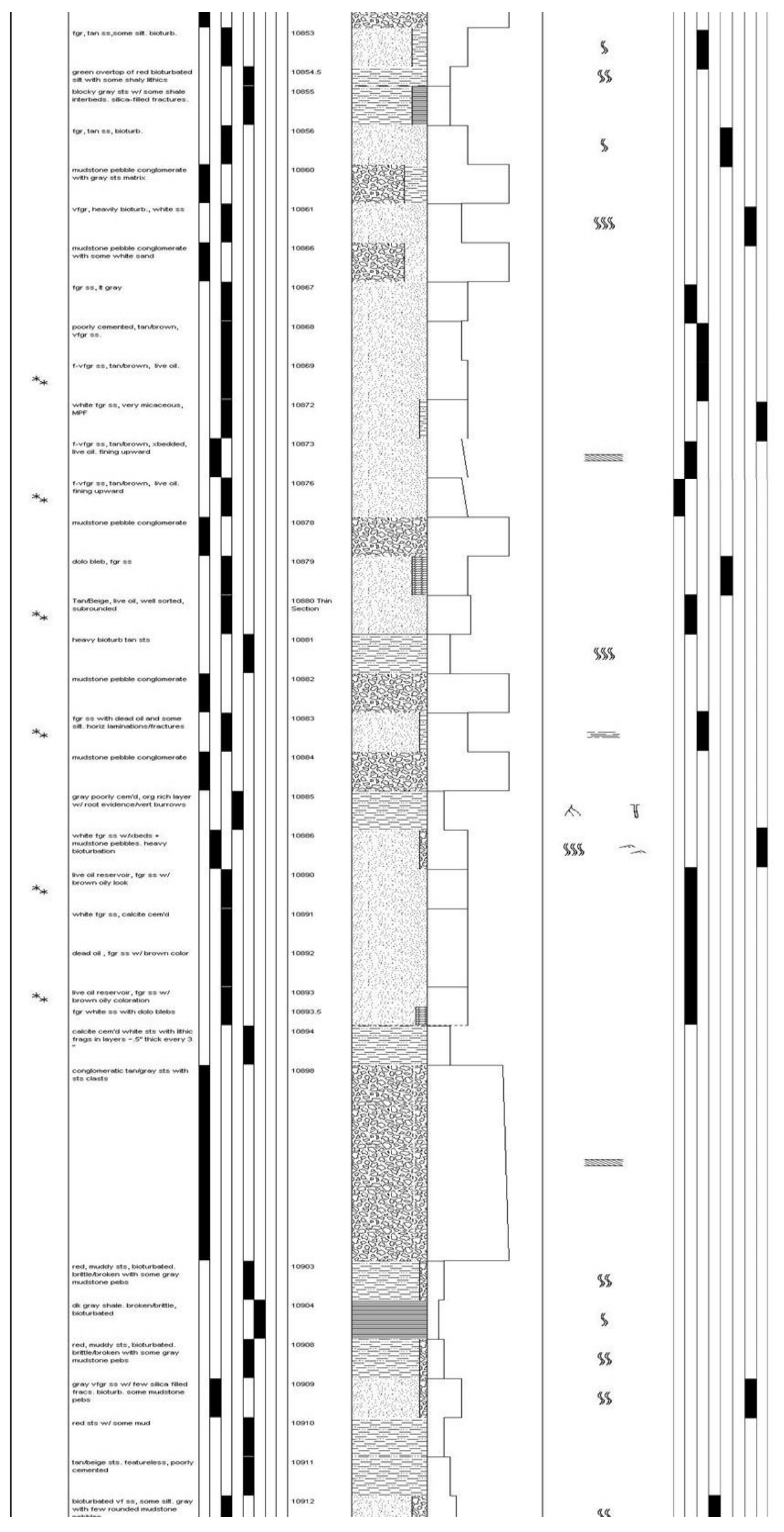




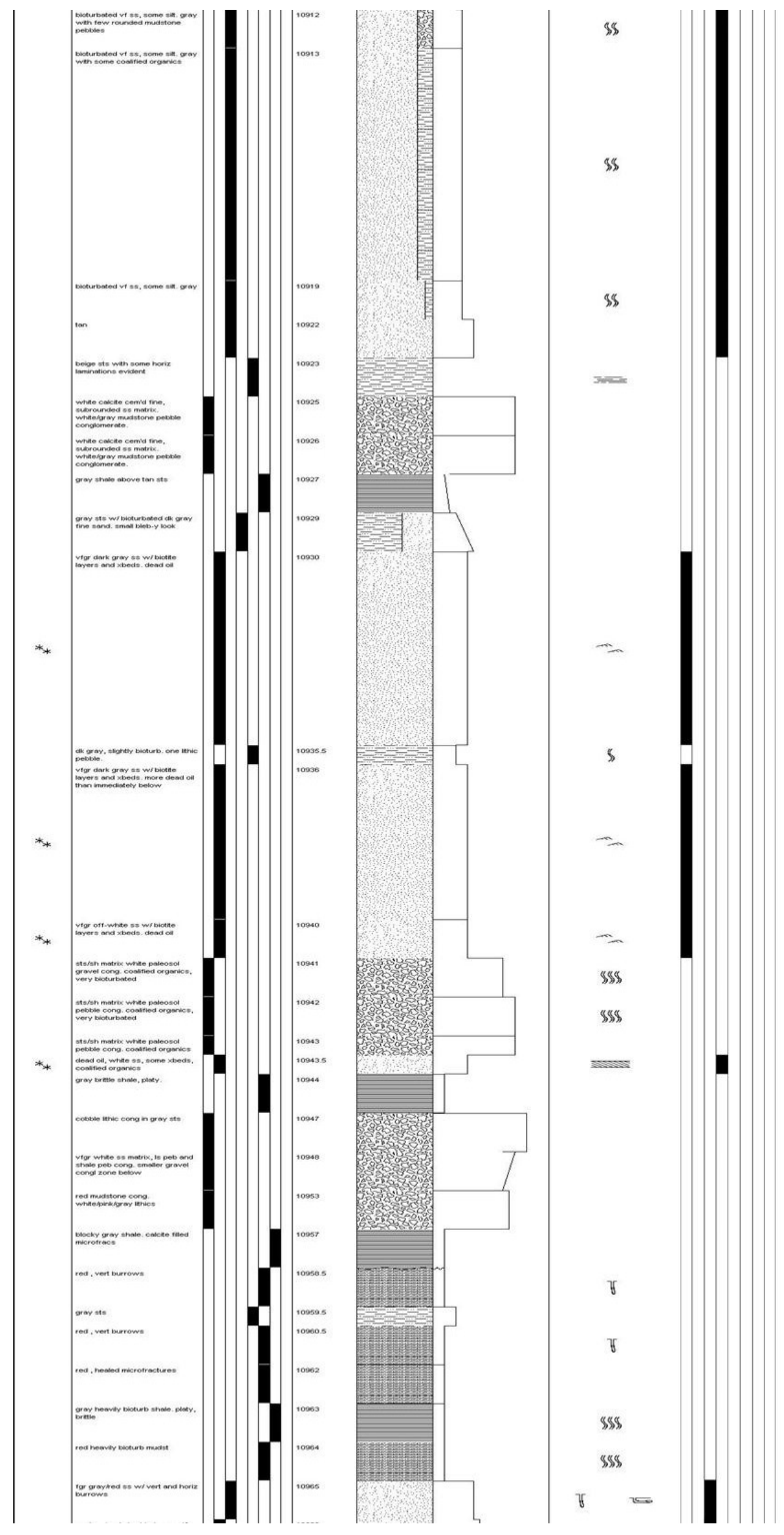




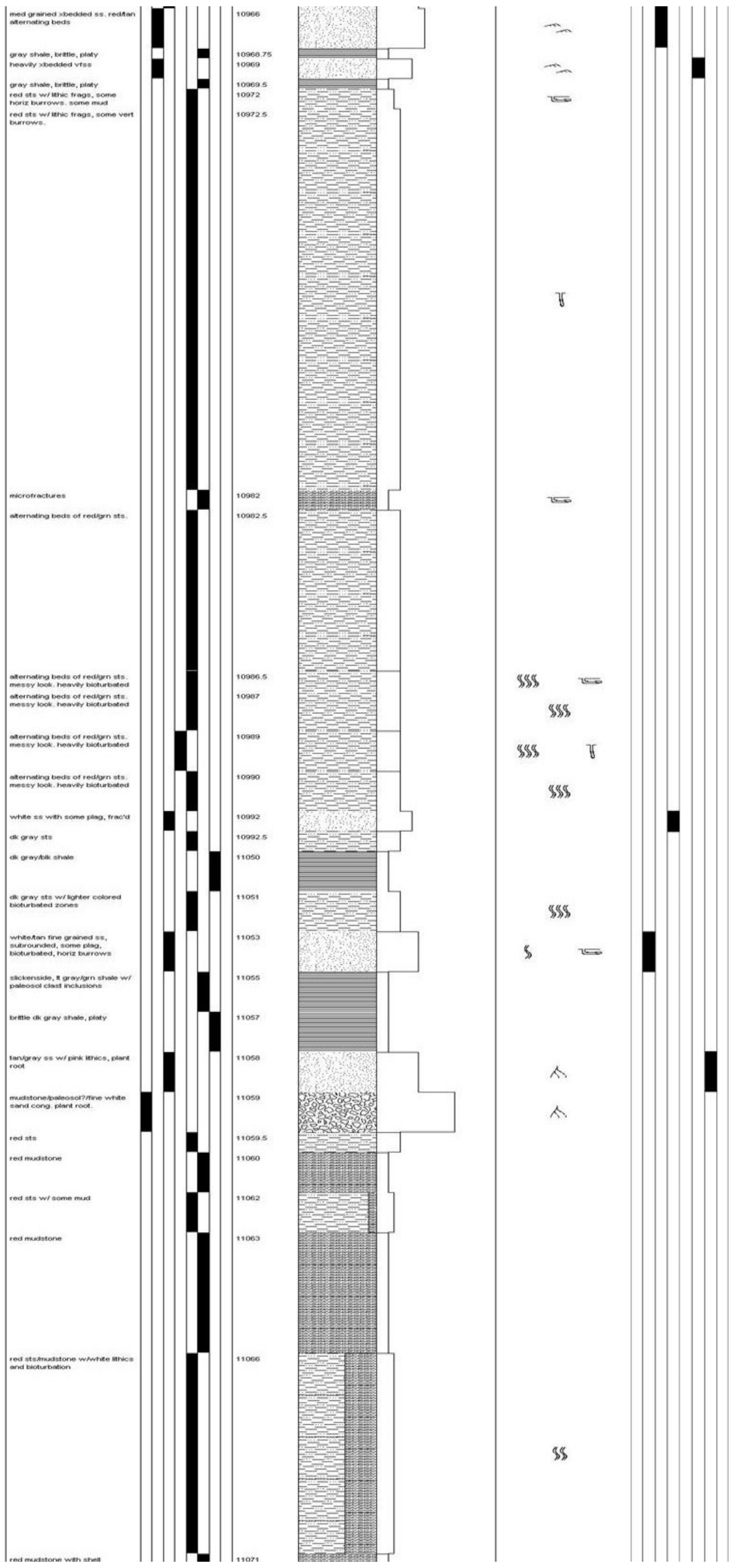




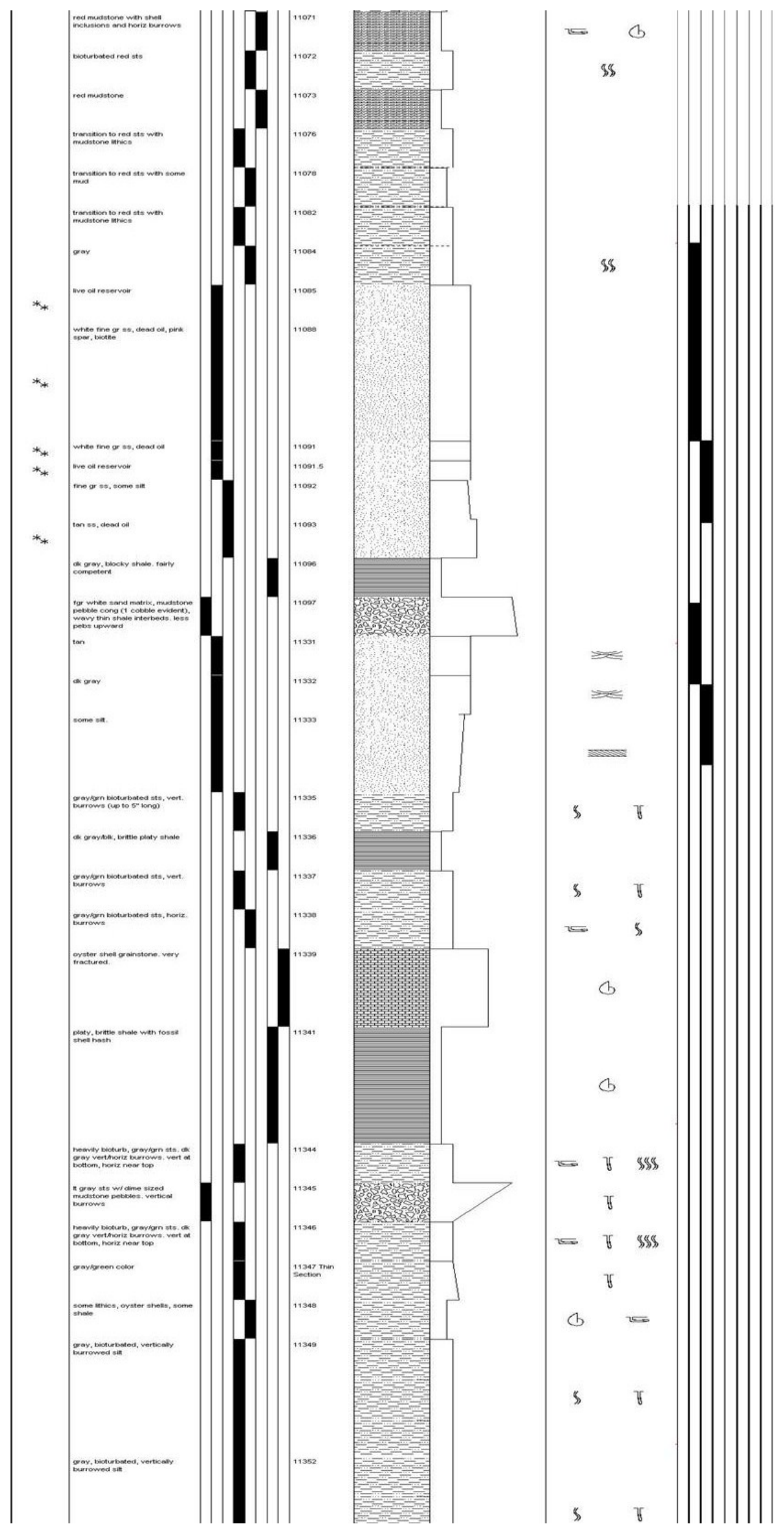




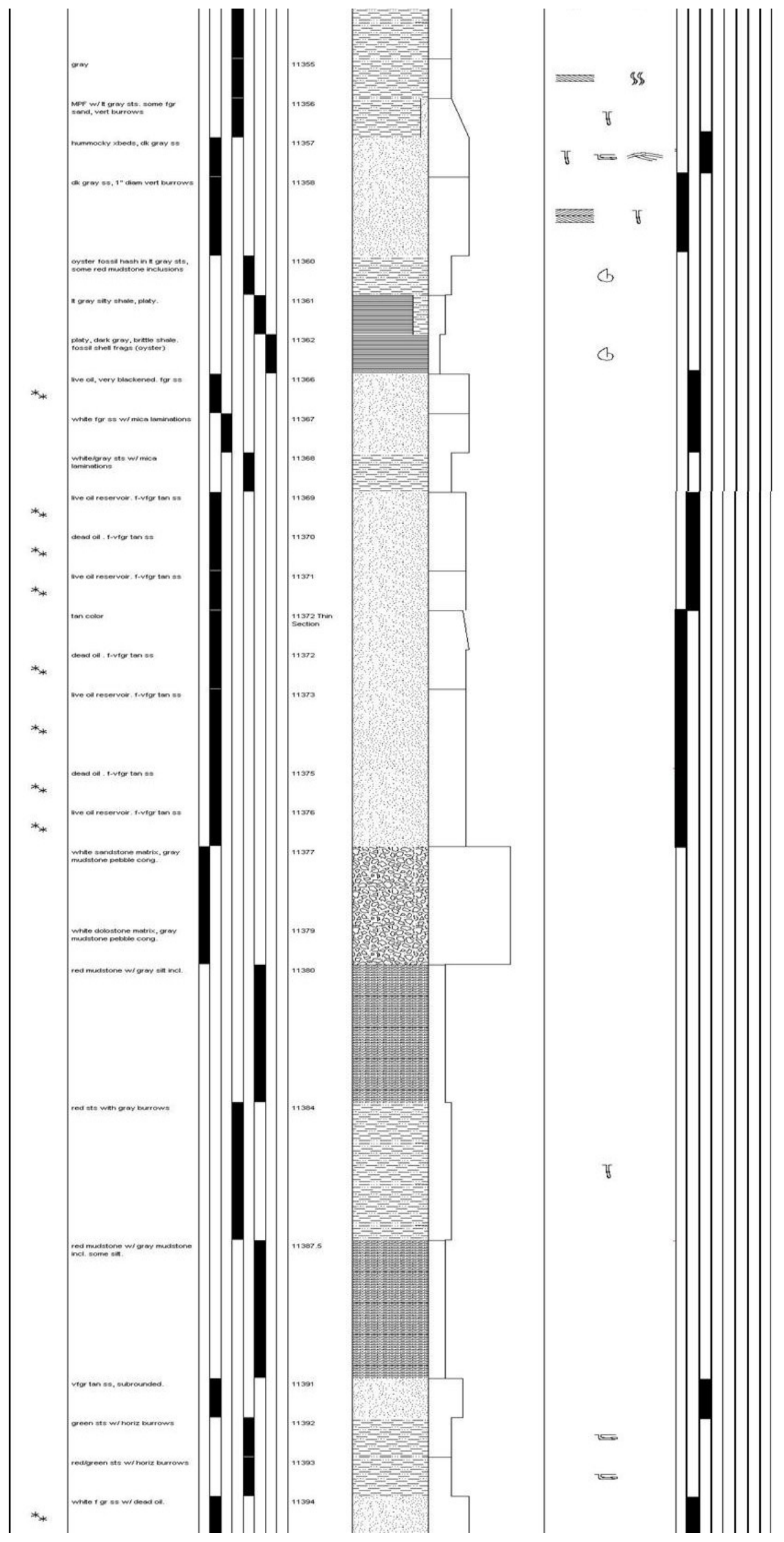




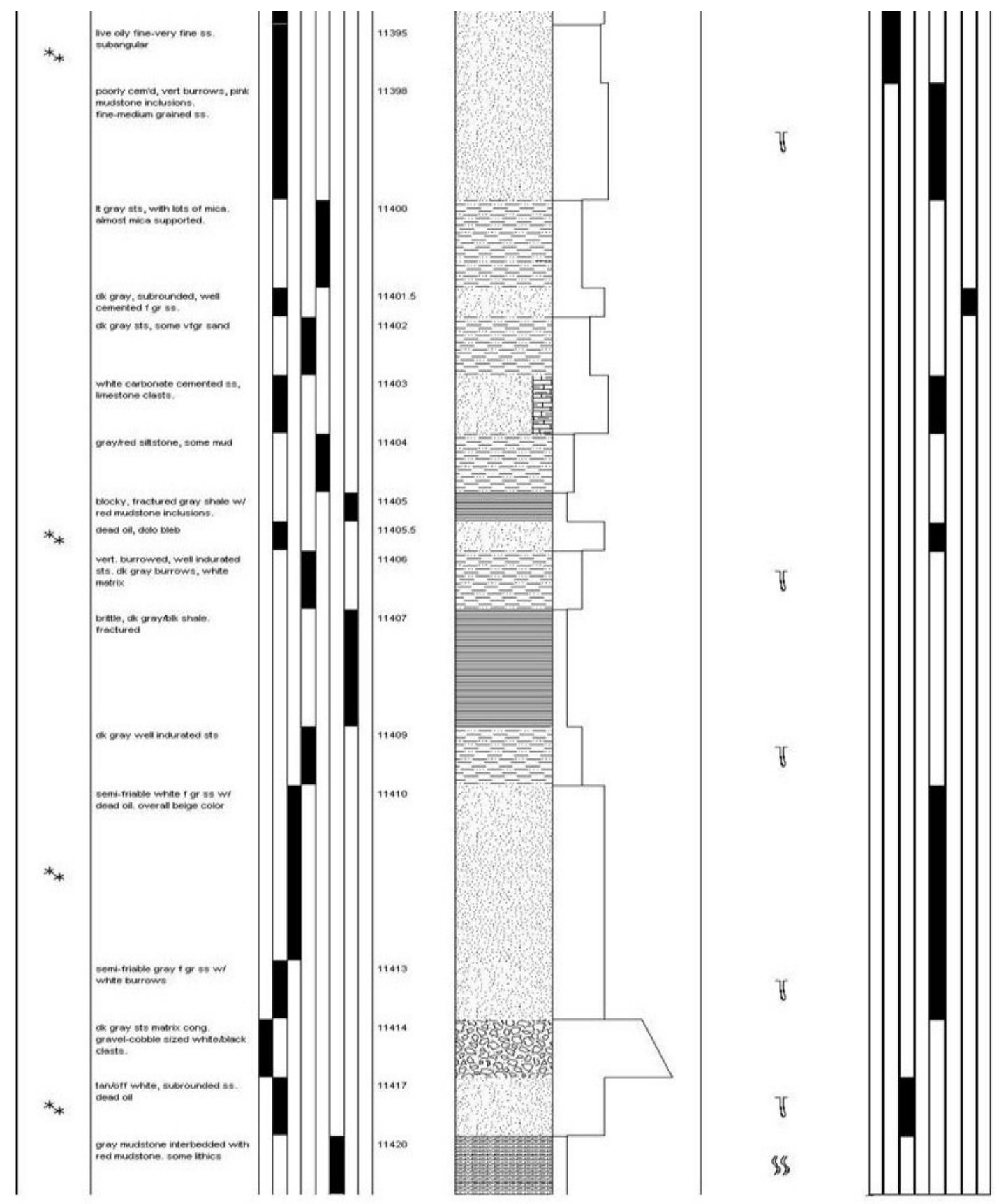


Plate 3a. Petrofacies A-C, correlated from well permit \#3232 graphic log (left) to petrophysical well log (right). Petrofacies A and B are outlined in yellow and petrofacies $C$ is outlined in blue on both logs. Colored zones are presented side-by side to illustrate their lithology and representative well log signature. Red rectangles alongside depth indicate that core was described for that depth.
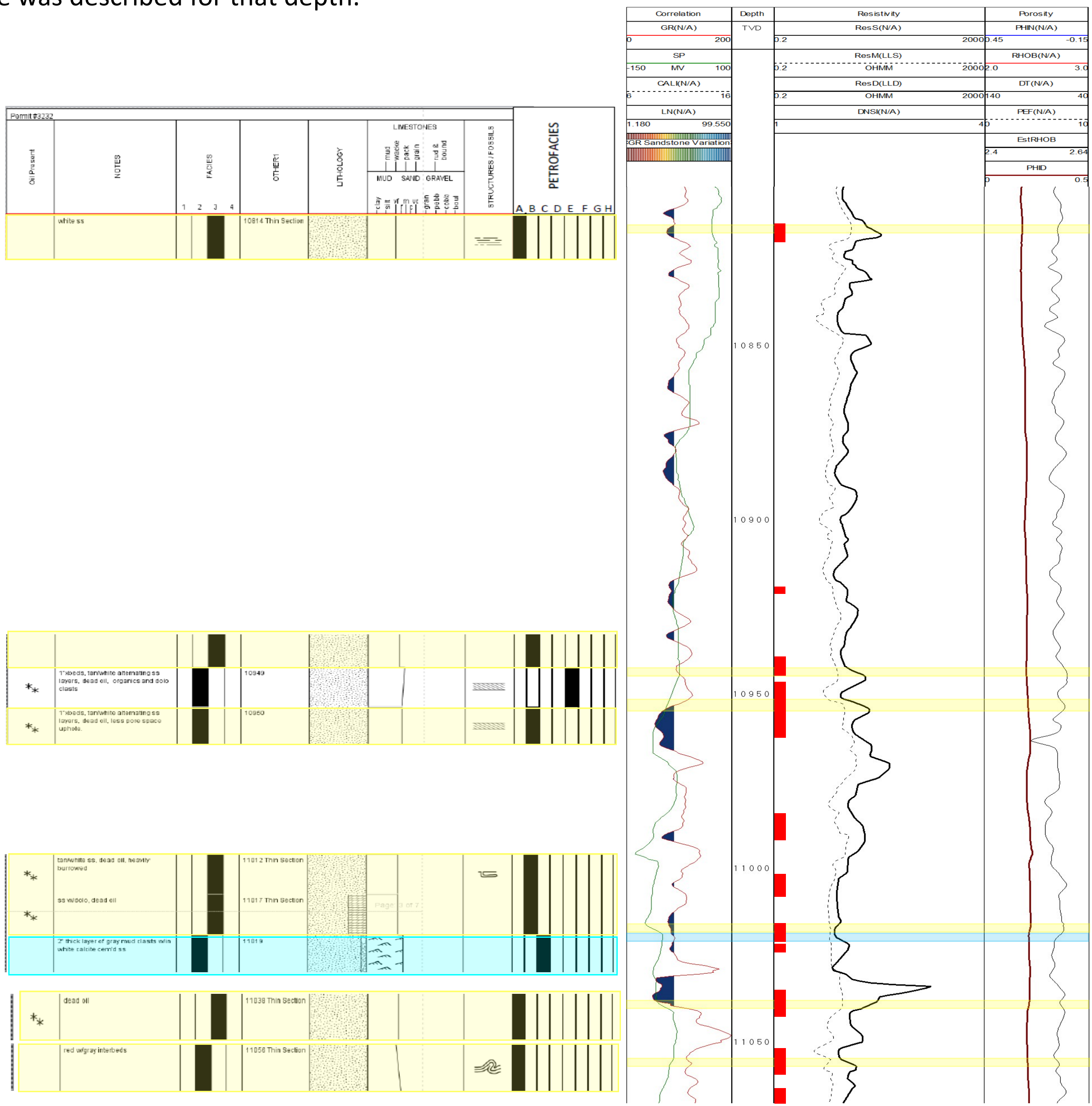
Plate 3b. Petrofacies A-C, correlated from well permit \#633 graphic log (left) to petrophysical well log (right). Petrofacies A and B are outlined in yellow and petrofacies $C$ is outlined in blue on both logs. Colored zones are presented sideby side to illustrate their lithology and representative well log signature. Red rectangles alongside depth indicate that core was described for that depth.

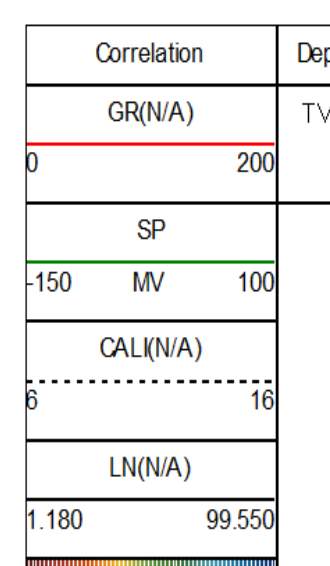

GR Sandstone Variation GI
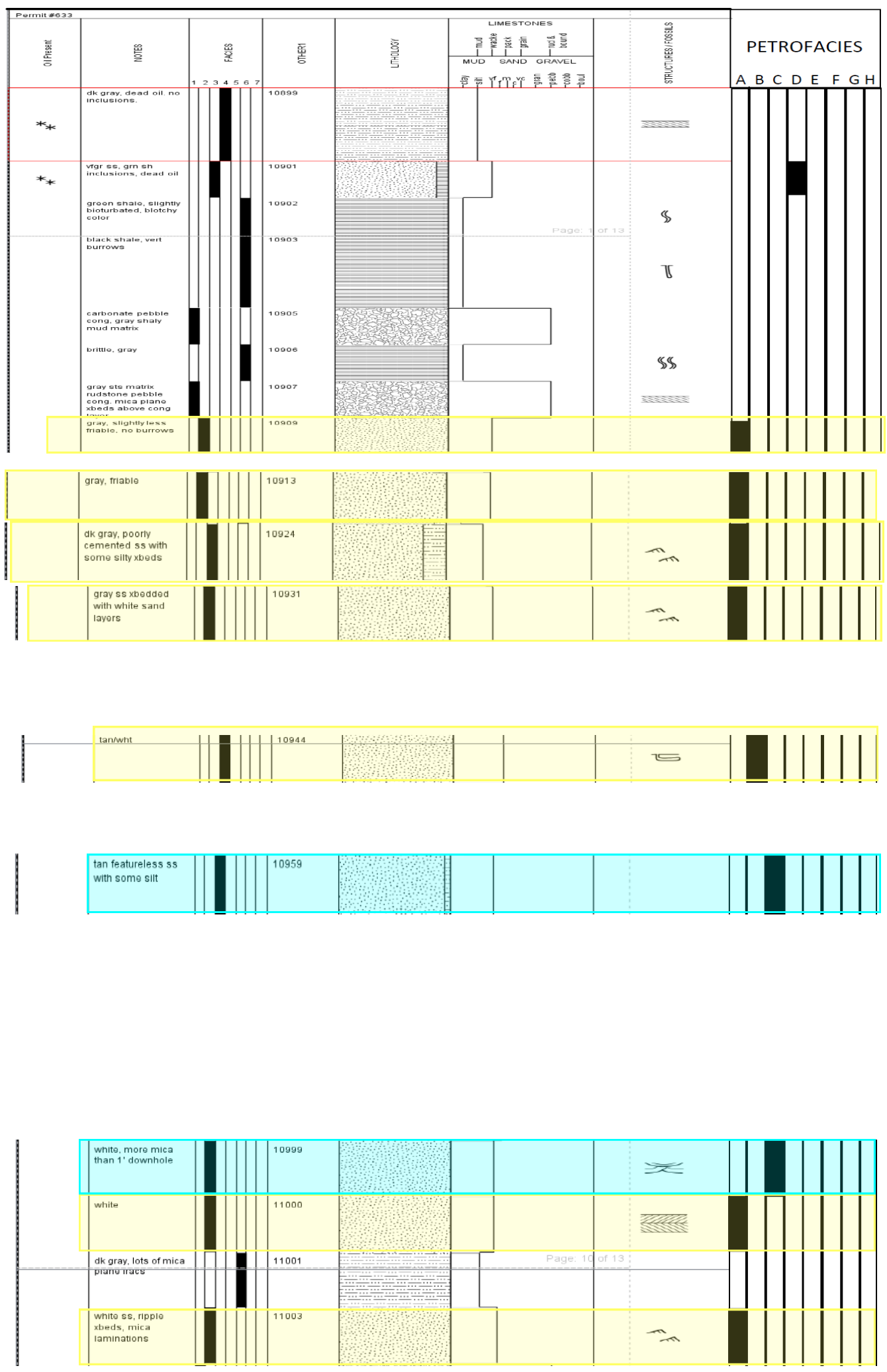
Plate 3c. Petrofacies A-C, correlated from well permit \#706 graphic log (left) to petrophysical well log (right). Petrofacies $A$ and $B$ are outlined in yellow and petrofacies $C$ is outlined in blue on both logs. Colored zones are presented side-by side to illustrate their lithology and representative well log signature. Red rectangles alongside depth indicate that core was described for that depth.
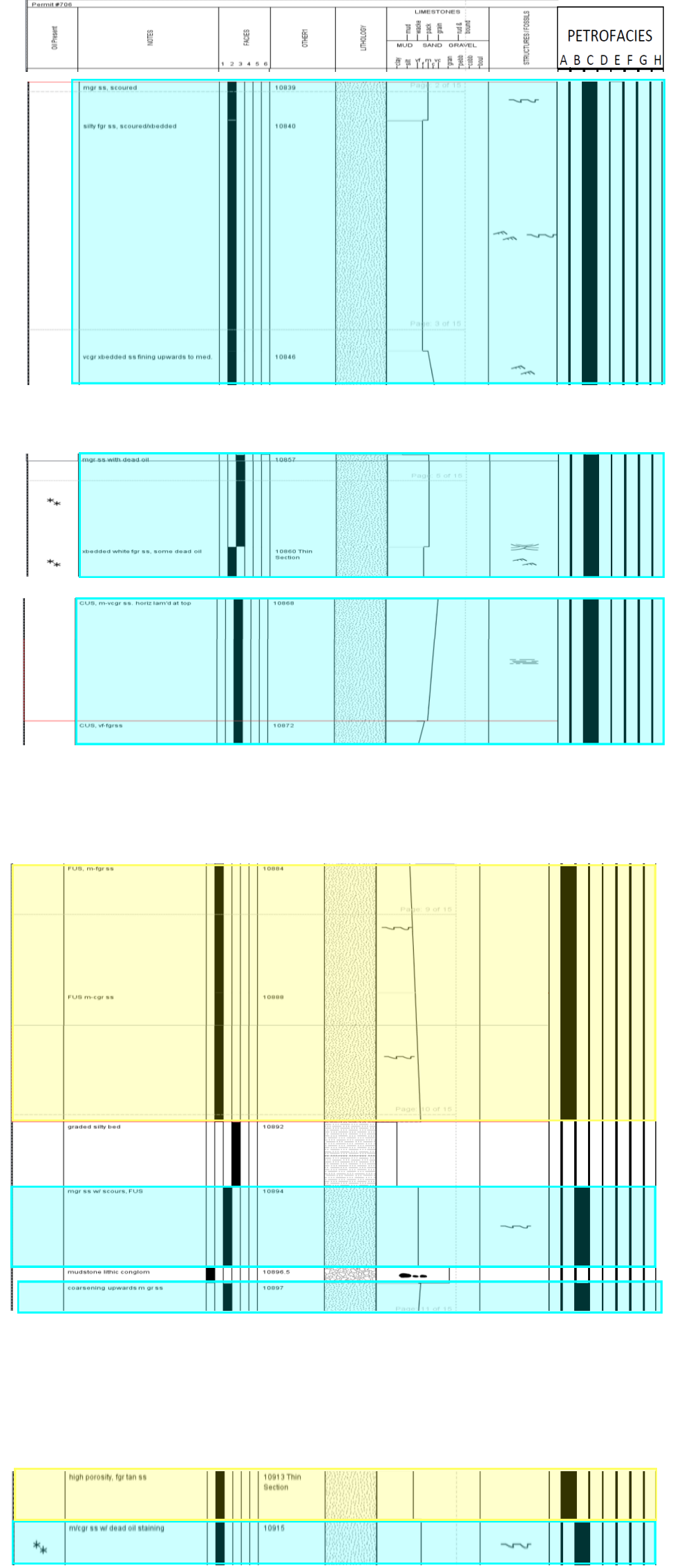

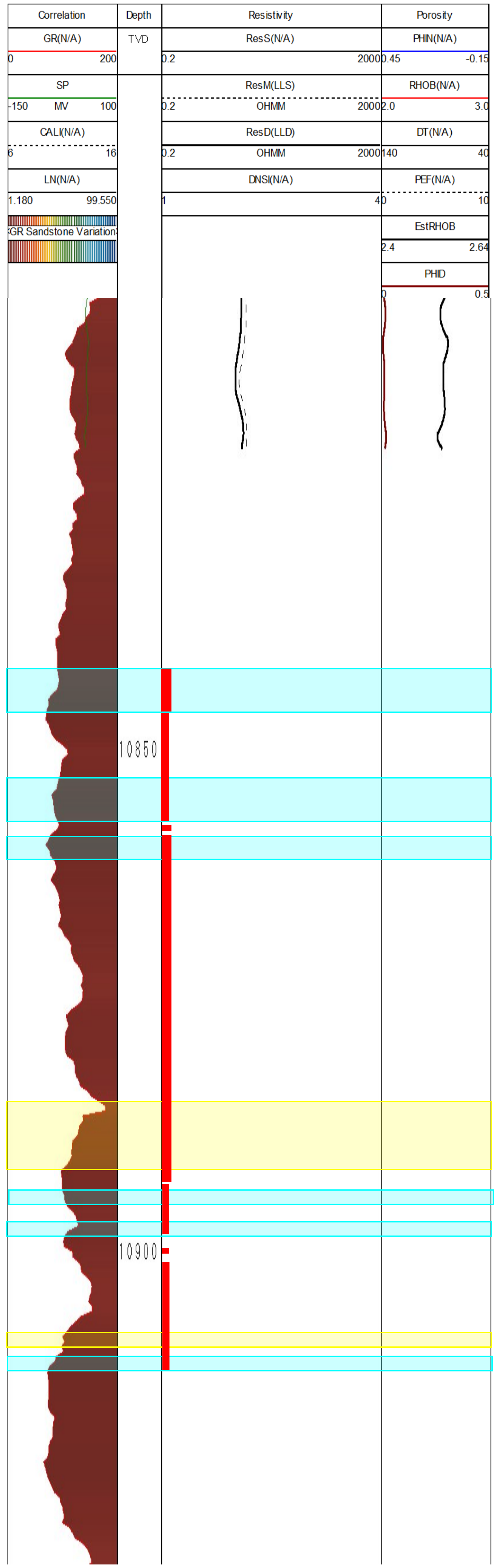


Table 1: Raw point count data gathered from thin section samples.

$\begin{array}{cc}\text { Well permit \# - } & \text { Sandstone } \\ \text { depth sampled } & \text { Petrofacies } \\ 624-10934 & \text { G } \\ 624-11410 & - \\ 624-11428 & \text { E } \\ 624-11446 & \text { E } \\ 633-10947.5 & \text { F } \\ 633-10994.5 & - \\ 633-10995.5 & \text { F } \\ 633-11009.5 & \text { G } \\ 713-10880 & \text { B } \\ 713-11347 & - \\ 713-11372 & \text { A } \\ 2993-10978 & \text { G } \\ 3198-11087 & \text { G } \\ 3198-11117 & \text { E } \\ 3198-11130 & - \\ 3198-11131 & \text { E } \\ 3198-11136 & \text { E } \\ 3198-11323 & - \\ 3198-11466 & \text { F } \\ 706-10852 & \text { D } \\ 706-10853 & \text { D } \\ 706-10860 & \text { C } \\ 706-10865 & \text { F } \\ 706-10913 & \text { B } \\ 706-10916-25 & \text { D } \\ 3232-10814 & \text { A } \\ 3232-10815 & \text { D } \\ 3232-10943 & \text { D } \\ 3232-10944 & \text { B } \\ 3232-11012 & \text { B } \\ 3232-11017 & \text { B } \\ 3232-11023 & \text { E } \\ 3232-11038 & \text { A } \\ 3232-11056 & \text { A } \\ 3232-11057 & \text { G } \\ 3232-11060 & \text { E } \\ 3232-11378 & \text { B } \\ 3232-11381.9 & \text { G } \\ & \end{array}$

\begin{tabular}{|c|c|c|}
\hline $\begin{array}{c}\text { Quartz } \\
\text { (monocryst.) }\end{array}$ & $\begin{array}{c}\text { Quartz } \\
\text { (polycryst.) }\end{array}$ & $\begin{array}{l}\text { Feldspar } \\
\text { (undiff.) }\end{array}$ \\
\hline 101 & 0 & 252 \\
\hline 89 & 0 & 134 \\
\hline 137 & 4 & 231 \\
\hline 145 & 2 & 193 \\
\hline 56 & 6 & 256 \\
\hline 13 & 3 & 90 \\
\hline 83 & 4 & 278 \\
\hline 91 & 5 & 249 \\
\hline 112 & 3 & 237 \\
\hline 136 & 3 & 115 \\
\hline 140 & 6 & 216 \\
\hline 59 & 6 & 272 \\
\hline 67 & 6 & 264 \\
\hline 135 & 15 & 207 \\
\hline 13 & 1 & 121 \\
\hline 102 & 32 & 216 \\
\hline 114 & 22 & 219 \\
\hline 29 & 0 & 211 \\
\hline 105 & 7 & 263 \\
\hline 80 & 0 & 246 \\
\hline 109 & 0 & 250 \\
\hline 119 & 0 & 237 \\
\hline 139 & 0 & 245 \\
\hline 101 & 1 & 257 \\
\hline 129 & 0 & 241 \\
\hline 122 & 0 & 246 \\
\hline 135 & 1 & 229 \\
\hline 105 & 3 & 238 \\
\hline 174 & 2 & 197 \\
\hline 147 & 0 & 189 \\
\hline 133 & 7 & 217 \\
\hline 149 & 3 & 180 \\
\hline 148 & 4 & 174 \\
\hline 155 & 1 & 163 \\
\hline 179 & 0 & 127 \\
\hline 164 & 13 & 144 \\
\hline 203 & 15 & 146 \\
\hline
\end{tabular}

Feldspar

\section{(twinned}

plag.) Lithic

\begin{tabular}{|c|}
\hline Muscovite \\
\hline 1 \\
\hline 75 \\
\hline 8 \\
\hline 17 \\
\hline 11 \\
\hline 7 \\
\hline 1 \\
\hline 2 \\
\hline 7 \\
\hline 106 \\
\hline 8 \\
\hline 7 \\
\hline 10 \\
\hline 12 \\
\hline 2 \\
\hline 17 \\
\hline 13 \\
\hline 6 \\
\hline 5 \\
\hline 43 \\
\hline 8 \\
\hline 13 \\
\hline 8 \\
\hline 4 \\
\hline 8 \\
\hline 8 \\
\hline 18 \\
\hline 26 \\
\hline 18 \\
\hline 33 \\
\hline 13 \\
\hline 8 \\
\hline 7 \\
\hline 15 \\
\hline 76 \\
\hline 7 \\
\hline 6 \\
\hline
\end{tabular}

\begin{tabular}{|c|c|c|}
\hline Biotite & Microcline & $\begin{array}{c}\text { Calcite } \\
\text { (det.) }\end{array}$ \\
\hline 5 & 1 & 0 \\
\hline 78 & 0 & 0 \\
\hline 6 & 8 & 0 \\
\hline 17 & 1 & 0 \\
\hline 16 & 5 & 0 \\
\hline 1 & 3 & 0 \\
\hline 0 & 3 & 0 \\
\hline 4 & 4 & 0 \\
\hline 4 & 10 & 0 \\
\hline 19 & 2 & 0 \\
\hline 5 & 1 & 0 \\
\hline 1 & 0 & 0 \\
\hline 0 & 0 & 0 \\
\hline 5 & 0 & 0 \\
\hline 0 & 2 & 0 \\
\hline 1 & 3 & 0 \\
\hline 9 & 0 & 0 \\
\hline 1 & 1 & 0 \\
\hline 2 & 1 & 0 \\
\hline 4 & 0 & 0 \\
\hline 4 & 1 & 0 \\
\hline 13 & 1 & 0 \\
\hline 0 & 0 & 0 \\
\hline 2 & 6 & 2 \\
\hline 1 & 1 & 2 \\
\hline 0 & 3 & 0 \\
\hline 0 & 2 & 1 \\
\hline 0 & 1 & 3 \\
\hline 0 & 0 & 1 \\
\hline 0 & 0 & 0 \\
\hline 0 & 3 & 3 \\
\hline 1 & 3 & 2 \\
\hline 0 & 2 & 2 \\
\hline 4 & 0 & 2 \\
\hline 0 & 0 & 1 \\
\hline 0 & 4 & 15 \\
\hline 4 & 0 & 14 \\
\hline
\end{tabular}

Hematite Titanium oxide

(det.)

mineral Dead oil

15

1
8
8

10

17
7

11

19
28

7

15
18

20 


\begin{tabular}{|c|c|c|c|c|c|c|c|}
\hline $\begin{array}{l}\text { Anhydrite } \\
\text { (det.) }\end{array}$ & Porosity & $\begin{array}{l}\text { Calcite } \\
\text { cement }\end{array}$ & $\begin{array}{l}\text { Silica } \\
\text { cement }\end{array}$ & $\begin{array}{c}\text { Hematite } \\
\text { cement }\end{array}$ & $\begin{array}{l}\text { Dolomite } \\
\text { cement }\end{array}$ & Matrix & $\begin{array}{c}\text { Total } \\
\text { (frmwrk+acc.) }\end{array}$ \\
\hline 16 & 4 & 5 & 6 & 0 & 0 & 0 & 400 \\
\hline 14 & 0 & 2 & 0 & 0 & 0 & 46 & 403 \\
\hline 5 & 13 & 2 & 1 & 0 & 0 & 0 & 414 \\
\hline 12 & 5 & 0 & 7 & 0 & 0 & 0 & 402 \\
\hline 7 & 0 & 1 & 0 & 0 & 18 & 1 & 402 \\
\hline 2 & 1 & 87 & 0 & 0 & 87 & 0 & 418 \\
\hline 0 & 0 & 91 & 0 & 0 & 61 & 0 & 406 \\
\hline 24 & 9 & 18 & 0 & 0 & 148 & 0 & 406 \\
\hline 11 & 0 & 13 & 2 & 0 & 0 & 30 & 431 \\
\hline 0 & 7 & 4 & 0 & 15 & 0 & 32 & 405 \\
\hline 8 & 3 & 13 & 0 & 0 & 0 & 12 & 400 \\
\hline 9 & 0 & 81 & 0 & 0 & 0 & 3 & 414 \\
\hline 9 & 0 & 36 & 0 & 0 & 4 & 0 & 411 \\
\hline 4 & 3 & 1 & 0 & 0 & 0 & 12 & 405 \\
\hline 13 & 0 & 60 & 0 & 0 & 0 & 0 & 400 \\
\hline 17 & 1 & 12 & 0 & 0 & 0 & 0 & 412 \\
\hline 6 & 21 & 21 & 0 & 0 & 0 & 2 & 400 \\
\hline 6 & 1 & 60 & 0 & 0 & 142 & 0 & 446 \\
\hline 5 & 3 & 54 & 1 & 0 & 0 & 1 & 431 \\
\hline 24 & 19 & 8 & 0 & 0 & 0 & 10 & 411 \\
\hline 18 & 19 & 21 & 0 & 0 & 0 & 5 & 416 \\
\hline 15 & 7 & 7 & 0 & 0 & 0 & 8 & 407 \\
\hline 5 & 2 & 29 & 0 & 0 & 0 & 3 & 417 \\
\hline 8 & 53 & 3 & 0 & 0 & 0 & 5 & 401 \\
\hline 10 & 19 & 1 & 0 & 0 & 0 & 4 & 409 \\
\hline 10 & 26 & 17 & 4 & 0 & 0 & 10 & 402 \\
\hline 4 & 12 & 23 & 0 & 0 & 0 & 11 & 408 \\
\hline 7 & 15 & 19 & 0 & 0 & 0 & 20 & 406 \\
\hline 9 & 32 & 18 & 0 & 0 & 0 & 4 & 413 \\
\hline 16 & 22 & 12 & 0 & 1 & 0 & 6 & 402 \\
\hline 6 & 16 & 7 & 1 & 14 & 0 & 4 & 402 \\
\hline 8 & 24 & 45 & 0 & 3 & 0 & 12 & 413 \\
\hline 13 & 14 & 8 & 0 & 0 & 0 & 1 & 405 \\
\hline 6 & 31 & 1 & 0 & 1 & 0 & 16 & 401 \\
\hline 10 & 11 & 36 & 0 & 0 & 0 & 6 & 405 \\
\hline 5 & 11 & 25 & 0 & 0 & 0 & 2 & 405 \\
\hline 4 & 22 & 19 & 0 & 0 & 0 & 4 & 413 \\
\hline 4 & 5 & 43 & 0 & 0 & 0 & 2 & 400 \\
\hline
\end{tabular}


Table 2: Quartz, feldspar, and lithic fragment percentages used in QFL diagram creation.

$\begin{array}{ccccc}\text { Well permit \# - Depth Sampled } & \text { \% Quartz } & \text { \% Feldspar } & \text { \% Lithic } & \text { \% Porosity } \\ 624-10934 & 27.08 & 71.58 & 1.34 & 1.0 \\ 624-11410 & 38.70 & 58.70 & 2.61 & 0.0 \\ 624-11428 & 37.01 & 62.73 & 0.26 & 3.0 \\ 624-11446 & 41.76 & 57.67 & 0.57 & 1.2 \\ 633-10947.5 & 17.66 & 77.78 & 4.56 & 0.0 \\ 633-10994.5 & 4.03 & 24.43 & 71.54 & 0.2 \\ 633-10995.5 & 22.77 & 75.65 & 1.57 & 0.0 \\ 633-11009.5 & 26.23 & 73.22 & 0.55 & 1.5 \\ 713-10880 & 29.79 & 68.65 & 1.55 & 0.0 \\ 713-11347 & 52.85 & 46.39 & 0.76 & 1.6 \\ 713-11372 & 38.62 & 61.11 & 0.26 & 0.7 \\ 2993-10978 & 17.47 & 77.96 & 4.57 & 0.0 \\ 3198-11087 & 20.22 & 78.67 & 1.11 & 0.0 \\ 3198-11117 & 39.27 & 59.95 & 0.79 & 0.7 \\ 3198-11130 & 5.69 & 51.63 & 42.68 & 0.0 \\ 3198-11131 & 35.92 & 62.73 & 1.34 & 0.2 \\ 3198-11136 & 36.76 & 62.70 & 0.54 & 4.7 \\ 3198-11323 & 11.28 & 83.66 & 5.06 & 0.0 \\ 3198-11466 & 28.07 & 69.67 & 2.26 & 0.6 \\ 706-10852 & 23.81 & 75.30 & 0.89 & 4.2 \\ 706-10853 & 29.07 & 68.27 & 2.67 & 4.3 \\ 706-10860 & 32.87 & 65.75 & 1.38 & 1.6 \\ 706-10865 & 34.84 & 62.91 & 2.26 & 0.4 \\ 706-10913 & 27.06 & 71.62 & 1.33 & 11.5 \\ 706-10916.25 & 33.42 & 64.77 & 1.81 & 4.4 \\ 3232-10814 & 32.02 & 65.88 & 2.10 & 5.7 \\ 3232-10815 & 35.98 & 62.70 & 1.32 & 2.6 \\ 3232-10943 & 29.35 & 69.29 & 1.36 & 3.3 \\ 3232-10944 & 45.71 & 53.77 & 0.52 & 6.9 \\ 3232-11012 & 41.64 & 56.37 & 1.98 & 5.0 \\ 3232-11017 & 37.14 & 62.33 & 0.53 & 3.6 \\ 3232-11023 & 40.11 & 52.24 & 7.65 & 4.8 \\ 3232-11038 & 44.31 & 55.39 & 0.29 & 3.3 \\ 3232-11056 & 42.16 & 46.22 & 11.62 & 6.9 \\ 3232-11057 & 57.01 & 41.08 & 1.91 & 2.4 \\ 3232-11060 & 52.68 & 44.35 & 2.98 & 2.5 \\ 3232-11378 & 58.13 & 41.33 & 0.53 & 4.8 \\ 3232-11381.9 & 49.84 & 50.16 & 0.00 & 1.1\end{array}$

Calculations:

$\%$ Quartz $=$ Tqtz $/($ Tqtz + Tfspar + Tlith $)$

$\%$ Feldspar $=$ Tfspar $/($ Tqtz + Tfspar+Tlith $)$

$\%$ Lithic $=$ Tlith/(Tqtz+Tfspar+Tlith)

$\%$ Porosity $=$ Tphi/Tgrain

Key to Calculations:

Tgrain - total solid sediment grain points counted in respective thin section

Tfspar - total feldspar points counted in respective thin section

Tlith - total lithic fragment points counted in respective thin section

Tphi - total porosity points counted in respective thin section

Tqtz - total quartz points counted in respective thin section

(\% Porosity was not used in QFL diagram, but is included for reference.) 